Subsurface Monitoring of

Reservoir Pressure,

Temperature, Relative

Humidity, and Water Content

at the CAES Field Experiment,

Pittsfield, Illinois:

System Design

March 1983

Prepared for

Pacific Northwest Laboratory

Underground Energy Storage Program

under Subcontract B-82313-A-O

Pacific Northwest Laboratory

Operated for the U.S. Department of Energy

by Battelle Memorial Institute 


\title{
DISCLAIMER
}

This report was prepared as an account of work sponsored by an agency of the United States Government. Neither the United States Government nor any agency thereof, nor any of their employees, makes any warranty, express or implied, or assumes any legal liability or responsibility for the accuracy, completeness, or usefulness of any information, apparatus, product, or process disclosed, or represents that its use would not infringe privately owned rights. Reference herein to any specific commercial product, process, or service by trade name, trademark, manufacturer, or otherwise, does not necessarily constitute or imply its endorsement, recommendation, or favoring by the United States Government or any agency thereof. The views and opinions of authors expressed herein do not necessarily state or reflect those of the United States Government or any agency thereof.

\author{
PACIFIC NORTHWEST LABORATORY \\ operated by \\ BATTELLE \\ for the \\ UNITED STATES DEPARTMENT OF ENERGY \\ under Contract DE-AC06-76RLO 1830
}

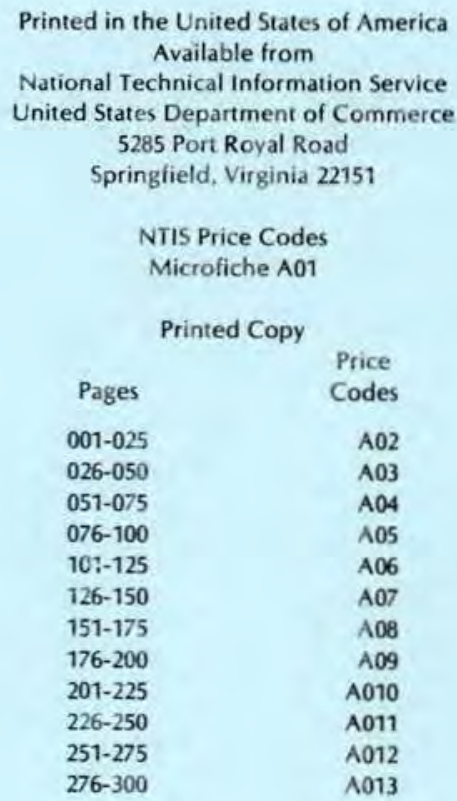




\section{SUBSURFACE MONITORING \\ OF RESERVOIR PRESSURE, TEMPERATURE, RELATIVE HUMIDITY, AND WATER CONTENT AT THE CAES FIELD EXPERIMENT, PITTSFIELD, ILLINOIS: SYSTEM DESIGN}

D. D. Hostetler

S. W. Childs

S. J. Phillips

Energy Resource Management

Tucson, Arizona

March 1983

Prepared for

Pacific Northwest Laboratory

Underground Energy Storage Program

under Subcontract B-82313-A-0

Pacific Northwest Laboratory

Richland, Washington 99352 

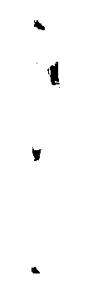


\section{PACIFIC NORTHWEST LABORATORY PERSPECTIVE}

Compressed air energy storage (CAES) is a technique that transfers energy from off-peak to peak demand time for electric utility systems. It incorporates modified state-of-the-art gas turbines and underground reservoirs--aquifers, salt cavities, or mined hard rock caverns. The compressor and turbine sections of the gas turbine are alternately coupled to a motor/generator for operation during different time periods. During nocturnal and weekend off-peak periods, base load plants not using petroleum fuels provide energy to compress air, which is stored in the underground reservoirs. During the subsequent diumal peak-load periods, the compressed air is withdrawn from storage, mixed with fue1, combusted and then expanded through the turbines to generate peak power. Because the turbine is not required to drive a compressor, this concept reduces peaking plant consumption of petroleum fuel by more than $60 \%$. Some second-generation CAES concepts require no petroleum fuels.

Since 1975, the Pacific Northwest Laboratory (PNL) has served as the U.S. Department of Energy's lead laboratory in managing research and development efforts to support CAES technology commercialization.

A substantial part of the CAES Technology Projects is represented by the Reservoir Stability Studies. The goal of these studies is to ensure long-term stable containment of air in the underground reservoirs used in conjunction with CAES plants. The specific objective is to develop stability criteria and engineering guidelines for designing CAES reservoirs in each of the three major 
reservoir types, including aquifers, salt cavities, and mined hard rock caverns. Such information is essential to gain utility confidence in CAES as a viable alternative to conventional electric energy production techniques.

Three parallel studies based on reservoir type have been performed. Each contained a survey of the state-of-the-art and numerical and experimental studies. The mined hard rock and salt studies were completed and final criteria documents have been issued. The aquifer study has also been completed as a generic study but has been extended to include a specific field experiment, the Pittsfield Aquifer Test.

This document covers design work performed in support of that field study by Energy Resource Management (ERM) as a second tier subcontractor to PNL. The primary field study contractor to PNL, PB-KBB, Inc. of Houston, Texas, was responsible for design, construction and operation of the Pittsfield Aquifer Test. Energy Resource Management prepared the subsurface monitoring system design documented herein as part of their responsibility to design, calibrate, and assist in the installation of downhole instrumentation. The criteria this design is intended to fulfill are to acquire continuous, three-dimensional in situ data on pressure, temperature and water content within the aquifer storage reservoir near the injection point, and to record and maintain that data in usable forms for later analysis.

The information presented here does not constitute the total and final instrumentation system design for the Pittsfield test, but is part of a larger surface and geophysical monitoring system installed by $\mathrm{PB}-\mathrm{KBB}$ at the site. Within that context, however, it does represent a good example of the state-of-the-art techniques that are being utilized in this test. This system design is an application of specialized 
instrumentation to a sma11-scale research and development oriented field test. As such, the system may or may not prove to have applicability to full-scale operational systems, where strictly operational considerations could dictate a different approach to instrumentation system requirements.

Our intent is that surface, subsurface and geophysical data from the Pittsfield Aquifer Test will provide the industry with a solid technical basis for proceeding with the commercialization of the compressed air energy storage technology.

T. J. Doherty, Manager Compressed Air Energy Storage Project Pacific Northwest Laboratory 
$\checkmark$
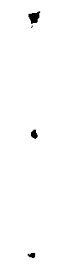
PREFACE

The Compressed Air Energy Storage (CAES) Program is sponsored by the U.S. Department of Energy, Division of Energy Storage Systems. This report was sponsored by $\mathrm{PB}-\mathrm{KBB}$, Inc., Subsurface Systems \& Technology, the CAES field-experiment project manager. PB-KBB is a major subcontractor to Pacific Northwest Laboratory, who manages the CAES Program for the U.S. Department of Energy. The purpose of the field experiment at Pittsfield, Illinois, is to assist in developing reservoir stability criteria and operational designs for commercial-scale CAES plants. The ultimate goal of the CAES concept is to improve the cost and efficiency of electrical power generation.

The system design described in this report was formulated during the summer of 1982. As additional information concerning the field experiment becomes available, modification can be expected in the system design. The authors believe that the present design will be successful in obtaining the maximm amount of valuable and reliable data; however, due to the research nature of the project, the standard waiver of liability is taken.

This report was prepared as an account of work sponsored by the United States Government. Neither the United States Government, Pacific Northwest Laboratory, PB-KBB, Inc., Energy Resource Management, nor the employees of each makes any warranty, express or implied, or assumes any legal liability or responsibility for the accuracy, completeness, or usefulness of any information, apparatus, product, or process disclosed, or represents that its use would not infringe on 
privately owned rights. The views, opinions, and conclusions contained in this report are those of the authors and do not necessarily represent those of the U.S. Department of Energy, Pacific Northwest Laboratory, or $\mathrm{PB}-\mathrm{KBB}$, Inc.

Special thanks are in order to the project manager, J. A. Istvan of $\mathrm{PB}-\mathrm{KBB}$, for his guidance and support throughout the project. Also, we would like to thank E. R. Cheatham of PB-KBB for his thorough review of the system design. Strong thanks are in order for the editing and manuscript preparation performed within short time frames by H. R. Hauck and E. M. Murphy.

D. D. Hostetler Energy Resource Management P. O. Box 42225 Tucson, Arizona 85717 June 1982 


\section{SUMMARY}

This subsurface-instrumentation design has been developed for the first Compressed Air Energy Storage (CAES) field experiment to be performed in porous media. Energy storage will be accomplished by alternating the injection and withdrawal of compressed air in a confined sandstone aquifer near Pittsfield, Illinois. The overall experiment objective is to characterize the reservoir's geochemical and thermohydraulic response to imposed CAES conditions. Specific experiment objectives require monitoring: (1) air-bubble development, (2) thermal development, (3) cyclic pressure response, (4) reservoir dehydration, and (5) water coning. Supporting these objectives, four parameters will be continuously monitored at depth in the reservoir. They are: (1) temperature, (2) pressure, (3) pore-air relative humidity, and (4) porewater content. Reservoir temperatures and pressures will range to maximum values approaching $200^{\circ} \mathrm{C}$ and $300 \mathrm{psi}$, respectively. Both pore-air relative humidity and pore-water content will range from $\sim 0-$ 100\%. This report discusses: (1) instrumentation design, (2) sensor and sensor system calibration, (3) field installation and testing, and (4) instrument-system operation.

No comprehensive off-the-shelf instrument package exists to adequately monitor CAES reservoir parameters at depth. The best available sensors were selected and adapted for use under expected ranges of reservoir conditions. The instrumentation design criteria required: (1) suitable sensor accuracy, (2) continuous monitoring capability, (3) redundancy, (4) maximum sensor integrity, (5) contingency planning, and (6) minimum cost-information ratio. Three wells will be instrumented: the injection/withdrawal (I/W) well and the two instrument wells. Sensors will be deployed by wireline suspension in both open and backfilled (with sand) wellbores. The sensors deployed in the I/W well will be retrievable; the instrument-well sensors will not. 
CONTENTS

Page

PACIFIC NORTHWEST LABORATORY PERSPECTIVE. . . . . . . . . . . . iii

PREFACE .......................... . vi vi

SUMMARY . . . . . . . . . . . . . . . . . . . . ix

LIST OF FIGURES . . . . . . . . . . . . . . . . . . xiii

LIST OF TABLES. . . . . . . . . . . . . . . . . . . xiv

INTRODUCTION. . . . . . . . . . . . . . . . . . . . . 1

OBJECTIVES . . . . . . . . . . . . . . . . . . . . 1

CAES Program Objectives . . . . . . . . . . . . . . 1

Field Experiment Objectives . . . . . . . . . . . . 2

Subsurface Instrumentation Objectives . . . . . . . . . . 2

RESERVOIR CONDITIONS ................... 3

Pretest Period. . . . . . . . . . . . . . . . . 4

Air-bubble Development. . . . . . . . . . . . . . 4

Air Cycling. . . . . . . . . . . . . . . . . . . . 4

Site Decommissioning. . . . . . . . . . . . . . 9

INSTRUMENTATION DESIGN. . . . . . . . . . . . . . . . 11

DESIGN CRITERIA AND ASSUMPTIONS. . . . . . . . . . . 11

Design Criteria .. . . . . . . . . . . . . . 11

Assumptions . . . . . . . . . . . . . . . . . 12

IMPLEMENTATION OF DESIGN CRITERIA. . . . . . . . . . . . . 13

Overall Implementation. . . . . . . . . . . . . . . . 14

Parameter-specific Implementation . . . . . . . . . . . . 15

SENSOR AND SENSOR-SYSTEM CHARACTERISTICS . . . . . . . . . . . 17

Platinum Resistance Elements. . . . . . . . . . . . 17

Thermocouples ................... 18

Silicon Crystal Strain Gages. . . . . . . . . . . . 20

Cellulose Strain Gages. . . . . . . . . . . . . 25

Thermocouple Psychrometers. . . . . . . . . . . . 25

Resistance Blocks . . . . . . . . . . . . . . . . 28

Neutron Logging Device. . . . . . . . . . . . . . . . 31 


\section{CONTENTS--}

Page

DESIGN OF FIELD DEPLOYMENT . . . . . . . . . . . . . 33

Backfilling . . . . . . . . . . . . . . . . . 33

Instrument Containers . . . . . . . . . . . . . . . 38

Instrumented Intervals. . . . . . . . . . . . . . 39

Injection/Withdrawal Well . . . . . . . . . . . 39

DATA ACQUISITION SYSTEMS . . . . . . . . . . . . . . . 43

CALIBRATION PROCEDURES FOR SENSORS AND

MONITORING SYSTEMS. . . . . . . . . . . . . . . . 55

CALIBRATION NEEDS OF PARTICULAR SENSORS. . . . . . . . . . . 56

Cellulose Strain Gage . . . . . . . . . . . . . . . 56

Silicon Strain Gage . . . . . . . . . . . . . . . 57

Platinum Resistance Elements. . . . . . . . . . . . 57

Resistance Blocks ................... 57

Thermocouple Psychrometers. . . . . . . . . . . . 57

CALIBRATION METHODS. . . . . . . .......... 58

Pore-water Content. . . . . . . . . . . . . . 59

Relative Humidity . . . . . . . . . . . . . . 62

Pressure and Temperature. . . . . . . . . .... 62

USE OF CALIBRATION DATA. . . . . . . . . . . . . . . 63

FIELD INSTALLATION AND TESTING OF SENSOR SYSTEM . . . . . . . . . 64

FIELD CHECKOUT . . . . . . . . . . . . . . 64

SENSOR-STRING DEPLOYMENT ................. . . . . 66

Sensor String Description . . . . . . . . . . . . 66

Sensor String Deployment. . . . . . . . . . . . . 68

IN-WELL TESTING. . . . . . . . . . . . . . . . . 70

WELL BACKFILLING AND CEMENTING . . . . . . . . . . . . . 71

STATIC TESTING . . . . . . . . . . . . . . . . . . . . . 72

MONITORING-SYSTEM OPERATIONAL CHECKOUT . . . . . . . . . . 72

MONITORING SYSTEM OPERATION DURING EXPERIMENTATION. . . . . . . 75

SYSTEM START-UP. . . . . . . . . . . . . . . . 75

DATA PROCESSING. . . . . . . . . . . . . . . . . . . 76

THERMOCOUPLE-PSYCHROMETER SCANNER OPERATION. . . . . . . . . . 76

MAINTENANCE. . . . . . . . . . . . . . . . . . . 77

CONTINGENCY PLANS. . . . . . . . . . . . . . . . . . 78

REFERENCES. . . . . . . . . . . . . . . . . 81

APPENDIX: VENDOR INFORMATION . . . . . . . . . . . . 83 


\section{LIST OF FIGURES}

Figure

Page

1. Lines of constant saturation versus radius for different time periods during bubble development. . . . . . . . . . . . . . .

2. Ranges of reservoir conditions used for instrument system design. . . . . . . . . . . . . . 8

3. A platinum resistance element. . . . . . . . . . . 19

4. Drawing of thermocouple psychrometer with a a porous ceramic shield. . . . . . . . . . 21

5. A thermocouple psychrometer with a porous ceramic shield . . . . . . . . . . . . . 22

6. Drawing of silicon crystal strain gage used to monitor pressure. . . . . . . . . . . 23

7. A silicon crystal strain gage used to monitor pressure ... . . . . . . . . . . .

8. A cellulose strain gage used to monitor relative humidity. . . . . . . . . . . . . . .

9. I)rawing of a resistance block used to measure pore-water content . . . . . . . . . . . . . . .

10. A resistance block used to measure pore-water content. . . . . . . . . . . . . . . . .

11. Drawing of neutron logging sonde for monitoring pore-water content . . . . . . . . . . . . 32

12. Generalized wellfield layout at Pittsfield, IL . . . . . 34

13. I/W well completion. . . . . . . . . . . . . 35

14. Three-meter instrument (F) well completion . . . . . . . 36

15. Six-metor instrument (G) well completion . . . . . . . 37

16. Sensor deployment scheme ............... 40

17. Water coning . . . . . . . . . . . . 42 


\section{LIST OF FIGURES--Continued}

Figure

Page

18. AIM 65 microcomputer. . . . . . . . . . . . . 46

19. Single unit housing the expansion memory and

A/D converters. . . . . . . . . . . . . . . . 47

20. Schematic of data acquisition system. . . . . . . . 48

21. Printer for microcomputer . . . . . . . . . . 50

22. Cassette tape recorder. . . . . . . . . . . . 51

23. A/D converters. . . . . . . . . . . . . 52

24. Thermocouple-psychrometer scanner . . . . . . . . . 54

25. Pressure chamber apparatus. ............. 60

26. Generalized drawing of pressure chamber apparatus . . . . 61

27. Generalized procedure for field testing and deployment of sensors and system evaluation . . . . 65

28. Drawing of sensor deployment in an instrument interval. . . . . . . . . . . . . . . 67

29. Drawing of instrument container (can) located in backfilled instrument well . . . . . . . . . . 69

30. Drawing of instrument wiring layout in surfacefacility building . . . . . . . . . . . . 73 


\section{LIST OF TABLES}

$\begin{array}{lll}\text { Table } & \text { Page }\end{array}$

1. Initial reservoir description ............. 5

2. Selected sensor types. . . . . . . . . . . 13

3. Sensor characteristics for CAES reservoir monitoring . . . 16

4. Sensor output signals to be processed by data acquisition system . . . . . . . . . . . . . . 44

5. Relative humidity for salt solutions at various temperatures............... . 62 


\section{INTRODUCTION}

The Pittsfield experiment is one phase of research directed at demonstrating the commercial viability of Compressed Air Energy Storage (CAES) in porous media. The natural-gas industry has had considerable similar experience in their "water-drive" or aquifer storage fields. The CAES concept differs from aquifer gas storage in that: (1) daily or weekly cycling is required instead of annual cycling, (2) air with its oxidizing potential and relatively high viscosity is stored rather than natural gas, and (3) the air may be injected at elevated temperatures to accelerate near-wellbore dehydration and increase energy efficiency for CAES (Allen, 1981).

\section{OBJECTIVES}

Three different, yet related, sets of objectives are embodied in the Pittsfield experiment. They are the objectives of the CAES Program, the field experiment as a whole, and the monitoring systems. This report addresses the objectives of the subsurface monitoring systems and the influence of field experiment goals.

\section{CAES Program Objectives}

Considerable research has been conducted by Pacific Northwest Laboratory (PNL) and its subcontractors addressing various aspects of CAES (Wiles and McCann, 1981a). The field experiment is a logical culmination of previous analytical, numerical, and laboratory analyses. The field test was designed to fulfill three specific objectives: (1) demonstrate the injection, storage, and recovery of compressed air; (2) evaluate numerical modeling and laboratory conclusions about CAES behavior: in aquifers; and (3) evaluate and modify preliminary reservoir stability criteria (Allen, Kannberg, and Doherty, 1981). To the extent 
field-experiment objectives are accomplished, clearer definition of the commercial viability of CAES will be possible.

Field Experiment Objectives

The overall objective of the experiment is to effectively characterize the thermohydraulic and geochemical reservoir response. The nature of this response will determine the aquifer's ability to receive, store, and deliver compressed air when subjected to CAES conditions. It should be noted that the field test has several unique features that distinguish it from the typical, commercial-scale CAES facility presently envisioned. These unique features are: (1) the air storage zone will be at low discovery pressure (shallower depths), (2) the air storage zone is vertically thin and possibly dominated by a capillary transition zone, and (3) there is only one injection/withdrawal (I/W) we11, not an entire well field (Wiles and McCann, 1981b).

Reservoir physical, chemical, and hydraulic properties are important during preoperational, operational, and postoperational periods. Reservoir selection, characterization, and monitoring activities were discussed by Istvan (1981). From an operational standpoint, the specific objectives of the field experiment are to monitor: (1) air-bubble development, (2) thermal development, (3) reservoir dehydration, (4) cyclic pressure response, and (5) water coning (Wiles, Erikson, Allen, and Doherty, 1981). Effective monitoring of these phenomena should provide important information supporting the overall field experiment goals.

\section{Subsurface Instrumentation Objectives}

Subsurface instmmentation will provide data supporting field experiment objectives. Two types of subsurface instrumentation are involved: (1) continuous monitoring and (2) geophysical logging and water sampling. This report discusses only the continuous monitoring systems (with the exception of neutron logging) designed to observe certain reservoir parameters at depth in three wells. These parameters 
are: (1) temperature, (2) pressure, (3) pore-air relative humidity, and (4) pore-water content. Monitoring these parameters will support an eva1uation of two-phase (liquid water and air-water vapor) mass and energy transport in the porous reservoir rock. In addition, instrument systems may provide information regarding permeability alterations, permeability stratification, heterogeneity, and other reservoir characteristics. Instrument systems will be optimized to provide maximum information supporting experiment goals. Optimization will be based on available numerical modeling and laboratory analyses, sponsor guidance, and the authors' collective experience in field instrumentation and energy storage.

\section{RESERVOIR CONDITIONS}

An understanding of reservoir conditions is essential to effective subsurface instrumentation. Obviously, precise definition of changing reservoir conditions is not currently possible; that is the purpose of the field experiment. Yet, ranges of expected conditions must be defined prior to facility operation for the following reasons:

1. Establishing design criteria for instrument systems.

2. Choosing sensor types based on appropriate sensing principles.

3. Specifying sensor and sensor system operating ranges.

4. Establishing calibration ranges for sensors.

5. Optimizing field installation procedures and sensor deployment configurations.

6. Maximizing information for numerical model verification and comparison with laboratory analyses.

Reservoir conditions will vary considerably over the duration of the experiment. Four distinct periods can be identified. They are the pretest, air-bubble development, air cycling, and site decommissioning periods. The expected reservoir conditions for each period will be briefly discussed as they relate to the subsurface instrumentation. 
$\underline{\text { Pretest Period }}$

The pretest reservoir conditions are important primarily for two reasons. First, subsurface instrumentation will be installed under these conditions. Second, the baseline data will be obtained at ambient reservoir conditions prior to experimentation. Table 1 outlines important ambient reservoir conditions as applied by Wiles and McCann (1981b) to numerical modeling of the demonstration site. Important points about the table are total dissolved solids and hydrostatic pressure. Instruments will have to be installed and tested in a wellbore filled with brackish water. This has direct implications on sensor selection and system deployment plans. In addition, it will be prudent to minimize the exposure time of sensor systems to these saturated conditions.

\section{Air-bubble Development Period}

The initial development of an air bubble is required to displace existing aquifer water. Low-temperature air will be continuously injected until an adequate cushion air mass has been established. Air injection will then cease, and a closure period will commence. During this time the air bubble will expand and flatten. Wiles and McCann (1981b) developed a two-dimensional two-phase (air-water), isothermal numerical model to evaluate air-bubble development. Their results are shown in Figure 1. Of particular interest during this time is reservoir desaturation and any evidence of air-bubble anisotropy and heterogeneity. Bubble flattening during closure will also be of interest.

\section{Air Cycling}

Air cycling is the alternating injection and withdrawal of compressed air. Present plans involve cycling air two to four times per day at increasing temperatures up to $200^{\circ} \mathrm{C}$. Instrumentation schemes should address three primary topics: water coning, thermal development, and near-wellbore dehydration. Effective monitoring of these phenomena are important for two reasons. First, reservoir absolute 
Table 1. Initial reservoir description. -- Data from Wiles and McCann (1981b, Table 1).

\section{Geometry}

Depth to top of structure

$215 \mathrm{~m}$

Caprock slope

$1 / 80$

Vertical thickness of storage zone

$68 \mathrm{~m}$

Injection well diameter

$20 \mathrm{~cm}$

Producing length

$3 \mathrm{~m}$

Outer radius of modeled region

$800 \mathrm{~m}$

Assumed radius to hydrostatic pressure

$10^{4} \mathrm{~m}$

\section{Properties}

Permeability (horizontal) ${ }^{\mathrm{a}}$

$700 \mathrm{md}$

Permeability $\left(\right.$ vertical) ${ }^{\mathrm{a}}$

$700 \mathrm{md}$

Porosity

$20 \%$

Rock thermal conductivity

$2.16 \mathrm{~W} / \mathrm{m}^{\circ} \mathrm{C}$

Rock thermal capacity ${ }^{b}$

$2.62 \mathrm{MJ} / \mathrm{m}^{3 \circ} \mathrm{C}$

Critical saturation for gas mobility

0.90

Critical saturation for liquid mobility

0.20

Discovery pressure

$10 \mathrm{~atm}$

Discovery temperature

$14^{\circ} \mathrm{C}$

Total dissolved solids ${ }^{c}$

$4000 \mathrm{ppm}$
a. Units in millidarcys.
b. Units in megajoules per meter ${ }^{3}$ per ${ }^{\circ} \mathrm{C}$.
c. J. A. Istvan (1982, oral communication). 
RADIUS, $\mathbf{m}$

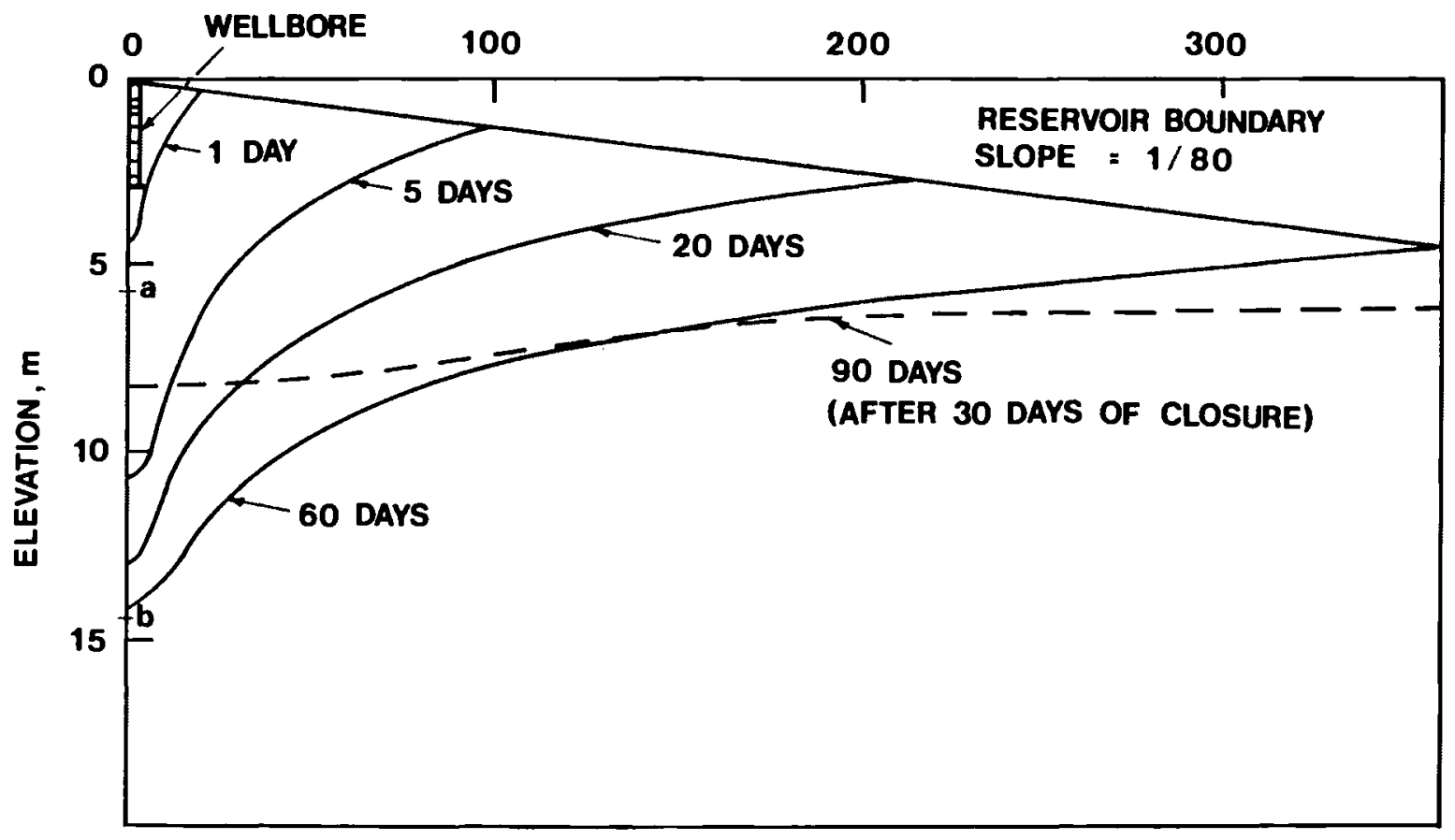

ADVANCE OF $50 \%$ SATURATION FRONT

Figure 1. Lines of constant saturation versus radius for different time periods during bubble development. $a=$ depth of penetration of $3-\mathrm{m}$ instrument well; $b=$ depth of penetration of 6-m instrument well. -- Adapted from Wiles and McCann (1981b, Figure 5) 
permeability may be reduced by geochemical reactions arising from the interaction of air and water at temperatures above about $75^{\circ} \mathrm{C}$ (Stottlemyre and Erikson, 1980). The complete dehydration of the nearwellbore region and the maintenance of this condition is critical. Second, water coning at elevated temperatures has not been examined numerically and is expected to be strongly coupled to thermal development and reservoir dehydration (Wiles and McCann, 1981b).

A central concern for the design of subsurface instrument systems is monitoring the movement of water, both in liquid and vapor phases. This is particularly important and complicated during air cycling. In order to properly design sensor systems, an understanding of the physical processes to be encountered was necessary. For definition purposes only, the following conceptualization of the reservoir is presented.

The CAES reservoir can be divided into three "liquid-water content" zones: dry, wet, and saturated, Our definition of terms is as follows. The dry zone contains almost no free liquid water $(<5 \%)$. The wet zone contains both liquid water and the air-vapor mixture. The saturated zone contains $100 \%$ liquid water (Figure 2). The two interfaces between the three zones are the wet and dry fronts. These interfaces are expected to be transitional.

Dehydration refers to the evaporation and convective transport of water vapor in air. Wiles (1979a) described this process in a CAES reservoir. "During injection of undersaturated air at elevated temperature, the air gains moisture as it moves radially outward. The air finally reaches a radial position where it is saturated at the local pressure and temperature. As the air moves beyond this point, condensation occurs. By this mechanism a dehydrated zone is established around the wellbore. Beyond this so-called 'dry front' there is a transition region characterized by some saturation build up. Water is eventually removed from the reservoir during a withdrawal cycle. Air moving towards the wellbore gains moisture as it enters the region of increasing temperature. However, it gains moisture only until it 


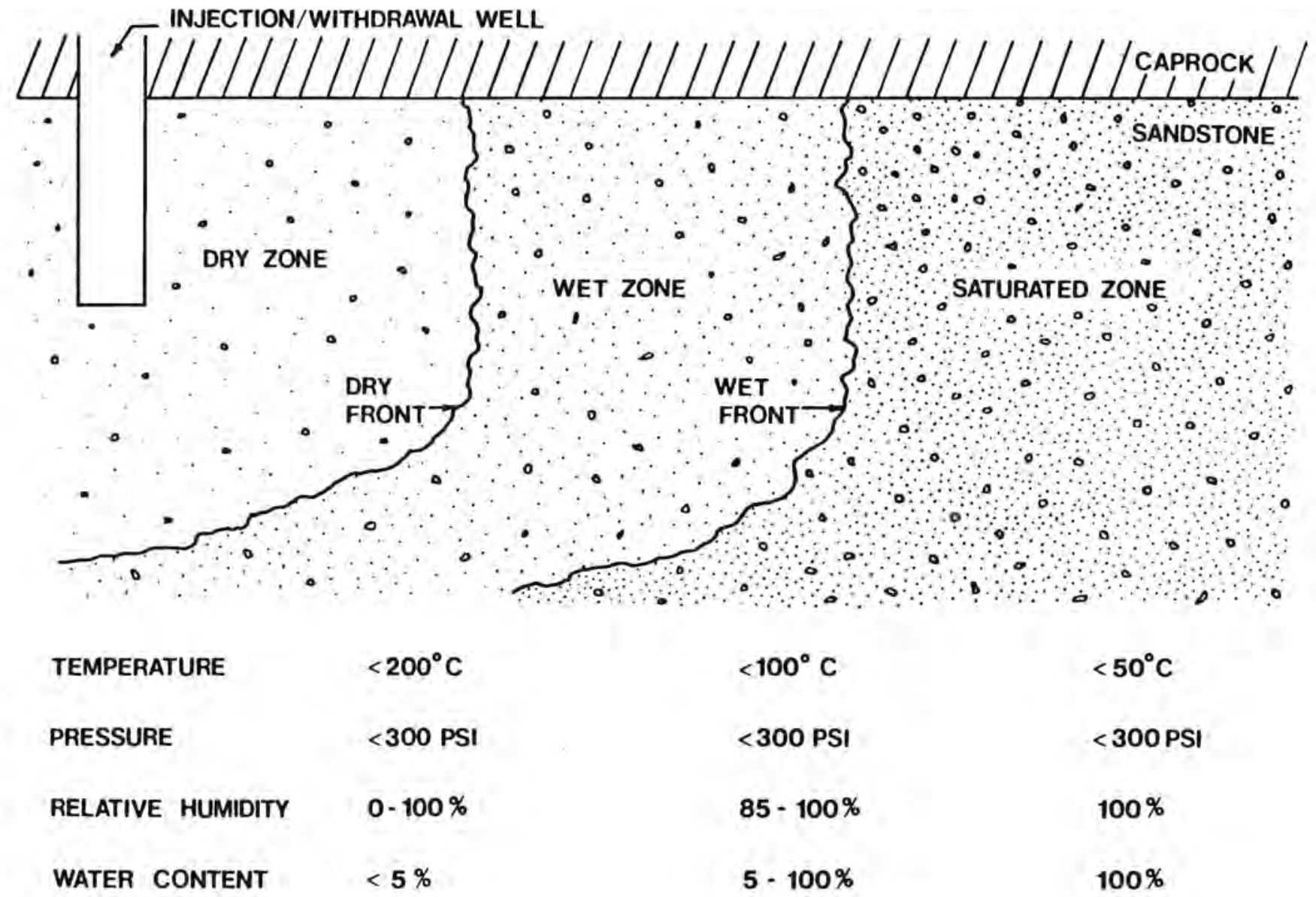

Figure 2. Ranges of reservoir conditions used for instrument system design 
reaches the dry front. The air is then withdrawn from the reservoir at a saturated state determined by the pressure and temperature of the dry front."

From the preceding description it is evident that the conditions of water transport differ between the three zones. Indeed, the reservoir conditions themselves differ markedly. These differences must be considered during monitoring-system design because sensor characteristics vary considerably through the ranges of reservoir conditions. Figure 2 shows the ranges of reservoir parameters expected to be encountered. These ranges are believed to be conservative. Time-dependent temperature and pressure can be superimposed on each zone to predict water transport.

The movement and distribution of water in the reservoir is important operationally, and consequently it is important to the evaluation of numerical modeling and laboratory analyses. Wiles (1979a) stated that the two most limiting nonisothermal model assumptions are those of zero liquid mobility during air cycling and the instantaneous saturation of the air-vapor mixture. It would be pointed out that reservoir heterogeneity will likely alter the conceptual uniform advance of the dry front. In fact, the observation wells themselves induce additional variability; however, these wells are the only mechanism through which estimates of reservoir conditions can be made. In summary, instmment systems must be designed to monitor all ranges of expected reservoir conditions and permit reliable interpretation of obtained data.

\section{Site-decomissioning Period}

The primary concern during this period is to monitor the resaturation of the aquifer during depressurization. If water coning and capillary action have not already presented operational problems during air cycling, it may be desirable to perform such tests. Water coning could be induced by controlled depressurization and repressurization. This could be equivalent to simulating "unscheduled depressurizations" in an operational facility. Unscheduled depressurization is reported to 
be an important concern (Allen, 1981). From an instrumentation standpoint, the concern will be to design sufficient redundancy and to maximize sensor integrity in order to provide adequate data during site-decommissioning tests. The time of sensor exposure to operational reservoir conditions is quite long (over one year), and sensor performance cannot be guaranteed. 


\section{INSTRUMENTATION DESIGN}

The following design for subsurface instrumentation systems was developed to monitor temperature, pressure, pore-air relative humidity, and pore-water content. Continuous monitoring of these four parameters in the reservoir will contribute to an evaluation of air-bubble development, thermal development, cyclic pressure response, reservoir dehydration, and water coning. The first step in the design process was the establishment of design criteria based on experiment goals and operational conditions. Next, the design criteria were implemented in the best possible way for the allotted resources. In addition to design criteria and their implementation, the following sections discuss sensor and serisor-system characteristics, field deployment, and data acquisition systems.

\section{DESIGN CRITERIA AND ASSUMPTIONS}

The instrumentation design criteria are the basic framework upon which subsequent design and development build. Because of their importarce, design criteria must be shaped by careful consideration for the specific application, the constraints of the application, and the objectives of the instrumentation.

\section{$\underline{\text { Design Criteria }}$}

The following design criteria were determined for the subsurface instrumentation at the Pittsfield site.

1. Suitable sensor accuracy.

2. Continuous monitoring capability.

3. Redundancy.

4. Maximum sensor integrity (durability).

5. Contingency planning.

6. Optimization of cost-information ratio. 
Suitable sensor accuracy means the best possible sensor accuracy over the range of CAES reservoir conditions. Continuous monitoring capability requires automated data acquisition and rapid sensor response. Automated data acquisition is also necessary due to the experiment duration and the need to maintain a continuous record of reservoir conditions.

Redundancy in measurement and data collection is vital for these reasons: the high cost of conducting the experiment (whose purpose is to obtain data), the extreme conditions of the CAES reservoir, and the irreplacability of some sensors once finally deployed. Not only should there be redundancy in the number of sensors, but also in the type of sensors. The use of sensors based on different sensing principles, where possible, should provide an added advantage in the unknown environment of a CAES reservoir.

Maximum sensor integrity can be achieved by the selection of durable sensors matched to the CAES environment. Contingency planning is important due to short time schedules and the complexity of the experiment. The goal of minimizing cost was also important due to limited program funding.

\section{Assumptions}

The instrument-systems design is based on the following assumptions:

1. Maximum air injection temperature will be $200^{\circ} \mathrm{C}$.

2. Maximum injection pressure will be 300 psig.

3. Trained site operators will be available for routine maintenance and operation of data loggers.

4. Injection air will be filtered, i.e., compressor oils removed.

5. No moderate to strong acids or bases will exist in the standing water columns during installation. 
6. The two instrument wells will be cemented from the caprock to the surface after sensor-string deployment.

7. The injection/withdrawal wellhead will permit effective exit/entry of instruments leads.

8. Setting of concrete in instrument wells will not harm lead-wire insulation (Teflon and PVC) or conductors.

\section{IMPLEMENTATION OF DESIGN CRITERIA}

Simultaneous energy and mass transfer in saturated and partially saturated porous media (e.g., the dry, wet, and saturated zones) involves complicated physical and chemical processes. Monitoring of energy and mass transfer under CAES conditions requires a sophisticated suite of instruments and data collection equipment. No single instrument or instrument package exists at present to fulfill CAES requirements. Hence, the design, modification and development of an integrated monitoring system were undertaken. The system design implements the design criteria. Table 2 shows parameters and selected sensor types. The implementation of design criteria will be discussed both from the overall and parameter- specific standpoints.

Table 2. Selected sensor types

\begin{tabular}{ll}
\hline \multicolumn{1}{c}{ Parameter } & \multicolumn{1}{c}{ Sensor Types } \\
\hline Temperature & $\begin{array}{l}\text { Thermocouple psychrometer } \\
\text { Platinum resistance element }\end{array}$ \\
Pressure & Silicon strain gage \\
Relative humidity & Thermocouple psychrometer \\
& Cellulose crystal strain gage \\
Water content & Thermocouple psychrometer \\
& Resistance block \\
& Neutron logging device \\
\end{tabular}




\section{Overall Implementation}

The design requirement for continuous monitoring was implemented by using electronic sensors for monitoring all four parameters. Electric output signals from each sensing element can be readily transmitted to the surface and recorded on data processing equipment. Suitable sensor accuracy will be attained by the selection of the best available sensors and their subsequent calibration under simulated reservoir conditions. Most sensors had to be modified in some fashion to withstand expected reservoir conditions. Several sensors will be stressed beyond their standard temperature and pressure ranges. Sensor operation in extended ranges is another reason that extensive calibration is required.

Sensor integrity can be degraded in three ways: physical, chemical, and thermal damage. Physical damage to sensors and their leads, which can occur during calibration, installation, or operation, can be avoided by proper planning and design. Chemical damage is to a large degree uncontrollable; however, durable and corrosionresistant materials were selected where possible. The exposed materials are ceramic, Teflon, stainless steel, chromel, epoxy resin, titanium, fiber glass, aluminum alloy, constantan, PVC, vinyl, platinum, copper, quartz, and cellulose crystallite. Precaution should be taken to assure that any chemicals used during well construction and completion have been dissipated before sensor deployment. Vinyl, PVC, and cellulose will degrade at temperatures above about $105^{\circ} \mathrm{C}-125^{\circ} \mathrm{C}$. Vinyl and PVC have been removed from areas exposed to these temperatures. Cellulose crystallite serves as the hygromechanical sensing element of the strain gage humidity sensor, and this sensor type will be rendered inoperative above these temperatures (refer to calibration section for more discussion of this point).

Redundancy will be achieved by multiple instrumented intervals within wells, redundant sensors within individual intervals, and the use of differing sensing principles. Table 2 shows redundancy of sensor types. 
Contingency planning is evidenced in the availability of spare sensors and lead wires, calibration and laboratory checkout of complete instrument systems, instrumentation design review, and extensive field testing of systems during deployment.

Instrumentation costs were minimized while satisfying design criteria and maximizing information from sensor systems. The most important cost savings also enhanced the instrument system capability. This was the integration of all subsurface continuous-monitoring instrumentation into one complete system with a common data logger for data processing and diagnostic output.

$\underline{\text { Parameter-specific Implementation }}$

The implementation of design criteria can be viewed in greater detail by examining the specific sensor characteristics used to monitor temperature, pressure, relative humidity, and water content. Table 3 lists the sensors and the operational characteristics of each.

Temperature. Two sensor types, platinum resistance elements and thermocouples, will be used to monitor temperature. Both have similar response characteristics but differ in accuracy.

Pressure. Only one sensor type, the silicon strain gage, will be used to monitor reservoir pore-fluid pressure. Hence, redundancy will only be in the number of sensors and not in sensor type. Wellhead pressures, however, will be monitored by the surface-facility instrumentation (not discussed in this report).

Relative Humidity. Relative humidity is monitored by thermocouple psychrometers and cellulose crystal strain gages. These operate over relative humidity ranges of $95 \%$ to $99.9 \frac{\circ}{0}$ and $\approx 0$ to $100 \%$, respectively. These sensors operate under partially saturated conditions; however, cyclic saturated/partially saturated reservoir transients are not expected to degrade the performance (operational accuracy) of the sensors. Note that the thermocouple psychrometer will operate ajequately under low to moderate temperature conditions The cellulose 
Table 3. Sensor characteristics for CAFS reservoir monitoring

\begin{tabular}{|c|c|c|c|c|c|c|c|}
\hline \multirow[b]{2}{*}{ Sensor Type } & \multicolumn{7}{|c|}{ Sensor Characteristics under Operational Environment } \\
\hline & $\begin{array}{l}\text { Temperature } \\
\text { Range } \\
\text { (ambient to) }\end{array}$ & $\begin{array}{c}\text { Pressure } \\
\text { Range } \\
\text { (ambient to) }\end{array}$ & $\begin{array}{l}\text { Relntive } \\
\text { Humidity } \\
\text { Range }\end{array}$ & $\begin{array}{l}\text { Pore-wnter } \\
\text { Content } \\
\text { Ronge }\end{array}$ & $\begin{array}{l}\text { Accuracy } \\
\text { (ambient) }\end{array}$ & $\begin{array}{l}\text { Accuracy } \\
\text { (Flevated } \\
\text { Tempernturc/ } \\
\text { Pressure) }\end{array}$ & $\begin{array}{l}\text { Exposed } \\
\text { Material }\end{array}$ \\
\hline \multicolumn{8}{|l|}{ Temperature } \\
\hline $\begin{array}{l}\text { Platinum } \\
\text { resistance } \\
\text { element }\end{array}$ & $>200^{\circ} \mathrm{C}$ & $>30$ bars & $\begin{array}{l}\text { Saturated/ } \\
\text { unsaturated } \\
\text { vapor } \\
\text { conditions }\end{array}$ & $\begin{array}{l}\text { Saturated/ } \\
\text { unsaturated } \\
\text { liquid } \\
\text { conditions }\end{array}$ & $\pm 0.01^{\circ} \mathrm{C}$ & $\pm 0.05^{\circ} \mathrm{C}^{\mathrm{A}}$ & $\begin{array}{l}\text { Teflon, ceramic, } \\
\text { platinum, PVC }\end{array}$ \\
\hline Thermocouple & $>200^{\circ} \mathrm{C}$ & $>\mathbf{3 0}$ bars & $\begin{array}{l}\text { Saturated/ } \\
\text { unsnturated } \\
\text { vapor } \\
\text { conditions }\end{array}$ & $\begin{array}{l}\text { Saturated/ } \\
\text { unsaturated } \\
\text { liquid } \\
\text { conditions }\end{array}$ & $\pm 0.1^{\circ} \mathrm{C}$ & $\pm 0.25^{\circ} \mathrm{C}^{\mathrm{B}}$ & $\begin{array}{l}\text { Ceramic, Teflon, } \\
\text { PVC , vinyl } \\
\text { chromel, constantan }\end{array}$ \\
\hline \multicolumn{8}{|l|}{ Pressure } \\
\hline $\begin{array}{l}\text { Silicon } \\
\text { strain gage }\end{array}$ & $200^{\circ} \mathrm{C}$ & $>\mathbf{3 0}$ bars & $\begin{array}{l}\text { Saturated/ } \\
\text { unsaturated } \\
\text { vapor } \\
\text { conditions }\end{array}$ & $\begin{array}{l}\text { Saturated/ } \\
\text { unsaturated } \\
\text { liquid } \\
\text { conditions }\end{array}$ & \pm 0.01 bar & \pm 0.05 bar $^{A}$ & $\begin{array}{l}\text { PVC }{ }^{b} \text {, quartz, } \\
\text { titanium, Teflon, } \\
\text { stainless steel, } \\
\text { epoxy resin }\end{array}$ \\
\hline \multicolumn{8}{|l|}{ Relative Humidity } \\
\hline $\begin{array}{l}\text { Thermocouple } \\
\text { psychrometer }\end{array}$ & $>80^{\circ} \mathrm{C}^{\mathrm{A}}$ & $>20$ bars $^{A}$ & $\begin{array}{l}958-99.9 q^{8} \\
(p 0 s s i b l y \\
\left.90 q-99.9 q^{n}\right)\end{array}$ & $\begin{array}{l}\text { Unsaturated } \\
\text { conditions }\end{array}$ & $\pm 0.58^{8}$ & $\pm 1.08^{8}$ & $\begin{array}{l}\text { Ceramic, Teflon, } \\
\text { PvC }{ }^{b} \text {, vinyl }{ }^{b} \text {, chromel, } \\
\text { constantan }\end{array}$ \\
\hline $\begin{array}{l}\text { Cellulose } \\
\text { st rain gage }\end{array}$ & $>125^{\circ} \mathrm{C}^{\mathrm{\theta}}$ & $>30$ bars & $20-1008$ & $\begin{array}{l}\text { Unsaturated } \\
\text { conditions }\end{array}$ & $\pm 2.08^{\mathrm{A}}$ & $\pm 5.08^{\mathrm{A}}$ & $\begin{array}{l}\text { St ainless steel, } \\
\text { inert cellulose, } \\
\text { epoxy resin } \\
\text { Teflon, PVC }\end{array}$ \\
\hline \multicolumn{8}{|c|}{ Pore-water Content } \\
\hline $\begin{array}{l}\text { Thermocouple } \\
\text { psychrometer }\end{array}$ & $>80^{\circ} \mathrm{C}^{A}$ & $>20$ bars $^{A}$ & -- & $\begin{array}{l}0.8 \text { to }>20 \\
\text { bars }\end{array}$ & \pm 0.2 bаr & (a) & $\begin{array}{l}\text { Teflon, } \mathrm{PVC}^{\mathrm{b}}, \\
\text { vinyl } \\
\text { constantan, ceramic }\end{array}$ \\
\hline $\begin{array}{l}\text { Resistance } \\
\text { block }\end{array}$ & $>200^{\circ} \mathrm{C}$ & $>30$ hars & -- & $\begin{array}{l}0.3 \text { to }>15 \\
\text { hars }\end{array}$ & \pm 0.5 bar $^{A}$ & (a) & $\begin{array}{l}\text { Fiber glass, PVC } \\
\text { Al alloy }\end{array}$ \\
\hline $\begin{array}{l}\text { Neutron } \\
\text { logging device }\end{array}$ & $70^{\circ} \mathrm{C}$ & $>30$ bars & $\begin{array}{l}\text { Unsaturated/ } \\
\text { snturated } \\
\text { vapor } \\
\text { conditions }\end{array}$ & $\begin{array}{l}\text { Unsaturatcd/ } \\
\text { saturated } \\
\text { liquid } \\
\text { conditions }\end{array}$ & \pm 2.08 & $\begin{array}{l}\text { not } \\
\text { applicable }\end{array}$ & -- \\
\hline
\end{tabular}

a. Exact values to be determined during calibrntion. b. Materials uscd only where temperatures $<100^{\circ} \mathrm{C}$. 
crystal strain gage will operate to temperatures slightly exceeding $125^{\circ} \mathrm{C}$ before it will become inoperable.

Water Content. Pore-water content in the reservoir proper and in the instrument wells is monitored by three different sensor types. The thermocouple psychrometer is used to monitor both relative humidity and pore-water content (relative humidity is determined directly, whereas pore-water content is determined indirectly by calibration) in the instrument wells. The resistance block also is used to determine pore-water content in the instrument wells. Neutron logging is used to determine pore-water content in the reservoir exterior to the wellbore of the logging and sampling wells (not instrument wells). Note that neutron logging is typically not done continuously and the logging tool has a thermal limitation of $70^{\circ} \mathrm{C}$.

SENSOR AND SENSOR-SYSTEM CHARACTERISTICS

All monitoring sensors are connected from their location in the reservoir to surface electronics via shielded, high-temperature leads. Surface electronics include power supplies, signal conditioners, amplifiers, and signal data preprocessing modules. These modules and sensor output signals, in turn, are coupled to an analog-to-digital (A/D) multiplexer and subsequently to a data logger and peripheral devices. The neutron logging device (sonde) and associated electronics, however, are read separately.

The following brief summaries of each sensor and associated electronics provide an overview of the configuration and operation of each device. Detailed specifications for each device (vendor specifications) are given in the appendix.

Platinum Resistance Elements

Platinum resistance elements (or RTDs) are used to precisely monitor temperature. These sensors are capable of rapid response and accuracies of $\pm 0.001^{\circ} \mathrm{C}$ under laboratory conditions to perhaps greater 
than $\pm 0.05^{\circ} \mathrm{C}$ under reservoir conditions. The electronic configuration of the sensor includes the fully encapsulated sensing element coupled to an independent, regulated current source ( $₫ 15 \mathrm{Vdc})$ and a bridge circuit. The bridge is coupled with an amplifier, linearizer, and span adjust components. Operationally, the sensing element's resistance changes in response to corresponding changes in reservoir temperature. The resistance change affects the current balance in the bridge circuit. This results in a corresponding change of voltage supplied at the regulated-current source. Linearization of the output signal is facilitated by positive voltage feedback. A three- or four-wire bridge configuration is used to minimize lead-wire resistance effects on the sensor output signal.

The sensor is illustrated in Figure 3. The sensor is resistant to thermal and physically induced strain, thermocouple effects, RF noise, and power dissipation. The sensor and associated electronics are capable of accurate temperature monitoring under all expected reservoir conditions.

Thermocouples

Thermocouples are also used to monitor temperature. The sensors have low heat capacity and instantaneous response and are used individually to monitor temperature or directly with thermocouple psychrometers. The sensor is fixed directly (booted) onto the housing of a thermocouple psychrometer (to be discussed latter). These sensors are quite rugged and reliable and are capable of monitoring temperatures in reservoirs with an accuracy of $\pm 0.25^{\circ} \mathrm{C}$.

Thermocouples operate by determining the electrical potential produced by the temperature difference between two junctions of dissimilar metals. Copper-constantan lead wires and two junctions (one monitoring junction and one reference junction) are used. The configuration of the sensor and associated electronics consists of an in situ monitoring junction, a fully temperature-compensated reference junction at the surface, an amplifier, and a millivoltmeter. This configuration is 

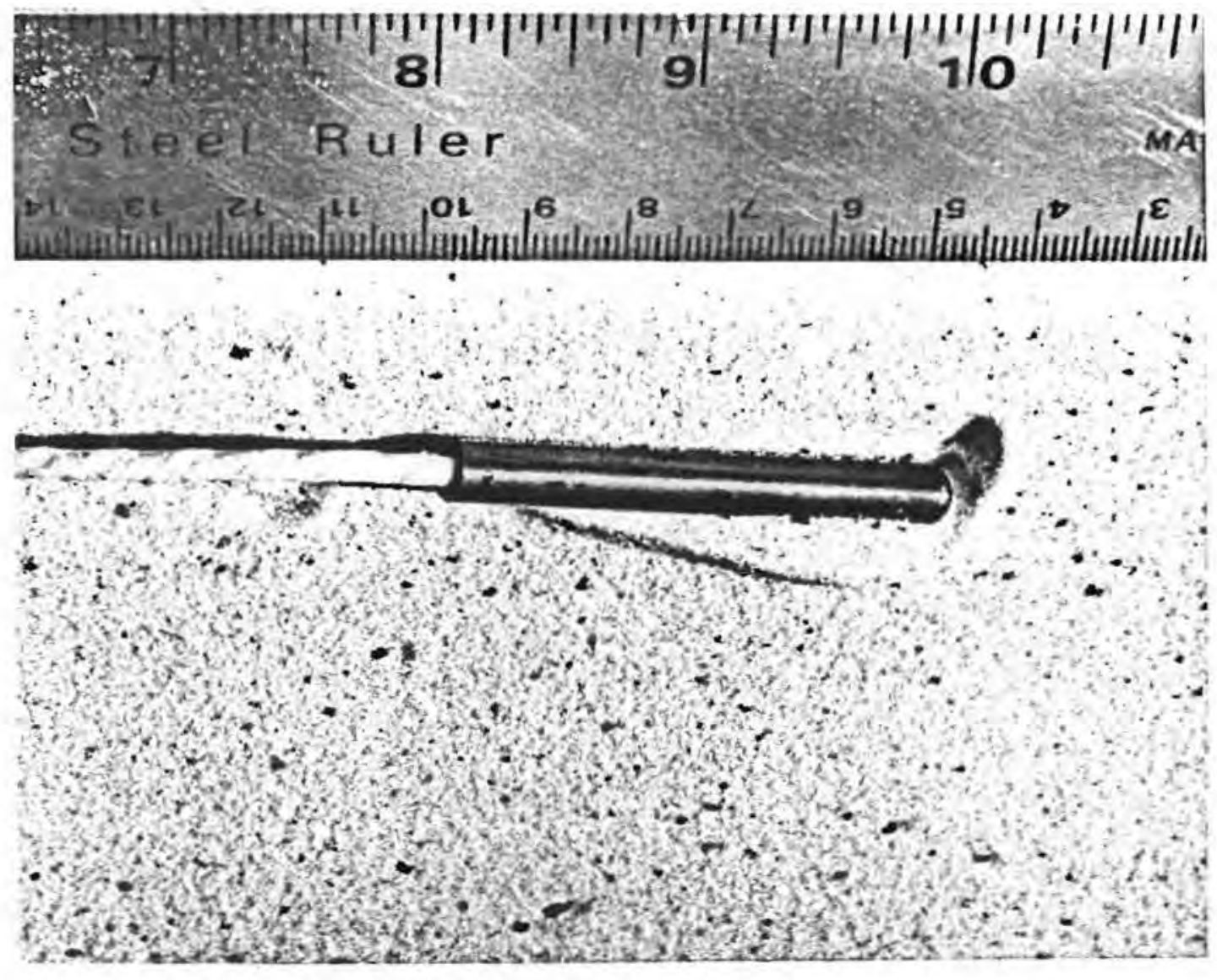

Figure 3. A platinum resistance element 
coupled to the thermocouple psychrometer readout device. This device monitors a 0 to 100 millivolt signal, which is amplified and supplied an as output signal to the data logger.

The sensor is shown as a drawing in Figure 4 and is illustrated in Figure 5. The sensor is located in the shielding surrounding the psychrometer housing. The thermocouple and associated electronics are capable of accurately monitoring temperature under all expected reservoir conditions. The sensor is used in conjunction with the thermocouple psychrometer to determine relative humidity and pore-water content.

\section{Silicon Crystal Strain Gages}

Pressure under all reservoir conditions throughout testing is monitored by perfectly elastic, fully compensated, silicon crystal strain gages. These sensors are rugged, non-hysteritic, rapid-response devices capable of accurately monitoring positive pressure to \pm 0.005 bar in the laboratory and \pm 0.05 bar under expected reservoir conditions.

The device configuration consists of a four-arm bridge circuit directly diffused onto a silicon diaphragm, coupled with an independently regulated-current source ( $\pm 10 \mathrm{Vdc}$ nominal), an amplifier, and linearizer. The sensor functions directly in response to deflection of the silicon crystal diaphragm in physical contact with the wellbore or reservoir environment. For high-temperature applications, the chamber housing the bridge circuit within the sensor is evacuated (fabricated under a negative pressure); whereas, for low-temperature applications the chamber is fabricated at atmospheric pressure. The strain gage bridge output is amplified and linearized $(0-10 \mathrm{Vdc})$. This output acts as a final signal to the data logger.

The sensor is illustrated in Figure 6 and shown pictorially in Figure 7. The sensor is rugged and durable, fabricated primarily from titanium. Calibration will be required to determine the accuracy of the sensor at elevated temperatures and pressures. 


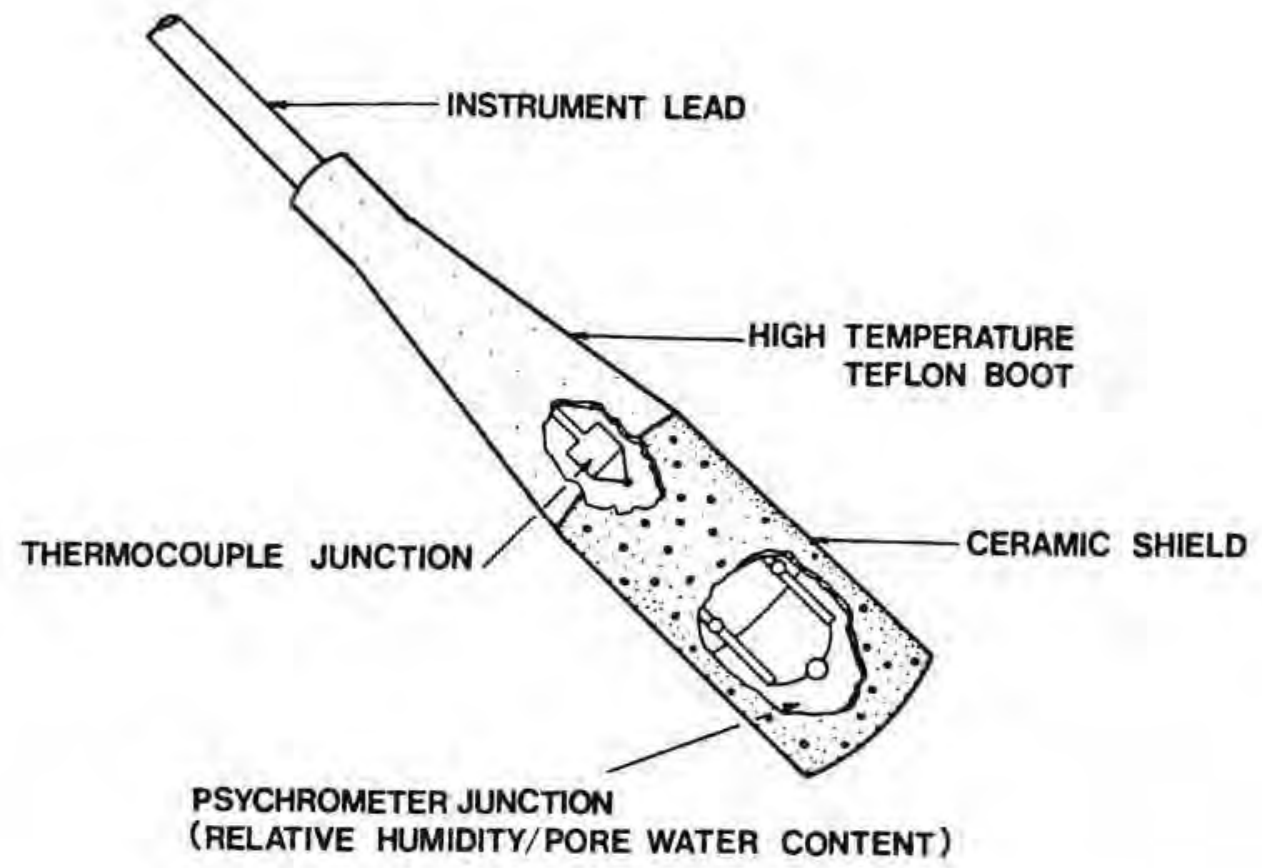

Figure 4. Drawing of thermocouple psychrometer with a porous ceramic shield. -- Not to scale 

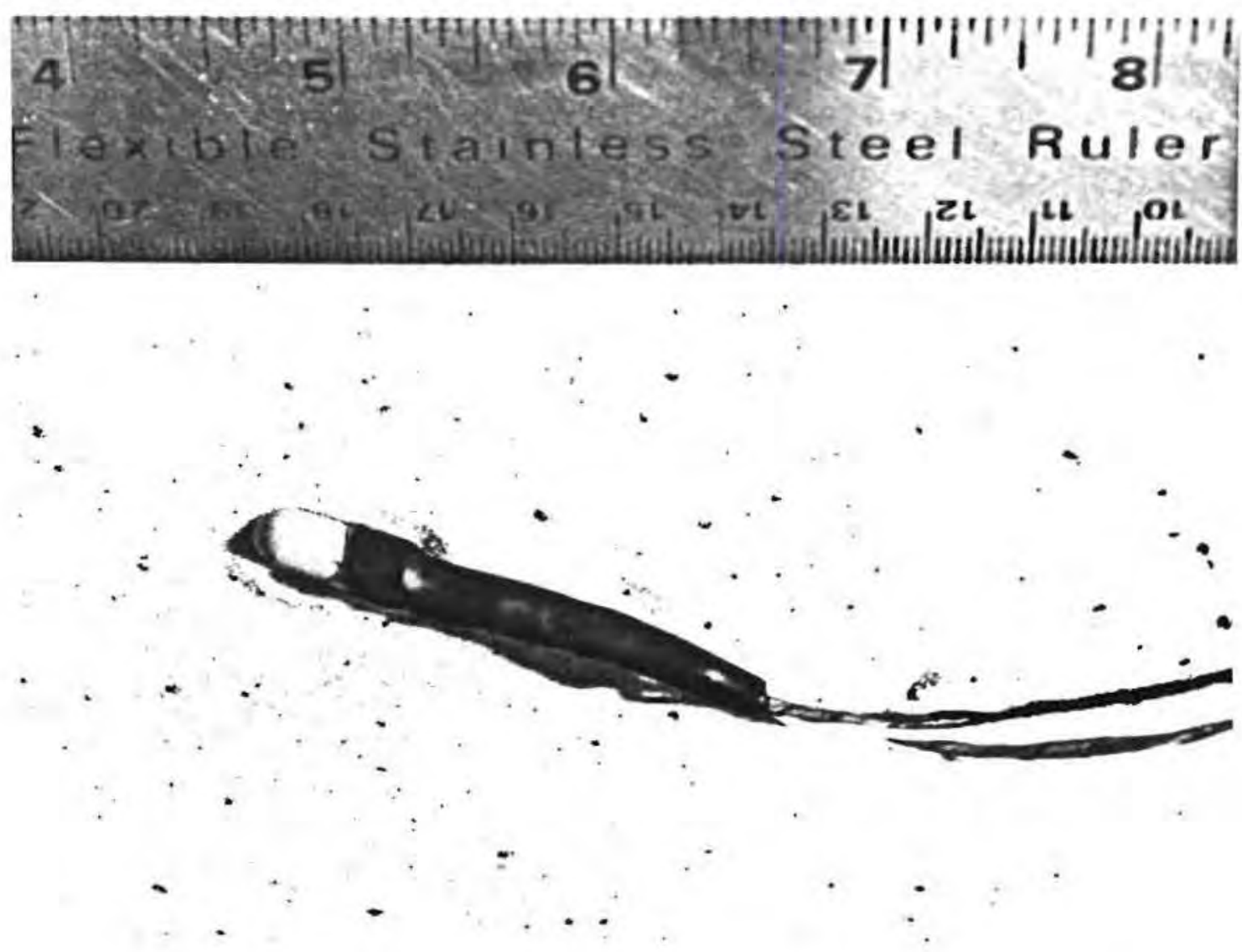

Figure 5. A thermocouple psychrometer with a porous ceramic shield 


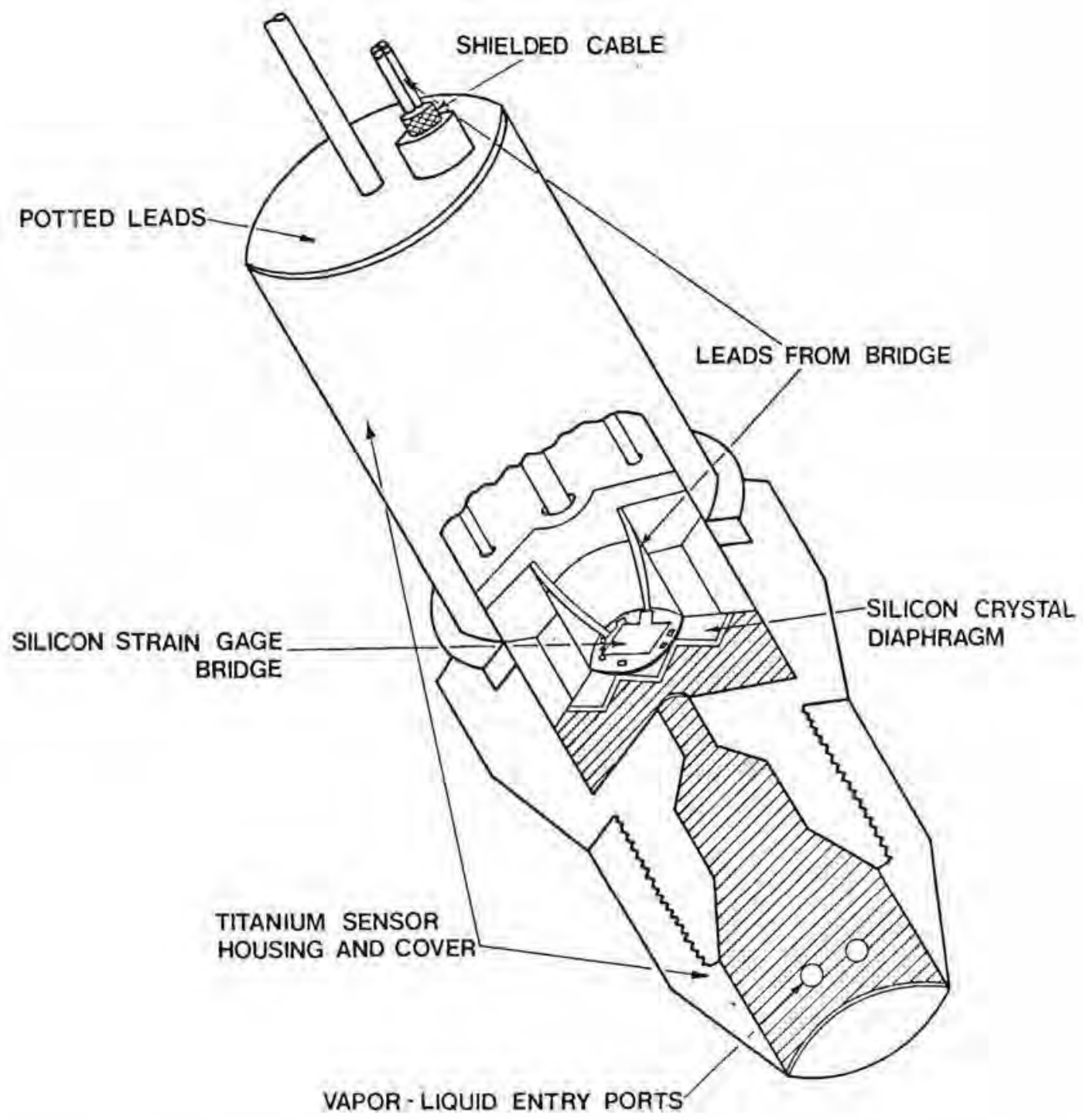

Figure 6. Drawing of silicon crystal strain gage used to monitor pressure. -- Not to scale 


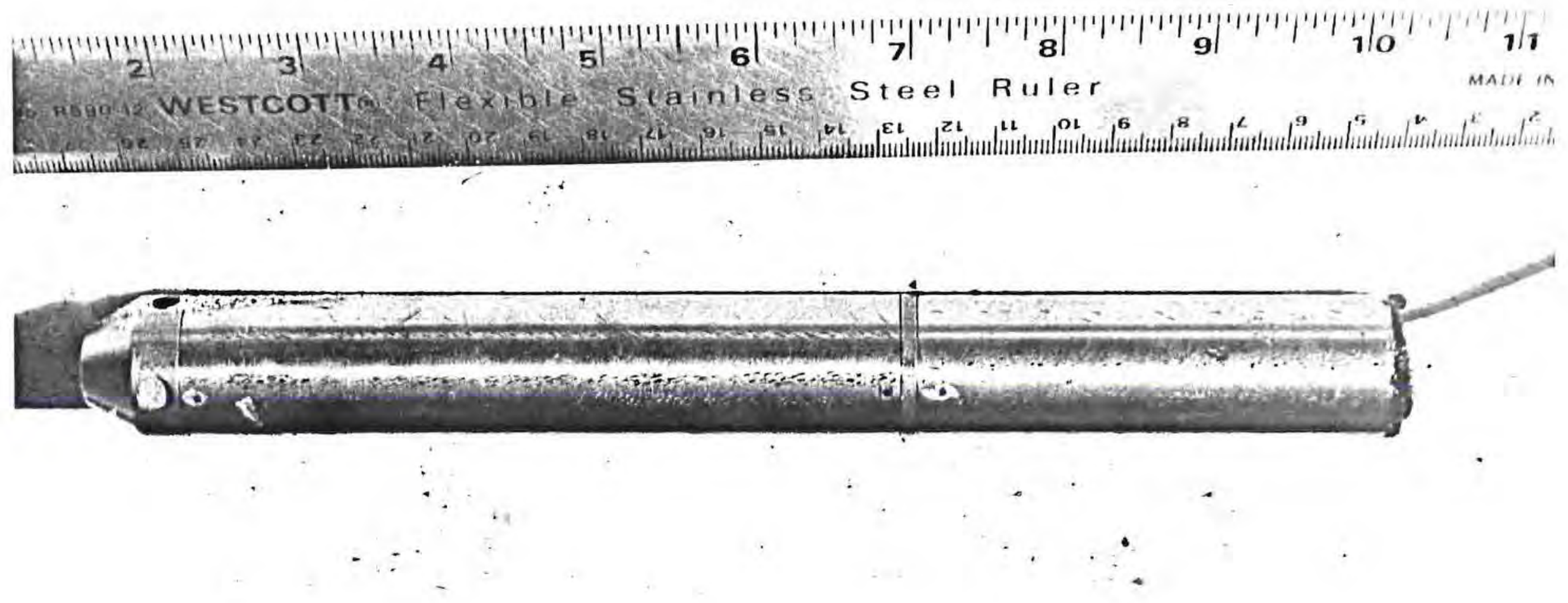

Figure 7. A silicon crystal strain gage used to monitor pressure 


\section{Cellulose Strain Gages}

Relative humidity in the open and backfilled wellbores is monitored in part by cellulose strain gages. These sensors detect watervapor concentration in the reservoir under partially saturated conditions; however, they can withstand immersion in water without either damage or shift in calibration. The accuracy of the sensors depends on the rate of change of relative humidity, air flow, and temperature. Accuracy limitations under expected reservoir conditions will exeed $\pm 2 \%$ and $\pm 5 \%$ at low and high temperatures, respectively. The operational range of the sensor between 0 and $100 \%$ relative humidity will be determined by calibration.

The cellulose strain gage sensor consists of a composite of organic and inorganic materials that respond to hygromechanical stress induced by water-vapor concentration. The crystalline material acts on a kovar beam onto which is diffused two thermally matched isolated silicon strain gages. The silicon piezoresistive strain gages are configured in a half-bridge circuit. The sensor is housed in an isolated probe protected with a porous ceramic cap and coupled with a current source $(+12 \mathrm{Vdc})$ and signal-conditioning electronics.

The bridge circuit voltage signal is amplified and linearized to provide an output voltage from 0 to $5 \mathrm{Vdc}$. This signal acts as a final input signal to the data logger. Note that the sensor is irreversibly damaged due to cellulose crystal degradation at temperatures greater than perhaps $125^{\circ} \mathrm{C}$. The operational limit for the sensor will be determined by calibration. The sensor is shown in Figure 8, The sensor will operate under partially saturated conditions over all reservoir pressures, both under static and dynamic air-flow conditions.

\section{Thermocouple Psychrometers}

Another sensor used to monitor relative humidity in $\mathrm{I} / \mathrm{W}$ and instrument wells is the thermocouple psychrometer. This sensor has as an integral part a thermocouple (discussed earlier). Thermocouple psychrometers are capable of monitoring both relative humidity and, by 


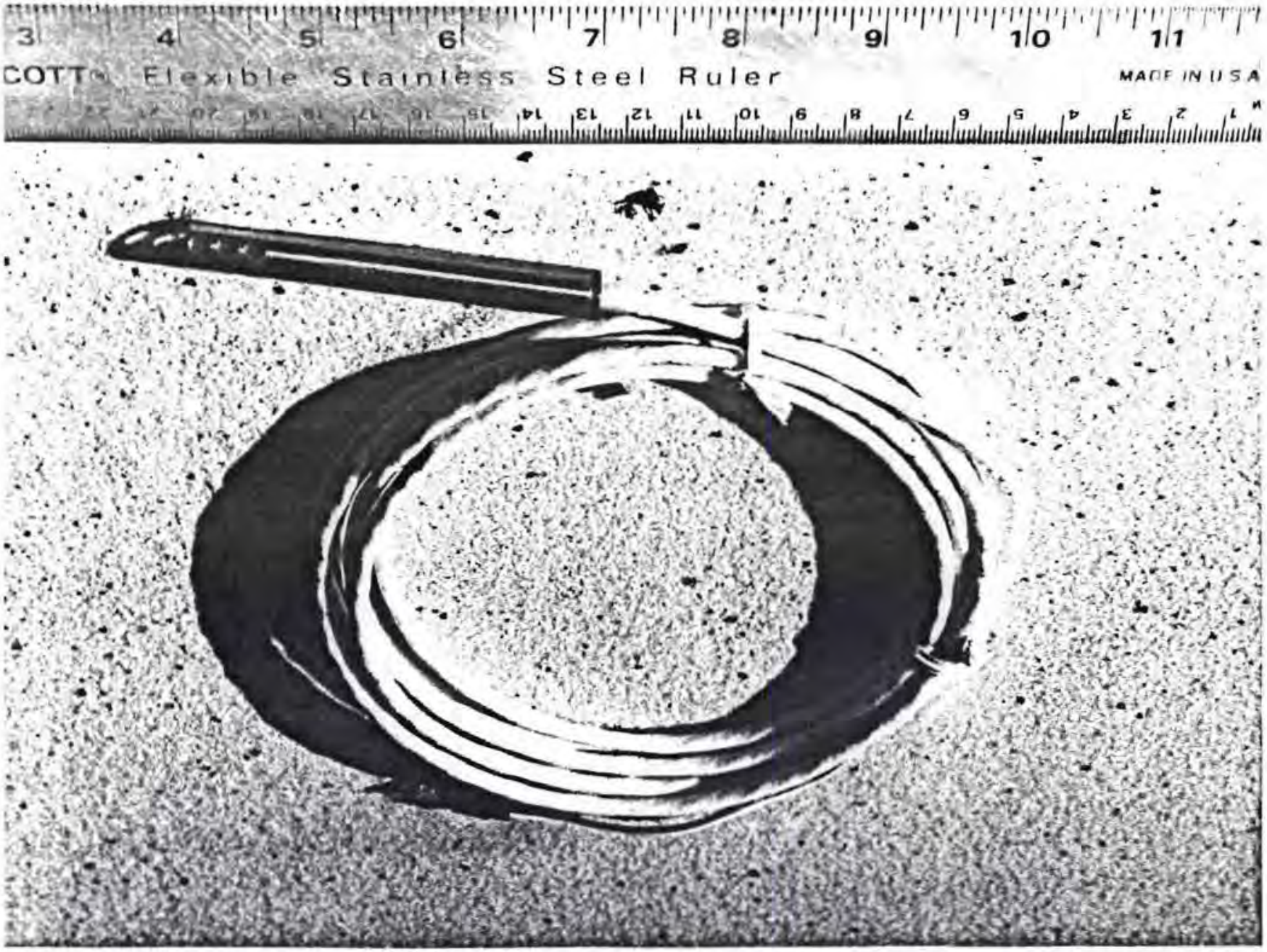

Figure 8. A cellulose strain gage used to monitor relative humidity 
special calibration, pore-water content. Pore-water content is determined indirectly by equating relative humidity to matric potential of the wellbore backfill material. Matric potential is the result of adsorption and capillarity in a porous medium. The sensors are capable of moderate temporal response to changes in relative humidity and pore-water content in partially saturated conditions. Thermocouple psychrometers have an accuracy greater than 0.2 bar (negative pressure, i.e., matric potential) for pore-water content and relative humidity under ambient reservoir conditions. For CAES conditions the accuracy can be determined only by extensive calibration over a wide range of temperatures and pressures. The electronics configuration of the sensors and auxiliary modules includes a thermocouple psychrometer junction coupled with a regulated-current source, oscillator, switching circuit, amplifier, signal conditioner, microvoltmeter, A/D converter, memory buffer, and a serial output interface. Relative humidity and/or pore-water content are monitored by determining water-vapor saturation in air as the ratio of the partial pressure of water vapor in air to the equilibrium partial pressure at vapor saturation. The ratio is determined by measuring the ambient temperature and either the wet-bulb or dew-point temperature. Physically, the sensor consists of two dissimilar metals and two thermocouple junctions. A cooling current (Peltier effect) is supplied to the junction located in the reservoir until condensation occurs at this junction. Once the cooling current is terminated, evaporative cooling occurs at the point of condensation on the junction. Evaporative cooling is related to vapor-pressure depression. The thermal electromotive force (EMF) between the junctions located at the surface (thermally compensated/controlled reference junction) and the junction in the wellbore is proportional to the temperature at the junctions and is potentiometrically measured. The analog EMF difference is amplified, linearized, and converted to digital format and stored in a surface electronics module. The digital signal is then periodically transmitted as final output to the data logger. 
Figures 4 and 5 show the sensor in diagrammatic and photographic form. The psychrometer junction is covered with a porous ceramic cap, which allows free vapor mass transfer while precluding particulate contamination of the junction. The sensor and associated electronics will require laboratory calibration to determine optimum cooling current time under various temperature and pressure conditions. The sensor will fail to operate when Peltier cooling will no longer permit condensation of water vapor at the dew point on the junction located in the wellbore.

\section{$\underline{\text { Resistance Blocks }}$}

Resistance blocks, along with thermocouple psychrometers, are used to monitor pore-water content. Resistance blocks monitor porewater content within backfill material placed in the instrument wells. These sensors are capable of accurate, moderate temporal response determination of pore-water content (matric potential) of greater than \pm 0.5 bar at low reservoir temperature and pressure conditions. As with thermocouple psychrometers, detailed calibration at elevated temperature and pressure will be required to determine accuracy at expected CAES conditions.

The sensor consists simply of an aluminum alloy housing enclosing two metal alloy screens isolated by an inert fiber glass material. The resistance between screens is a function of the water content of the inert material in equilibrium with the matric potential of the well backfill material, hence, pore-water content. To determine pore-water content, electronic modules (oscillator, amplifier, capacitance effect correction, signal conditioner, switching circuit, and linearizer electronics) are required. Sensor resistance is converted in surface modules to voltage ( 0 to $10 \mathrm{Vdc}$ ) output, which acts as a final input signal to the data logger.

The sensor is shown diagrammatically in Figure 9 and a photograph of the sensor is shown in Figure 10. Note that the resistance block as well as the thermocouple psychrometer measures 


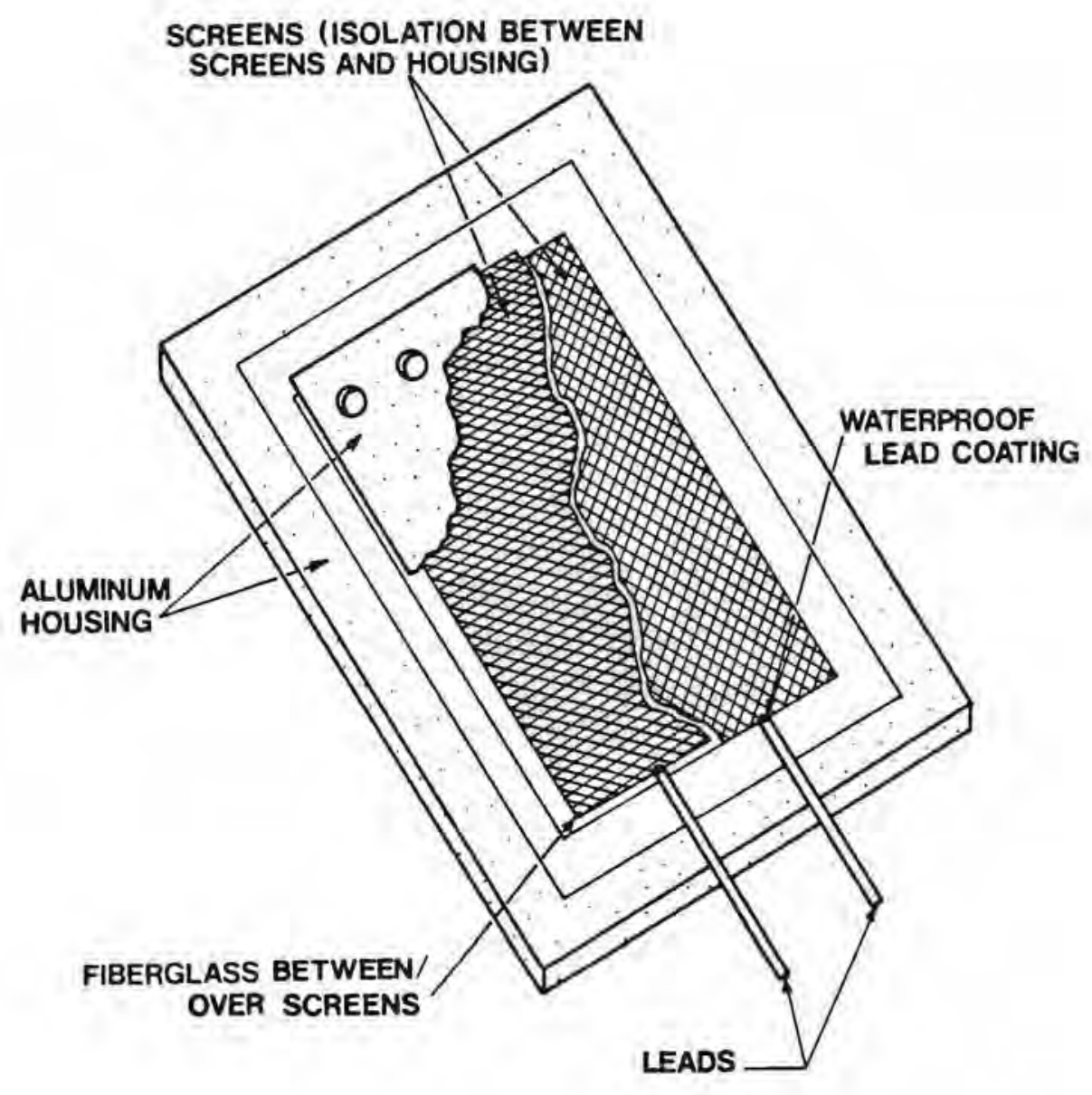

Figure 9. Drawing of a resistance block used to measure porewater content. -- Not to scale 

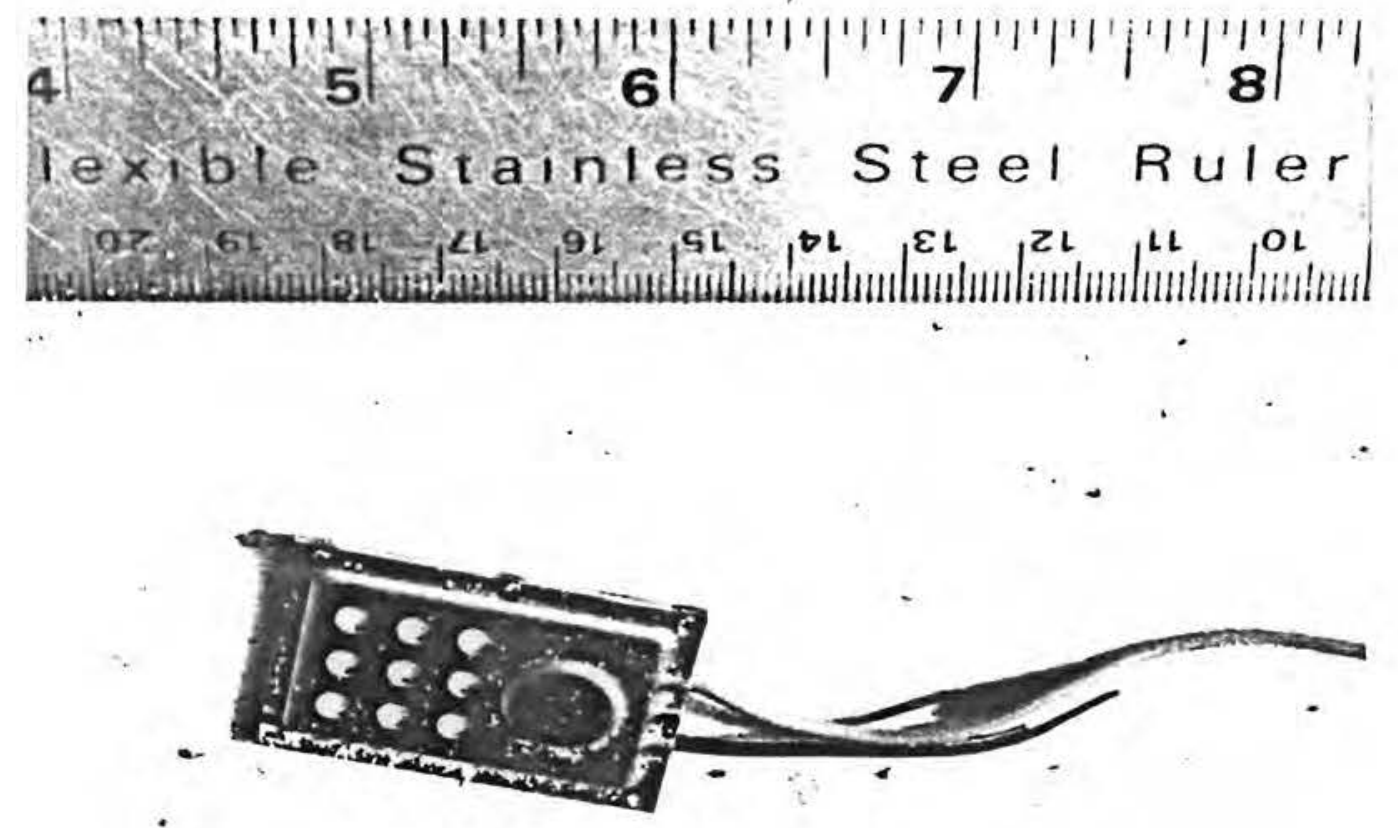

Figure 10. A resistance block used to measure pore-water content 
pore-water content in backfilled wells (backfill material is texturally different from that of the reservoir). As such the sensors function under nominally equilibrium conditions interrogating over limited distances away from each sensor. Thus, the measured pore-water content of the backfill material is accurately determined, yet may serve as only a semi-quantatative measurement of water content in the reservoir.

\section{Neutron Logging Device}

Neutron thermalization is a phenomenon occurring as a result of elastic collisions between neutrons and atomic nuclei. A logging device (sonde) uses neutron thermalization to measure the change of porewater content throughout specific depth intervals in a wellbore. The logging device is capable of monitoring pore-water content with an accuracy of greater than $2 \%$ by volume, or more appropriately, changes in pore-water content of the same accuracy limit. The accuracy depends primarily on the wellbore morphology and materials and the counting time.

Neutron thermalization occurs when high-energy neutrons $(0,1$ to $10 \mathrm{MeV})$ emitted from an americium-241 beryllium source $[(\gamma, \eta)$ reaction] elastically collide with primarily hydrogen nuclei in water. The neutrons are scattered and slowed (thermalized) on collision and detected by a boron-10 trifluoride proportional detector $[(\pi, \alpha)$ reaction]. The number of thermalized neutrons reaching the detector per unit time is then proportional to the pore-water content of the reservoir. The passive neutron source and the high-voltage detector are used in situ. Pulsed signal output from the detector is amplified, conditioned, scaled, and recorded at the surface.

The logging sonde (neutron source and detector) is shown diagrammatically in Figure 11. This tool may have accuracy limitations under high-temperature reservoir conditions. 


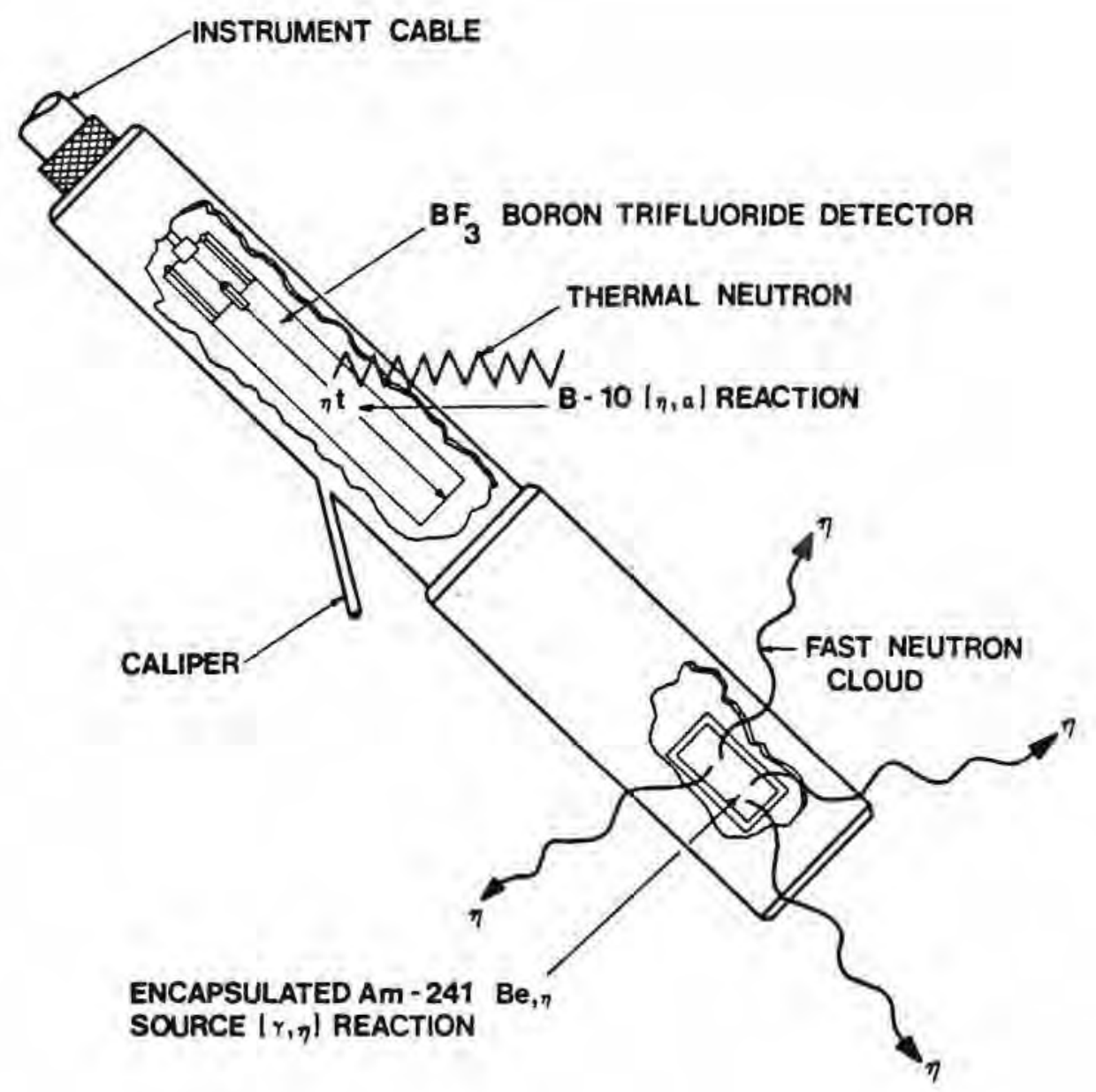

Figure 11. Drawing of neutron logging sonde for monitoring pore-water content. -- Not to scale 


\section{DESIGN OF FIELD DEPLOYMENT}

The field deployment design for sensor systems depends on the objectives of instrumentation, estimated reservoir conditions, and the sensor characteristics. The generalized well-field layout for the Pittsfield site is shown in Figure 12, The three close-in wells, the $I / W$ well and the $3-\mathrm{m}(\mathrm{F})$ and $6-\mathrm{m}(\mathrm{G})$ instrument wells, will be instrumented for continuous monitoring. The four outlying wells (A, B, C, D) will be used for neutron logging and water sampling. An additional logging well (not shown) may be added near the $I / W$ well. The construction of each well to be instrumented (but without instruments installed) is shown in Figures 13, 14, and 15. Instrument systems will be installed just prior to experiment start-up to minimize the exposure of sensors to brackish, saturated conditions. Based on available information and analyses, a field deployment design has been completed. It is believed that this design will maximize the amount of reliable, valuable data to be obtained. The following sections briefly describe four major considerations: (1) backfilling, (2) the function of instrument containers, (3) the number and location of instrumented intervals, and (4) the $I / W$ well instrumentation. The details of deployment will be described in a later section.

\section{Backfilling}

Backfilling refers to the placement of sand around sensors after their deployment in the two instrument wells. Backfilling is necessary for closer approximation of reservoir properties in the wellbore. An open wellbore is an obvious short circuit for mass and energy transport. For example, air reaching a saturated but open wellbore would bubble to the top of the wellbore. Thus, the open wellbore would be desaturated from the top down. Also, parameters (temperature, pressure, relative humidity) monitored in an open wellbore will be "averaged" over the entire interval. Such measurements will probably be dominated by the conditions of high flow zones within the interval. Backfill material increases wellbore resistance to flow. Thus, 


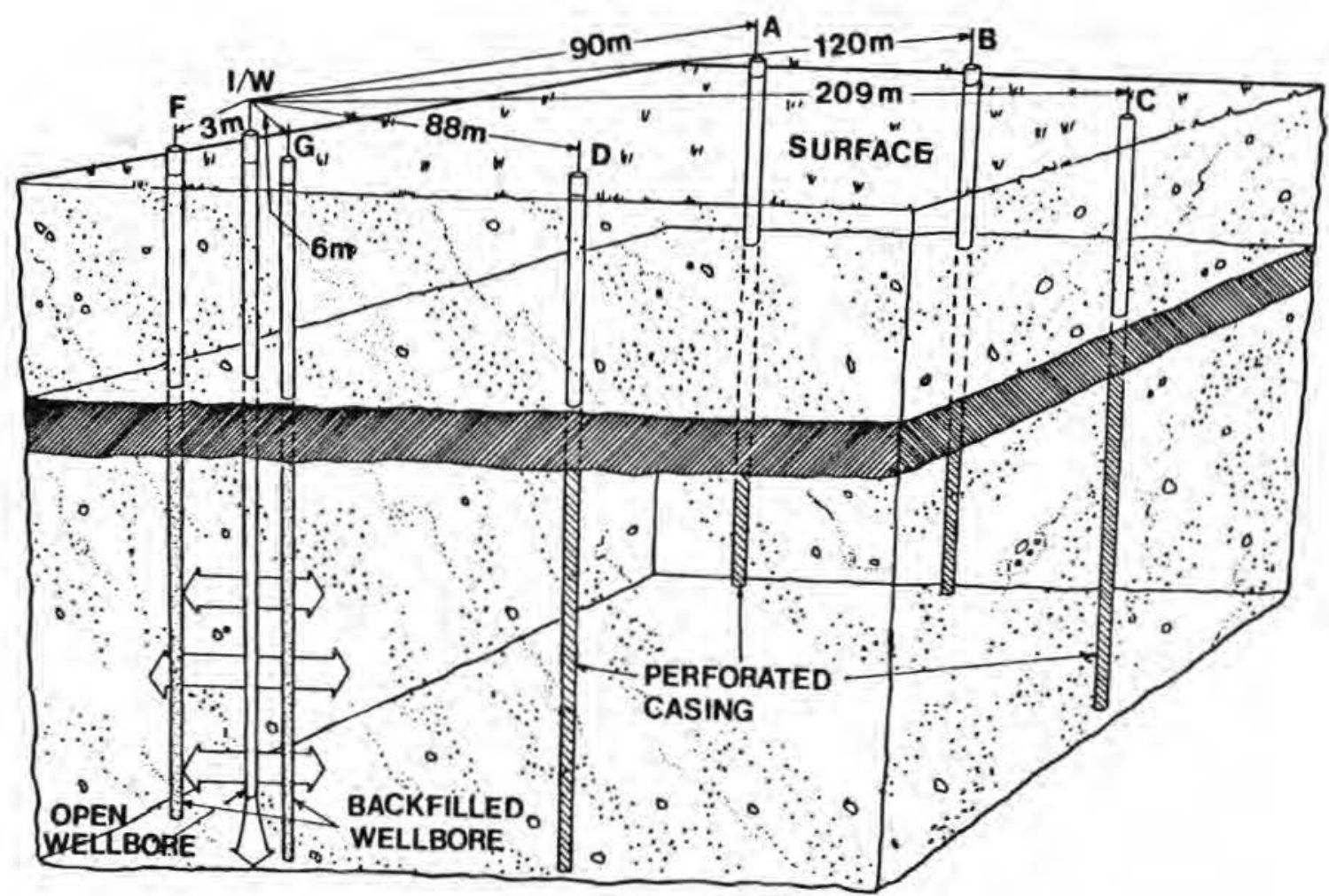

Figure 12. Generalized wellfield layout at Pittsfield, IL 


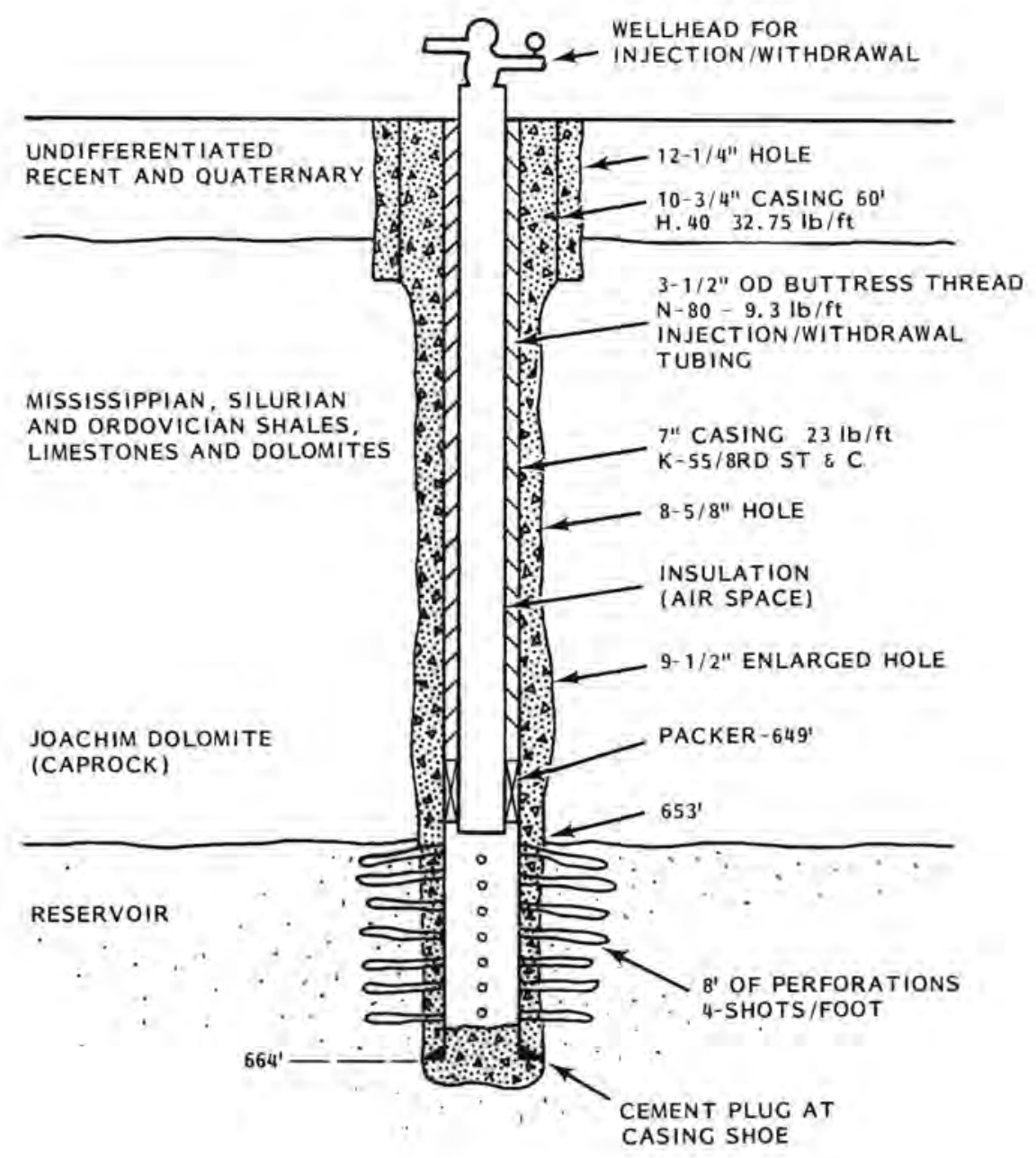

Figure 13. I/W well completion. -- From Bakhtiari (1982) 


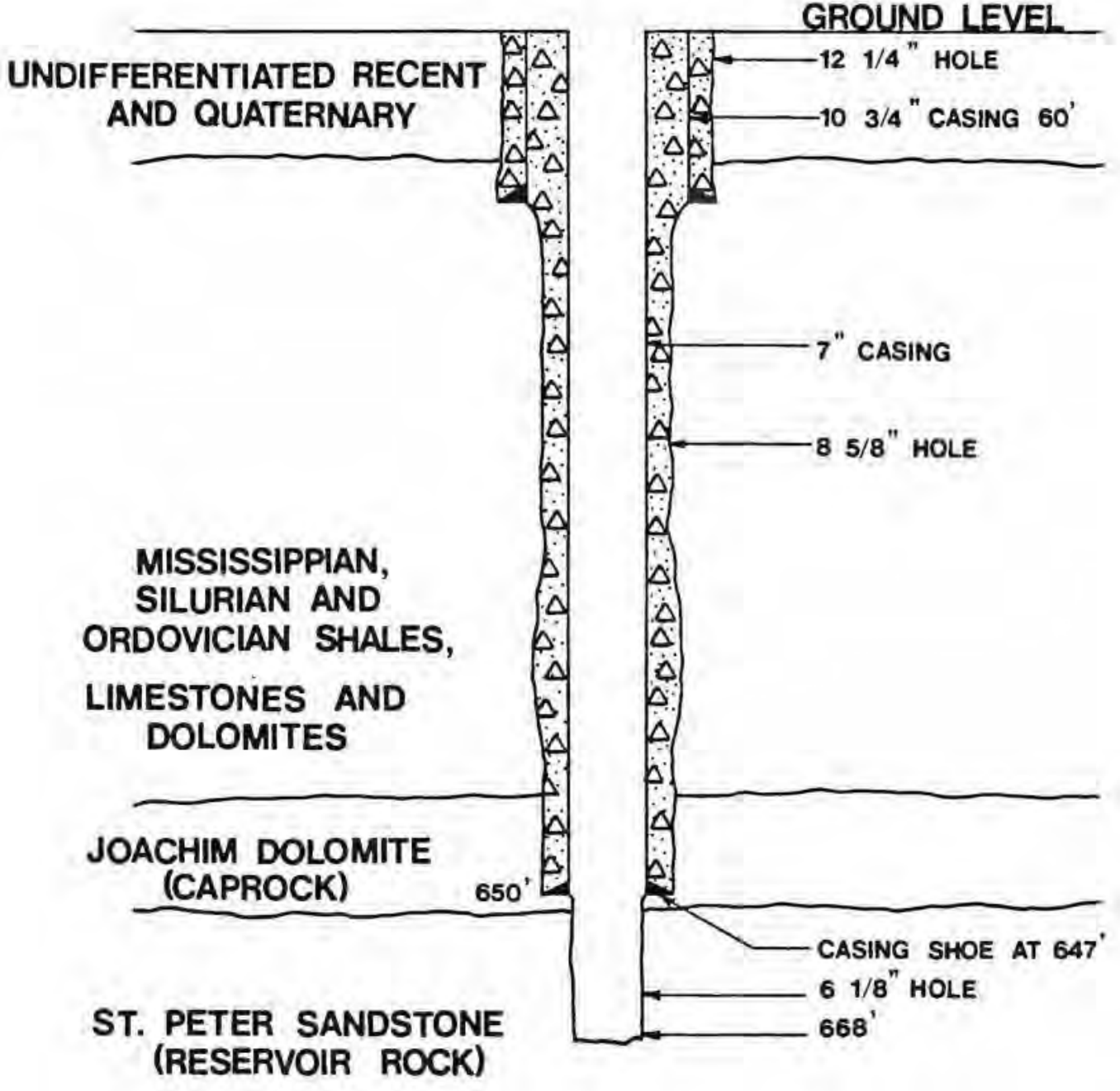

Figure 14. Three-meter instrument (F) well completion. From Bakhtiari (1982) 


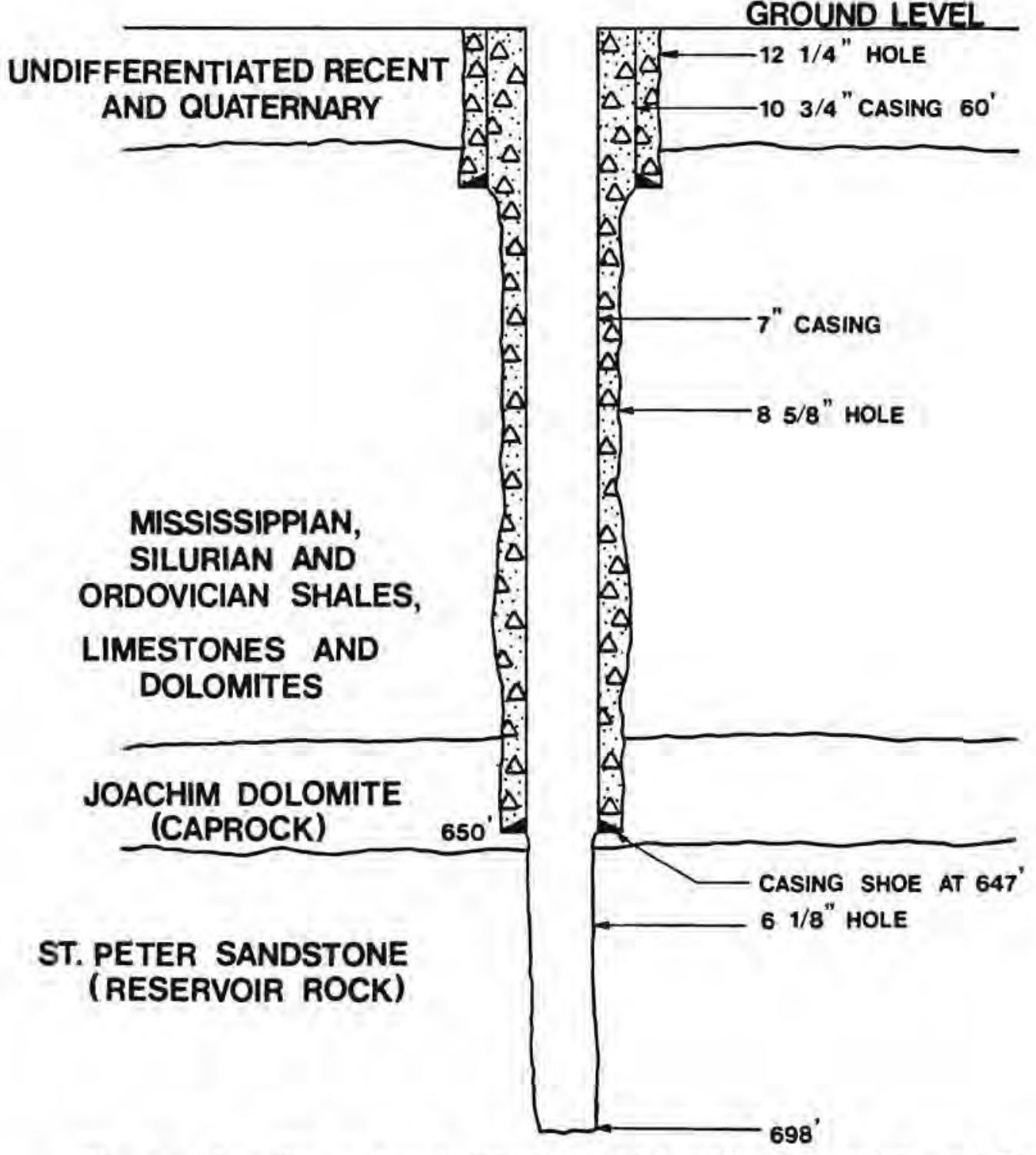

Figure 15. Six-meter instrument (G) well completion. -- From Bakhtiari (1982) 
measurements will be more "local averages." In addition, pore-water content measurements can be taken in the backfill material.

Instrument Containers

Two instrument containers (one in each instrument well) will be used. Instrument containers simply enclose a set of instruments and prevent backfill material from surrounding them. The instruments in the containers will help detect differences in the responses of an open wellbore and a backfilled one.

It is important to note that the instruments measuring parameters (especially pore-water content and relative humidity) in the wellbore may not be in equilibrium with the aquifer. There are two possible reasons for this disequilibrium. First, the backfill porosity will be larger than that of the sandstone (as an estimate, $40 \%$ porosity in the backfill, $20 \%$ in the sandstone (Table 1)). The larger porosity will be a comparatively lower resistance transport pathway between different depths in the aquifer. Therefore, vertical distribution of various properties (e.g., pressure, temperature, relative humidity) will be most representative when the aquifer approaches steady-state conditions.

A second mechanism that may cause disequilibrium between parameter measurements taken in the wellbore and actual reservoir conditions exterior to the wellbore is interface phenomena. An interface exists between the backfill material and the sandstone. This interruption of pore-space continuity will affect transport through the wellbore. When the wellbore and the sandstone are saturated, the interface is not likely to affect the lateral advance of an air front. It may be possible, however, for a rapidly advancing air front to penetrate around the interface and isolate the backfill pore water from the aquifer. If this occurs, the wellbore may remain in disequilibrium until air flow through the aquifer depletes the backfill pore-water content. Until the rates of air-front movement and the transport properties of both the aquifer and backfill material are known, the potential for and duration of disequilibrium cannot be estimated. A comparison of measurements inside and outside the instrument containers will indicate whether disequilibrium is 
occurring. Instrument containers are designed to contact the sandstone interface at several points, thus permitting more rapid response to flow conditions in the aquifer.

The instrument containers will definitely be important when a wetting front advances past an initially dry wellbore. This interface situation is common in soil physics; the wetting front will slow drastically when it encounters the wellbore. The sensors will therefore not register the passage of the wetting front immediately. As in the dry front case, the instruments in the container should respond first. In any event, the use of contained and uncontained sensors should facilitate an analysis of any reservoir-wellbore disequilibrium and the temporal response of sensors to these conditions.

\section{$\underline{\text { Instrumented Intervals }}$}

An instrumented interval contains a set of instruments. There are nine instrumented intervals in three wells: one in the I/W well, three in the $3-\mathrm{m}$ instrument well, and five in the $6-\mathrm{m}$ instrument well. Figure 16 shows this deployment scheme. Several points about the location of instrument sets should be made. First, the total number of intervals and their locations were decided from considerations for redundancy, resolution of reservoir processes, the amount of downwell instrumentation, and cost. Second, the instrument containers were placed at different elevations in separate wells, primarily to provide data from different levels of the reservoir rock. The container in the 6-m well was located such that it would be above the predicted airwater interface. Wiles and McCann (1981b) modeled the air-bubble development for Pittsfield, and their results are shown in Figure 1 , This figure has been adapted to show the vertical penetrations of both the $3-m$ and $6-m$ instrument wells.

\section{Injection/Withdrawal Well}

From a reservoir standpuint, the sandface of the I/W well is where flow starts and stops. Temperature and pressure extremes will 


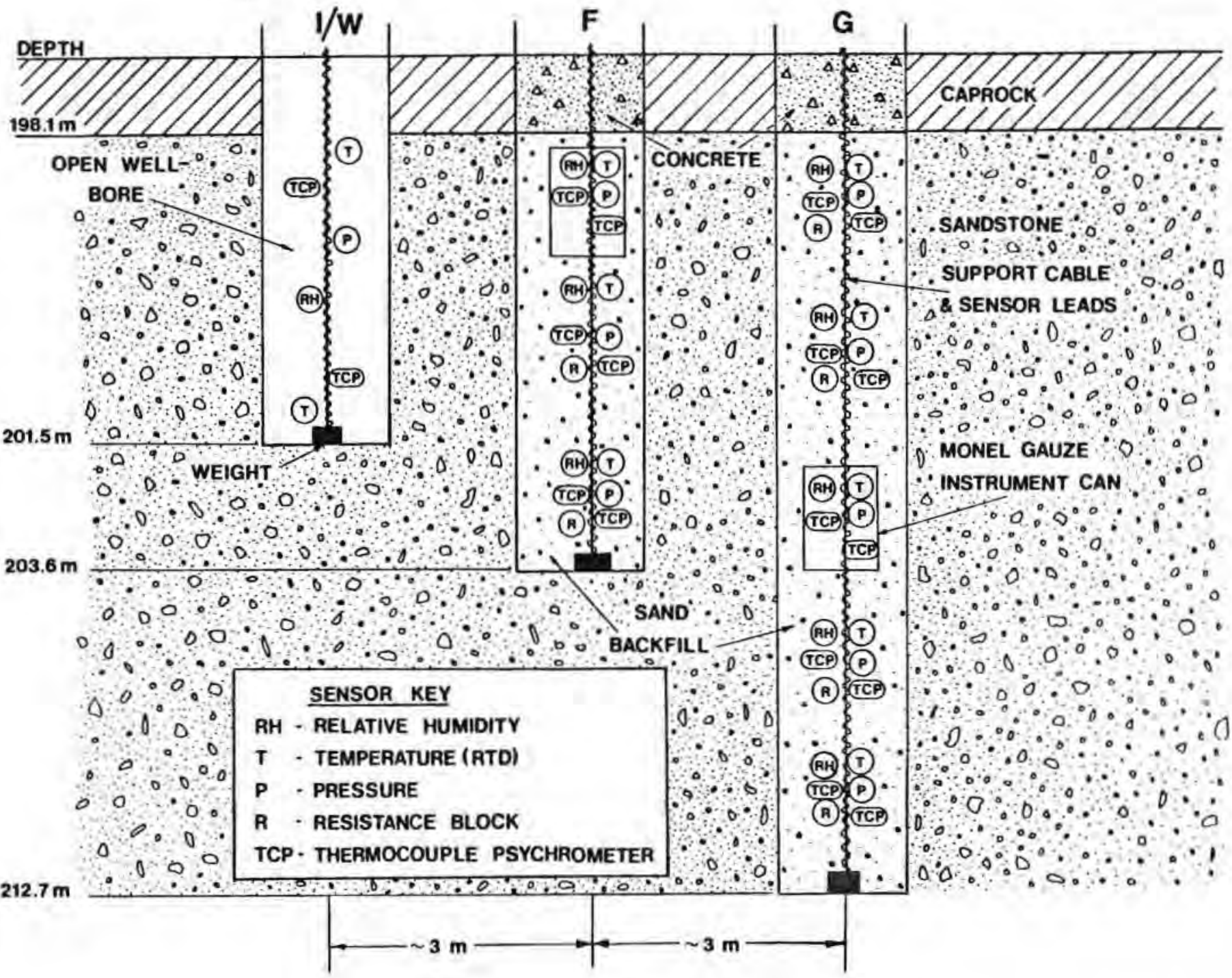

Figure 16. Sensor deployment scheme 
be the greatest at the sandface. Damage to the sandface directly affects reservoir performance. For these reasons and others, conditions at depth in the I/W well are important. Instrumentation will continuously monitor temperature, pressure, and relative humidity, but not water content. Such monitoring will provide information regarding wellbore heat losses, permeability stratification, wellbore integrity, and water coning. A brief discussion of each follows:

Wellbore Heat Losses. By measuring downwe11 and wellhead temperature, wellbore heat losses through the casing to the formation can be measured. This will be important for evaluating wellbore insulation techniques and decoupling wellbore vs, reservoir thermal cycling. Wiles (1979b) reported that wellbore heat losses can dramatically reduce thermal energy recovery and the extent of thermal cycling in the porous zone.

Permeability Stratification. Permeability stratification should be detectable using the highly accurate platinum resistance elements. Two sensors placed in the injection interval (one at the top and one at the bottom) will allow an estimate of vertical temperature gradients in the wellbore. This will have implications on the vertical positioning of flow in the reservoir during withdrawal. Also, changes in reservoir deliverability could possibly be attributed to changes in the hydraulic properties of the upper or lower part of the injection interval, if temperature data suggested that preferential flow was occuring.

Wellbore Integrity. Changes in the pressure drop between the wellhead and the injection interval (under similar flow conditions) may contribute information about wellbore integrity. The thermal extremes that wellbore materials will be exposed to are not necessarily different from those encountered in the petroleum or geothermal industries, but the thermal cycling is. Several authors (A1len, 1981; Stottlemyre, 1978) indicated that the effect of thermal cycling on well completion materials is important.

Water Coning. Measurement of relative humidity downwe11 should provide forwarining of water coning (Figure 17). As the water 


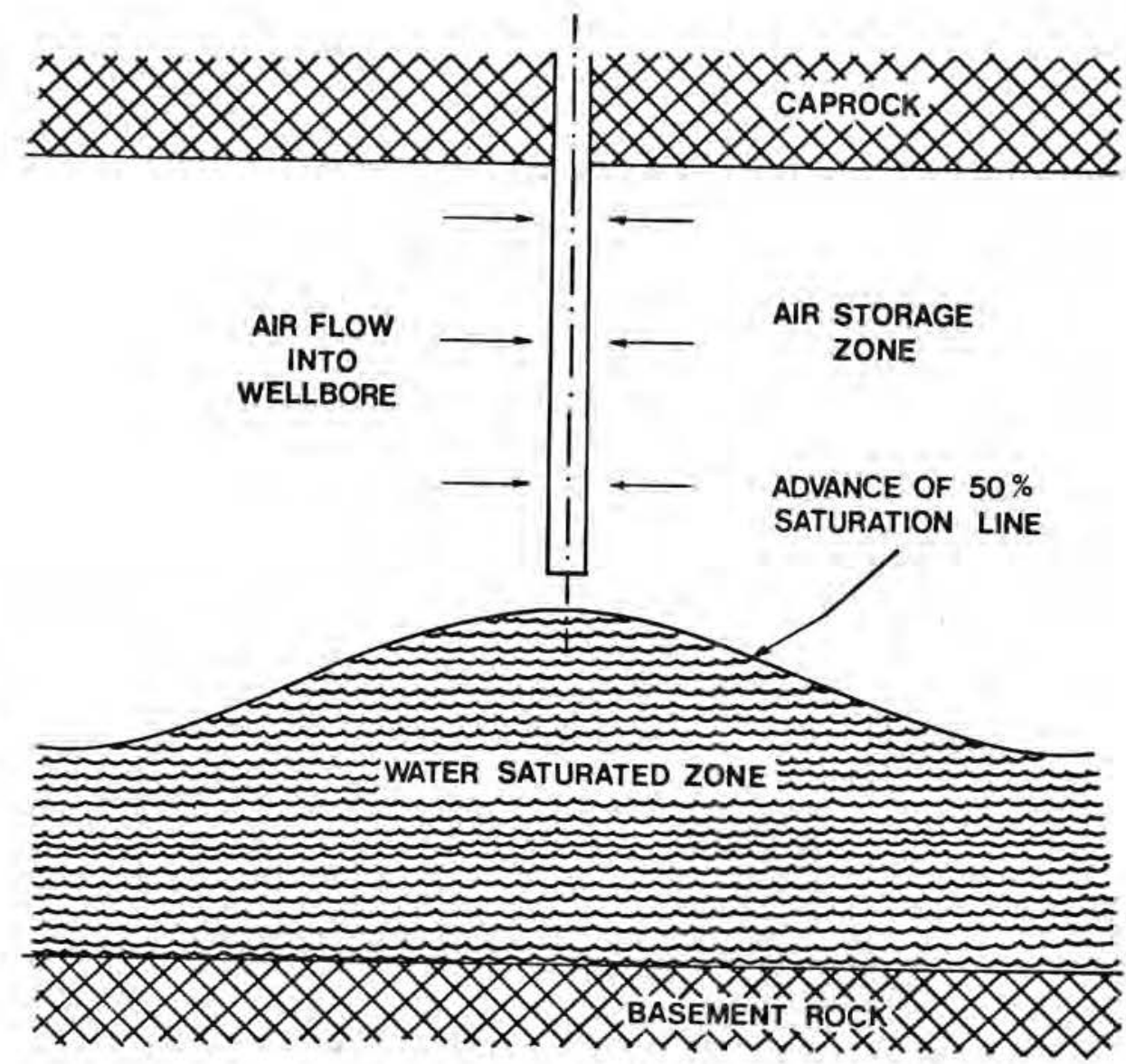

Figure 17. Water coning. -- From Wiles and McCann (1981b, Figure 7) 
cone approaches the wellbore, a capillary fringe (or zone of increasing saturation) will precede it. This will raise the relative humidity during production. A relative humidity sensor is being placed nearer the bottom of the interval to improve the detection of water coning.

\section{DATA ACQUISITION SYSTEMS}

The CAES subsurface data set will consist of time course determinations of temperature, pressure, relative humidity, and pore-water content at nine locations (six for pore-water content) in the storage aquifer. This data set consists of output from 70 sensors per instrument scan, which must be measured, recorded, stored, and processed. The instrumentation providing signals to the data acquisition system has been specified to provide scaled outputs to simplify data acquisition procedures. These are outlined in Table 4. Note that there are only 52 sensor elements in the subsurface network; there are 70 sensors because each thermocouple psychrometer measures both temperature and water potential; that is, relative humidity or pore-water content. Table 4 also includes signal information pertaining to a surface facility data acquisition system and four pressure sensors located at the outlying logging wells. The subsurface data acquisition system is designed to log the four pressure measurements. Provisions have been made to allow processing of surface data by the subsurface data acquisition system in the future.

The subsurface instrumentation system supplies as output 70 signals to be processed. The data acquisition system was designed to handle these as well as the extra signals shown in Table 4. In addition, several other capabilities were desired and the system was designed to provide them as well:

1. Signal resolution of at least $0.1 \%$ of full scale.

2. Logging flexibility in sampling rate, number of sensors scanned, and collection of integrated or point measurements. 
Table 4. Sensor output signals to be processed by data acquisition system

\begin{tabular}{|c|c|c|c|}
\hline Sensor & Number & Output Signal & $\begin{array}{l}\text { Input to Data } \\
\text { Acquisition System }\end{array}$ \\
\hline Temperature & 10 & $0-10 \mathrm{Vdc}$ & 12-bit $\mathrm{A} / \mathrm{D}$ converter \\
\hline Pressure & 9 & $0-10 \mathrm{Vdc}$ & 12-bit $\mathrm{A} / \mathrm{D}$ converter \\
\hline Relative humidity & 9 & $0-5 \mathrm{Vdc}$ & 10-bit A/D converter \\
\hline Resistance block & 6 & $0-10 \mathrm{Vdc}$ & 10-bit $\mathrm{A} / \mathrm{D}$ converter \\
\hline \multicolumn{4}{|l|}{$\begin{array}{l}\text { Thermocouple } \\
\text { psychrometer }\end{array}$} \\
\hline Temperature & 18 & 10-bit ASCII & $\begin{array}{l}\text { RS- } 232 \mathrm{C} \text { serial inter- } \\
\text { face port }\end{array}$ \\
\hline Water potential & 18 & 10-bit ASCII & $\begin{array}{l}\mathrm{RS}-232 \mathrm{C} \text { serial inter- } \\
\text { face port }\end{array}$ \\
\hline $\begin{array}{l}\text { Surface facility } \\
\text { data acquisition } \\
\text { facility }\end{array}$ & & 10-bit ASCII & $\begin{array}{l}\text { RS- } 232 \mathrm{C} \text { serial inter- } \\
\text { face port }\end{array}$ \\
\hline $\begin{array}{l}\text { Logging well } \\
\text { pressure }^{a}\end{array}$ & 4 & $0-10 \mathrm{Vdc}$ & 12-bit A/D converter \\
\hline
\end{tabular}

a. These sensors are not discussed in this report. 
3. Some real-time data processing capability to check for sensor degradation and to compare redundant data.

4. Relatively simple system operation with straightforward system checkout procedure.

5. Reliable system operation.

6. Reliable data output and storage.

This combination of design criteria essentially required a microcomputer-based system. The reliability considerations made it desirable to select a single system that could perform all or most of the required functions instead of an array of subsystems.

The selected system is based on a Rockwell AIM 65 microcomputer. This unit is 6502 microprocessor based and provides the hardware to support a $64 \mathrm{~K}$ memory. The unit supplies a typewriter-style keyboard, a small printer, and a one-line visual display (Fig. 18). In addition, this microcomputer has two external communications ports and can be programmed in both machine language and BASIC. The system configuration was supplied by Forethought Products, Inc. (see appendix for product literature). Their AIM-MATE series provides hardware and software support to the AIM 65 , which results in a $32 \mathrm{~K}$ memory system with four input/output ports and two locations for STD- BUS add-on circuitry. This capability is all under the control of the AIM 65 so that microcomputer control of a printer, an external data logger, and analog to digital (A/D) converters is possible. Furthermore, the microcomputer expansion memory and A/D converters are physically housed as one unit (Figure 19).

The data acquisition system is shown in Figure 20, Its major features are a $32 \mathrm{~K}$ microcomputer, 48 channels for $\mathrm{A} / \mathrm{D}$ conversion, an external data logger for thermocouple psychrometers, an external cassette tape recorder for program storage, and an output printer, Brief descriptions of these Jevices are as follows:

1. AIM 65 microcomputer. This component, previously discussed, controls the operation of the data acquisition system. In addition to 


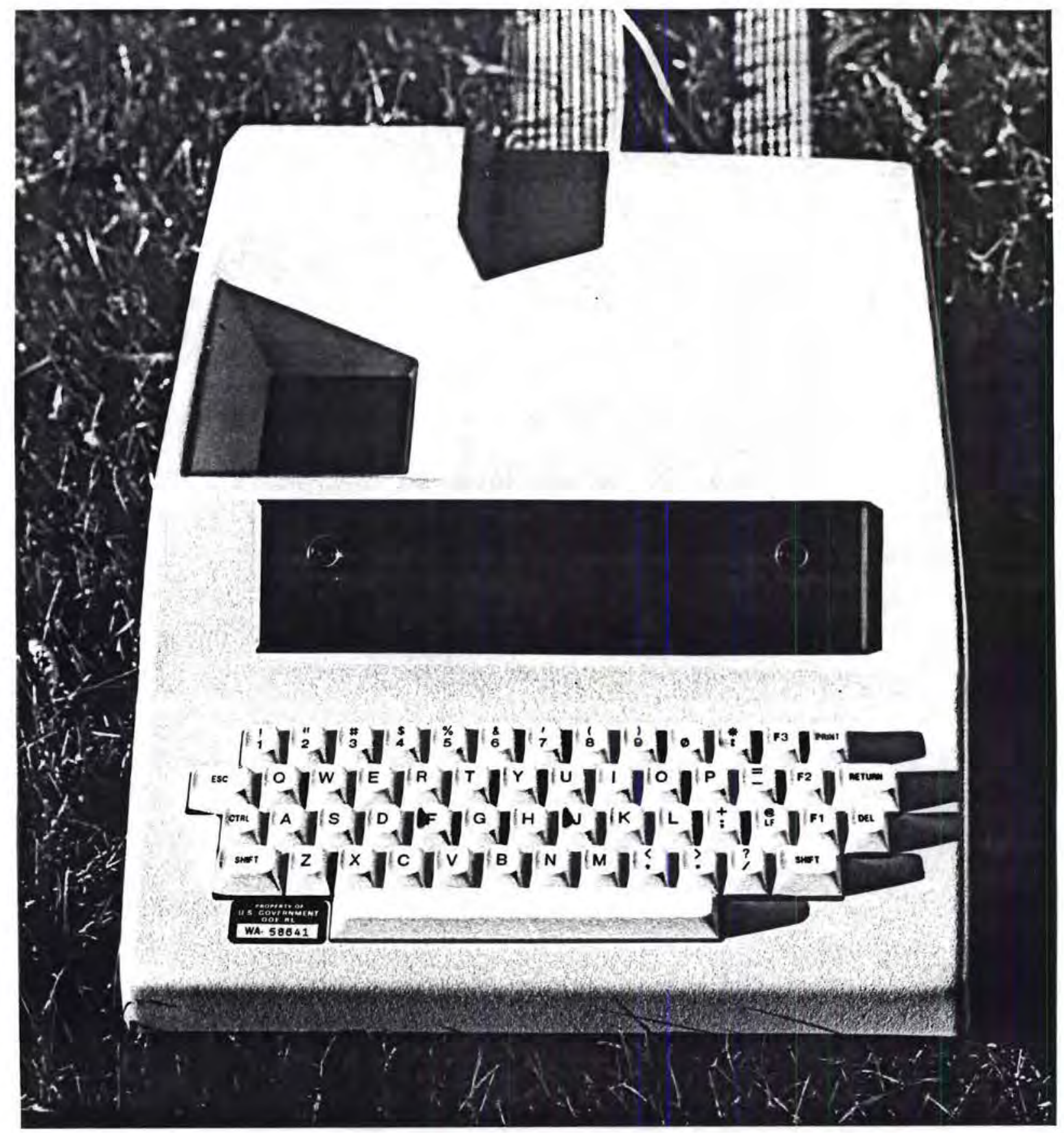

Figure 18. AIM 65 microcomputer 


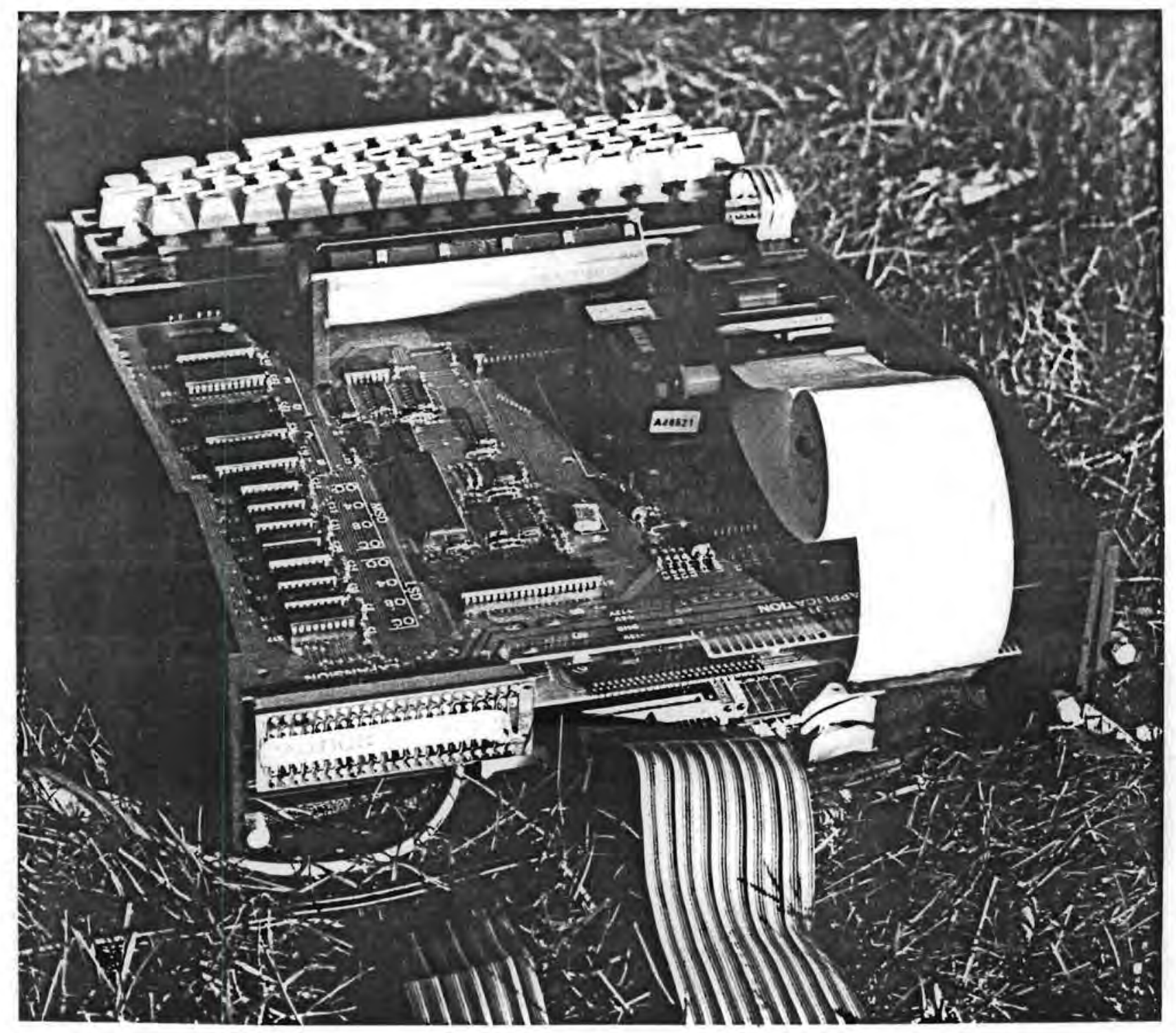

Figure 19. Single unit housing the expansion memory and A/D converters 


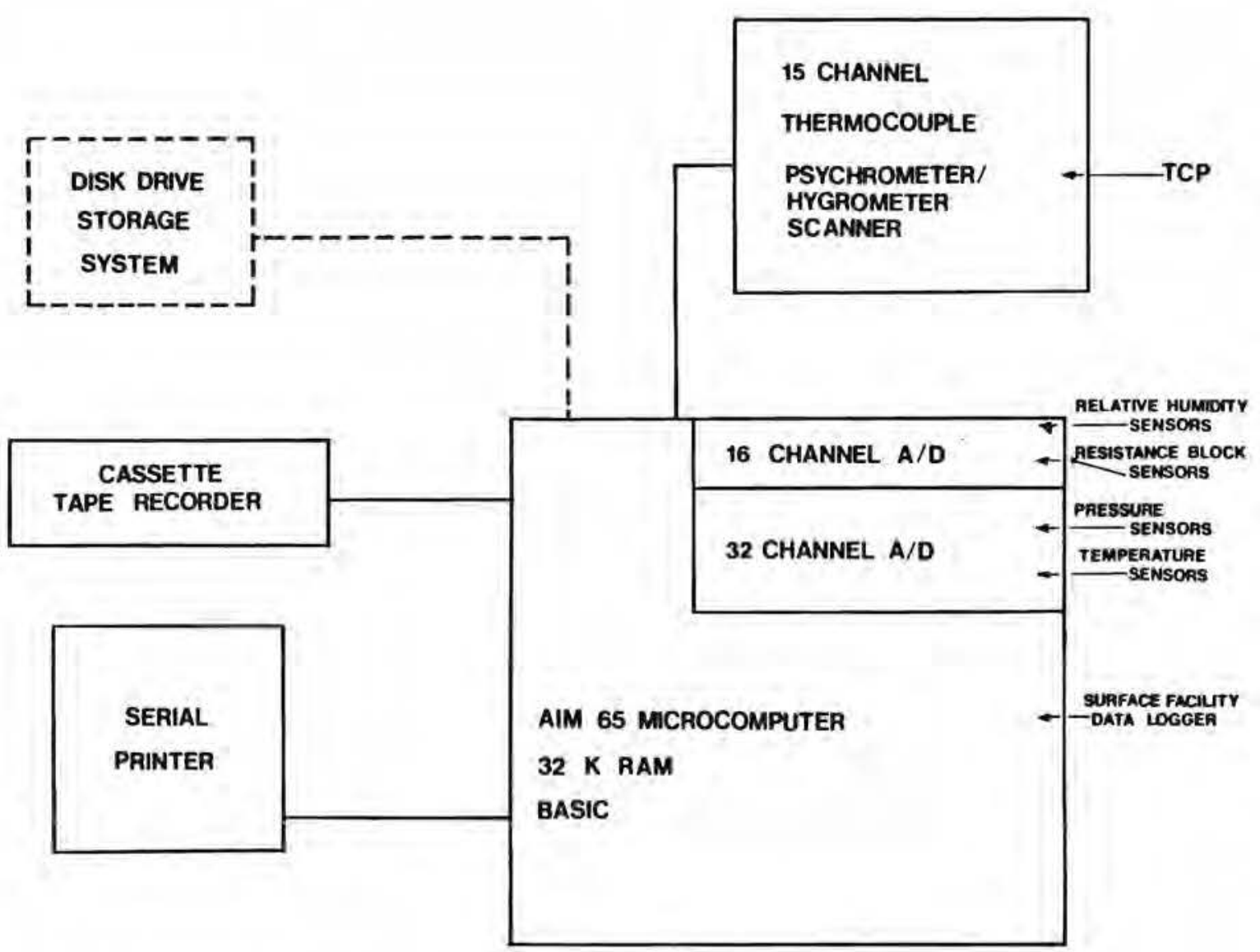

Figure 20. Schematic of data acquisition system 
control, the microcomputer also has enough memory to allow formatting of output, calculation of actual measurement values from voltages, and summing of measurements for calculation of integrated values.

2. Serial printer (Figure 21). The model used here is the Epson MX-80 (see appendix for specifications). It is an 80-character-persecond dot matrix printer driven by the microcomputer through a serial port. It supplies hard-copy output of the raw data and will also supply output for processed data and messages to the operator.

3. Cassette tape recorder (Figure 22). A Panasonic RQ-33SA unit (see appendix) is used to store system operation software. This device will be used to load programs into the computer memory at system startup or restart. Programs will include printer initialization, memory initialization and testing, parity check initialization, write protection for software, real-time clock initialization, and data acquisition software.

4. Sixteen-channel A/D converter (Figure 23). An Analog Devices RTI-1225 10-bit A/D converter (see appendix) is used to convert voltage from the cellulose strain gage sensors to digital signals in the microcomputer. Sixteen channels are available but only 9 will be used. The converter will be set to accept $+5 \mathrm{Vdc}$ full scale and will resolve $0.097 \%$ of full scale.

Both the 16- and 32-channel A/D converters listed here are STD-BUS electronics cards, which connect to the microcomputer through the two STD-BUS ports. This arrangement is especially advantageous because the cards are protected in the microcomputer housing and require no external power supply. In addition, the cards are memory mapped so that they can be configured as part of the microcomputer memory space. This allows the microcomputer direct access to the A/D converters for both initiating a measurement and reading an output.

5. Thirty-two-channel, 12-bit A/D converter. This unit, an Analog Devices RTI-1260 (see appendix) can resolve $0.024 \%$ of full scale $(+10 \mathrm{Vdc}$ in this application). 


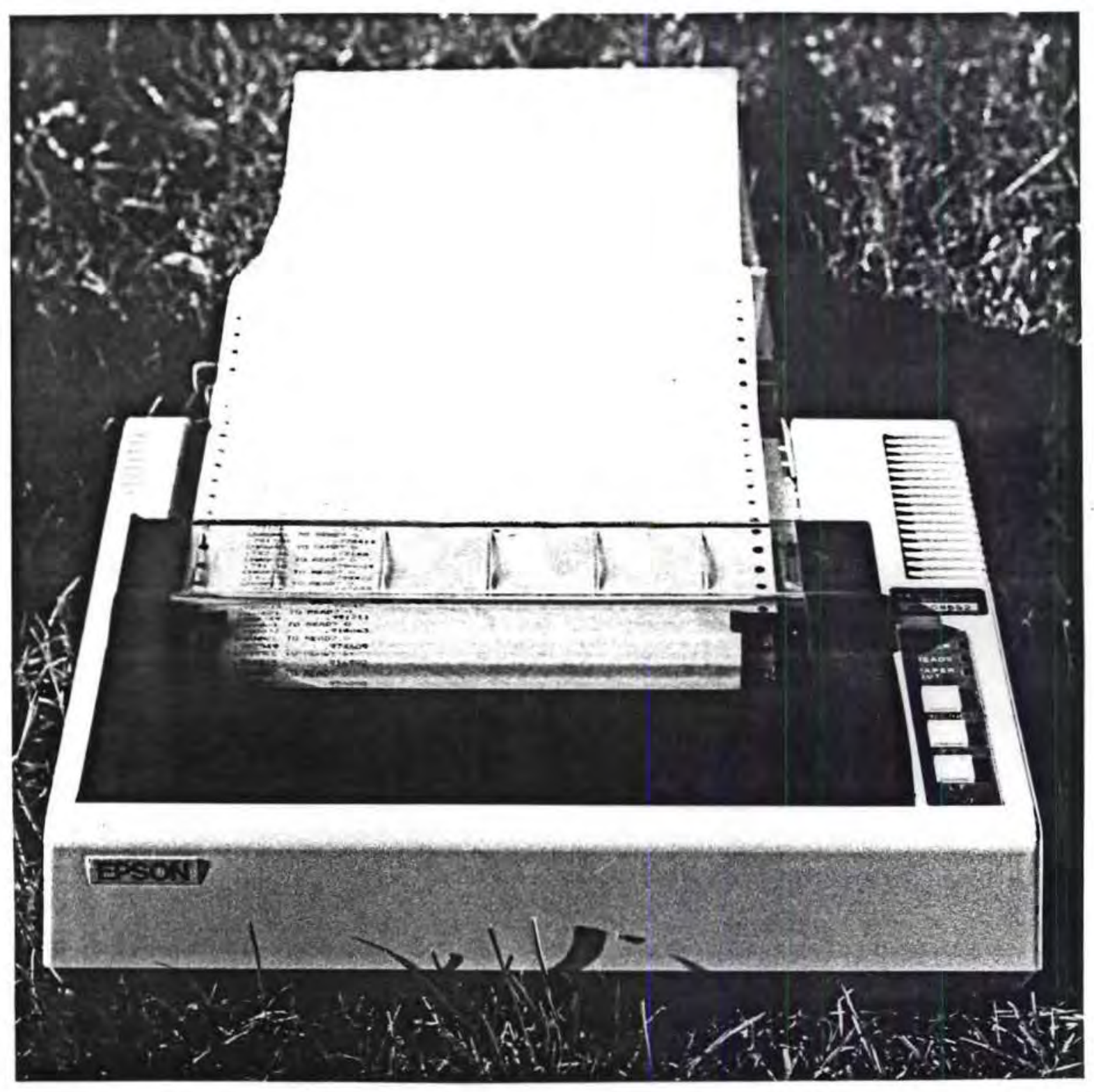

Figure 21. Printer for microcomputer 


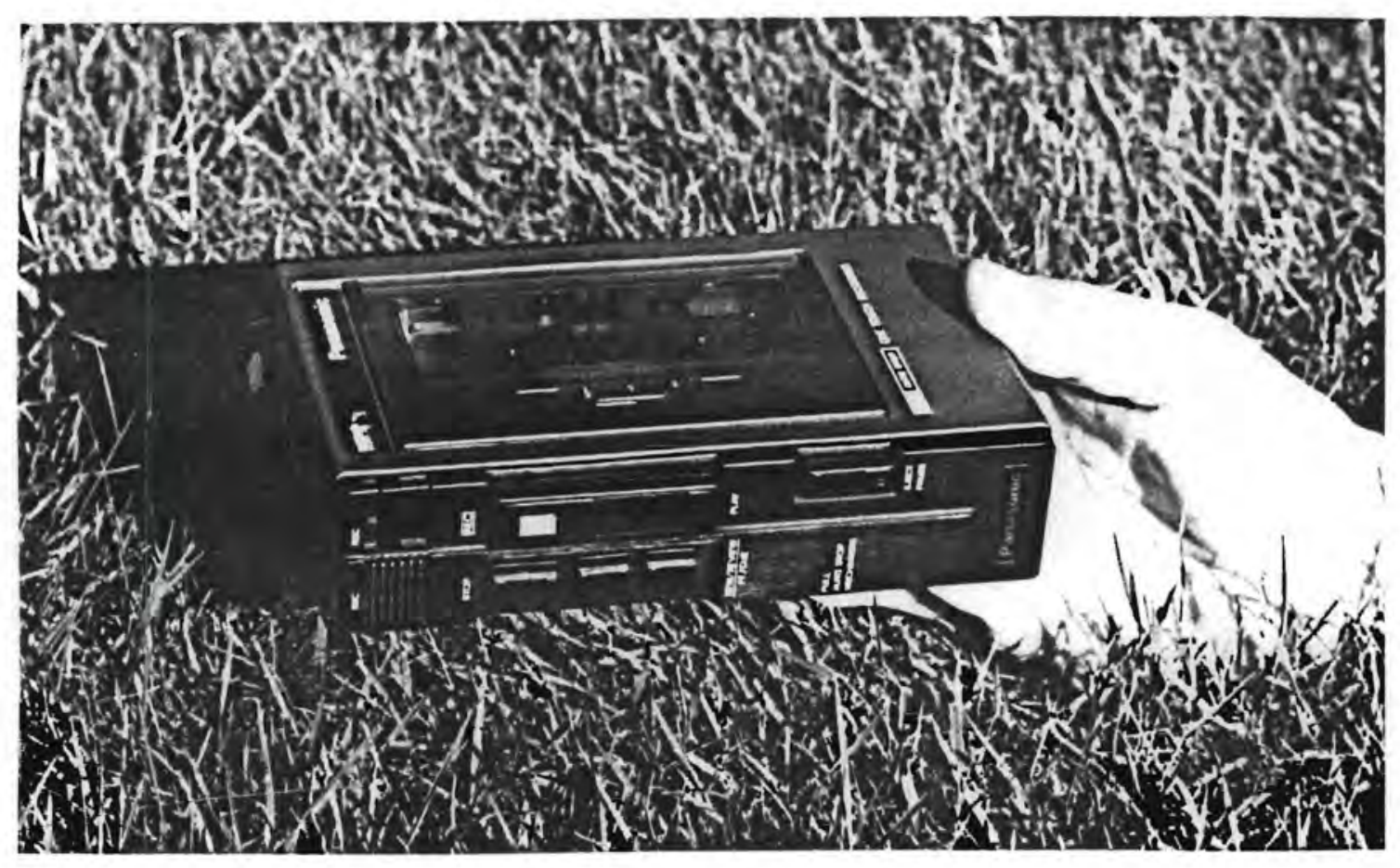

Figure 22. Cassette tape recorder 


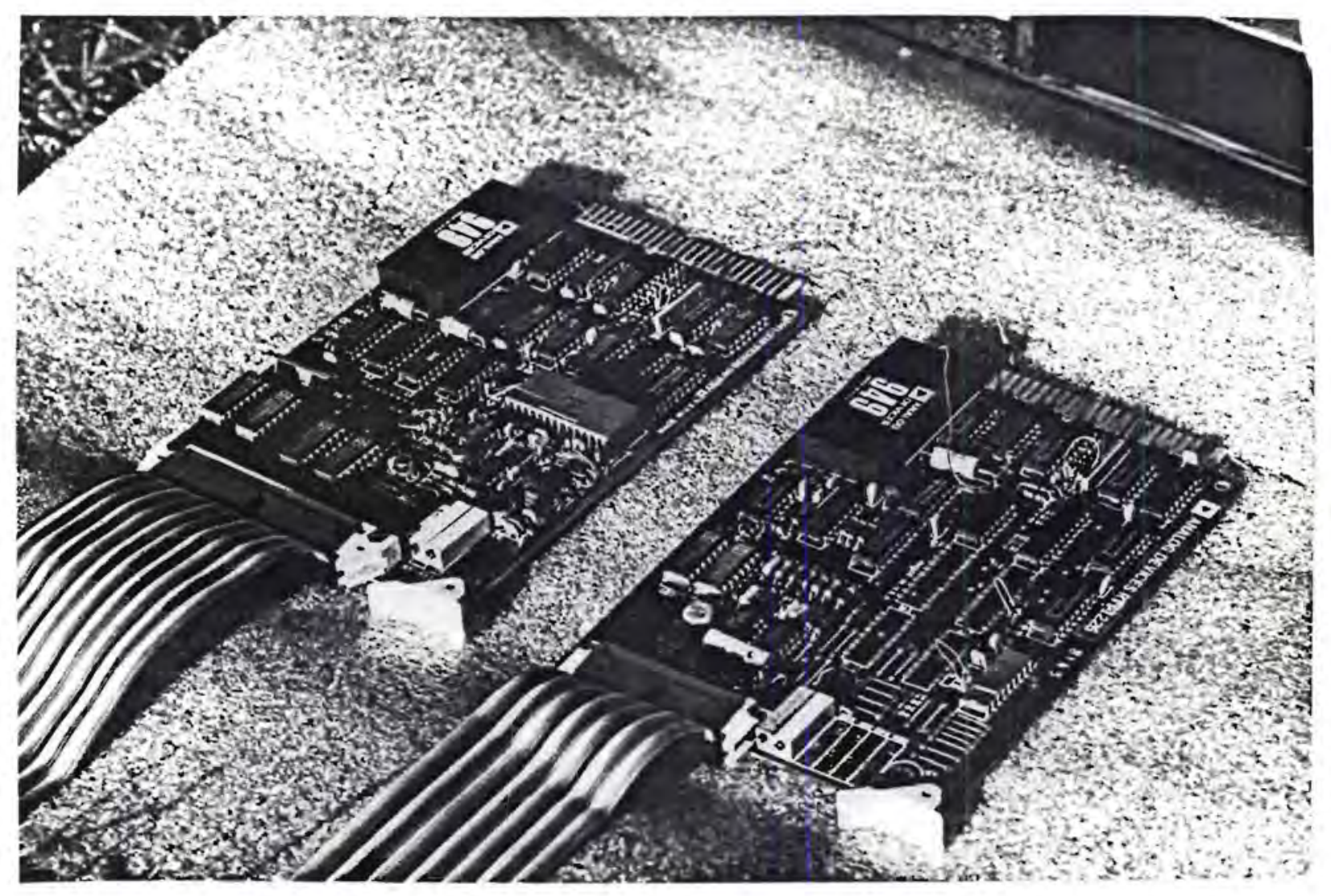

Figure 23. A/D converters 
6. Thermocouple psychrometer scanner (Figure 24). The Wescor HP-115 scanner (see appendix) controls, scans, times, and records data from 15 thermocouple psychrometer/hygrometers. It is battery powered and stores 3 days of hourly measurements for 15 sensors. The unit contains the circuitry to measure temperature and water potential in either psychrometric or hygrometric (dew-point) mode. Output data consist of date and time plus temperature, zero offset voltage, and the reading for each sensor scanned. These data are stored in the HP-115 memory until sent to the microcomputer. Data are sent using an operator-initiated interrupt procedure, and the computer and HP-115 are connected via a RS-232C serial interface port.

7. In addition to the equipment listed above, provision has been made to expand the system to include (1) an RS-232C serial link to the surface-facility data logger and (2) a disk-drive data storage system. 


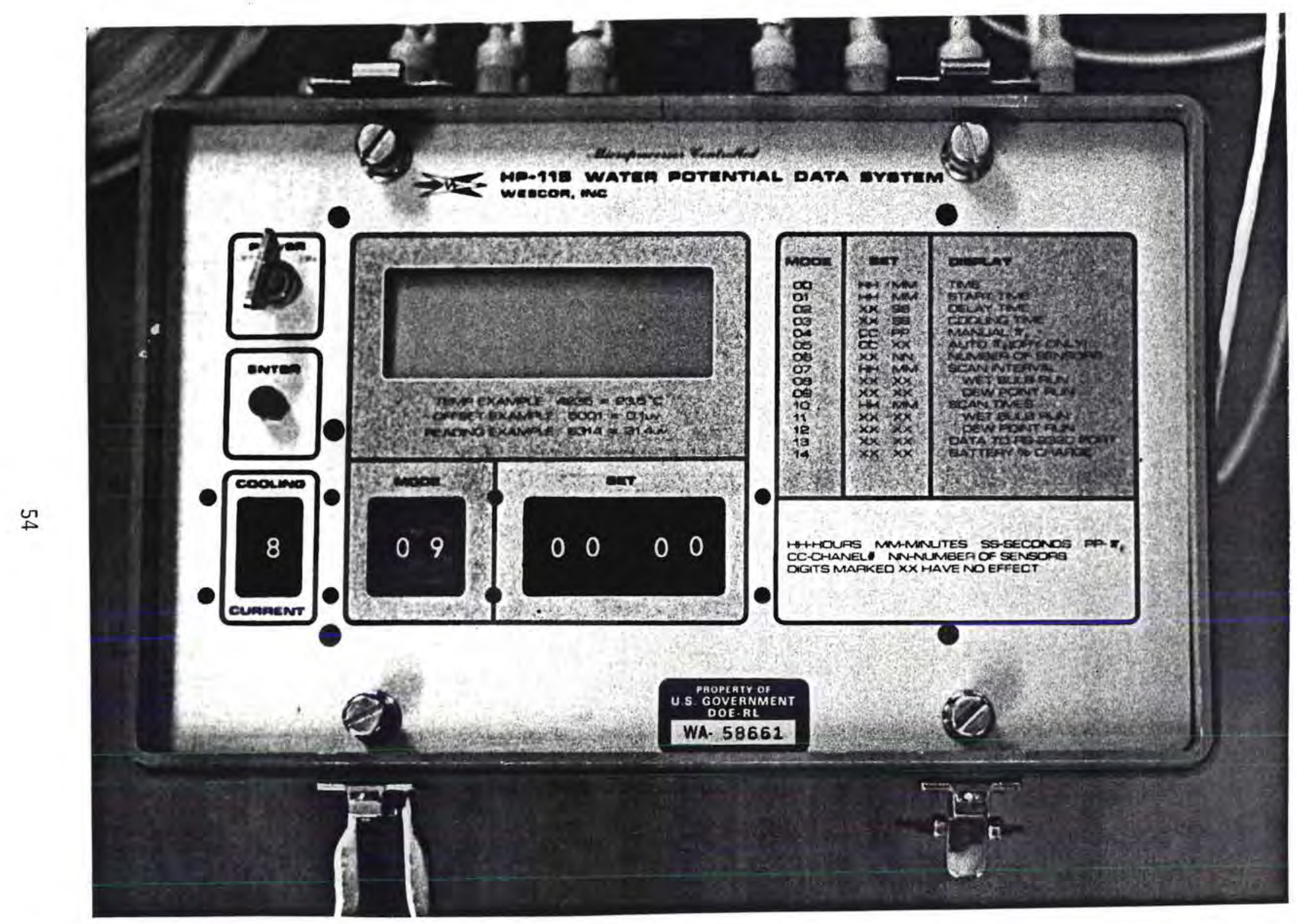

Figure 24. Thermocouple-psychrometer scanner 


\section{CALIBRATION PROCEDURES FOR SENSORS}

AND M!ONITORING SYSTEMS

All sensors to be used in subsurface monitoring require some degree of calibration. Resistance blocks and thermocouple psychrometers are shipped uncalibrated and therefore require complete calibration. Relative humidity sensors are factory calibrated at one temperature and must be corrected for other temperatures using theoretical strain-gage temperature coefficients. The quality of this correction should be assessed through calibration. The pressure and temperature sensors are designed to correct for both temperature and pressure differences from calibration conditions, but should be checked.

Although these reasons are sufficient to make individual calibration desirable, there are other reasons why calibration is necessary. First, all sensors will be deployed with at least 210 meters of lead wire. The measurement circuitry to be used has been selected to minimize common mode voltages, lead-wire capacitances, and differential lead-wire resistances; however, calibration tests should be performed with the leads attached in order to eliminate any of these effects from the random error associated with each measurement. Second, only one of the sensors (temperature) is designed to operate over the entire range of conditions expected in the CAES environment. The resistance blocks have not been extensively used at high temperatures. Consequently, their response is unknown. Thermocouple psychrometers and relative humidity sensors both cannot operate over the entire temperature range to be encountered. Also, the pressure sensor will be stressed to the thermal limit of its capability. Because the sensors will be taxed by the measurement conditions of the field test, calibration is required to establish the operating range for each sensor.

Another issue of concern is the behavior of the sensors under the cyclic pressure, temperature, and water-movement regimes that will 
be established in the reservoir during testing. Calibration procedures can test for evidence of hysteresis. Finally, calibration procedures will provide an opportunity to become familiar with sensor and data acquisition equipment response. Because the sensors will ultimately be irretrievably installed in the instrument wells, only calibration experience will be available to trouble shoot malfunctioning sensors.

\section{CALIBRATION NEEDS OF}

PARTICULAR SENSORS

Six sensor types based on different transducing principles will be used to monitor reservoir conditions. Refer to Table 2. The calibration needs of all transducers, except neutron logging, are discussed in the following paragraphs. Neutron logging will be performed by BPB Instruments of Evansville, Indiana.

\section{Cellulose Strain Gage}

The cellulose strain gages are supplied with a low-temperature calibration and a temperature correction factor. This factor should be checked during calibration. Also, the sensor is rated for temperatures less than $125^{\circ} \mathrm{C}$. This upper limit can be approached in calibration but should not be exceeded or the sensor will be destroyed. Response time of the sensor should be assessed because the sensor specifications show it to be rather slow ( 2 minutes to $63 \%$ response to a step change in relative humidity).

The $125^{\circ} \mathrm{C}$ temperature limit may be extended. Preliminary testing by the vendor suggests that performance degrades up to $200^{\circ} \mathrm{C}$, but the sensor may still provide useful data. The vendor has agreed to contribute a "test" sensor at no cost. During calibration the effect of temperatures above $125^{\circ} \mathrm{C}$ will evaluated. An increased temperature limit would be important for proposed air cycling at higher temperatures. These sensors will detect increasing humidity, and, as such, could be valuable indicators of incipient water coning in the $\mathrm{I} / \mathrm{W}$ well. 


\section{Silicon Strain Gage}

The silicon strain gages will be factory calibrated over the range of temperatures and pressures expected during the field test. Temperature and pressure will be varied separately, however, not together as will be encountered in the field. Consequently, some additional calibration will be necessary to define any combined influence of temperature and pressure on sensor accuracy. Also, these sensors should be checked for lead-wire or data-logger effects.

\section{Platinum Resistance Elements}

The factory calibration for temperature should be checked for pressure effects. Lead-wire effects should also be assessed.

\section{$\underline{\text { Resistance Blocks }}$}

These uncalibrated sensors should be initially screened to select a group of sensors with fairly uniform responses. Those selected should then be calibrated over expected reservoir pore-water content, pressure, and temperature ranges.

\section{Thermocouple Psychrometers}

Calibration of the thermocouple psychrometers will be straightforward for the copper-constantan thermocouple used for temperature measurements. The calibration for relative humidity and pore-water content will be more difficult. A major objective of the calibration will be to locate a temperature where a meaningful measurement can no longer be made. The measurement technique involves condensation of a drop of water on the measurement junction. This condensation is accomplished by Peltier cooling of the junction. Because at some temperature, the Peltier cooling circuit will not be able to remove energy faster than the environment can supply it, water will not condense and a measurement cannot be macie. This temperature will be the upper limit for measurements. It should be noted, however, that the sensor 
will not be destroyed at this temperature. Measurement can be resume when the temperature decreases.

Measurements with the thermocouple psychrometers can be made in two modes: psychrometric and dew point. The mode to be used in the field test will be determined after calibration is completed. The psychrometric mode has both temperature and pressure coefficients that affect its response (Peck, 1968; Richards, Low, and Decker, 1964), These must be determined by calibration. A limitation in the psychrometric technique is the decrease in output sensitivity with increasing pressure. As pressure increases from atmospheric to 15 bars, sensitivity $(\mu \mathrm{V} /$ bar $)$ decreases 82 percent. This is a limitation because aquifer discovery pressure is near 10 bars.

The dew-point measurement mode does not have an explicit pressure dependence because of a correction factor, the dew-point cooling coefficient. This coefficient compensates for pressure changes (Campbell, Campbell, and Barlow, 1973). In addition, the sensitivity of the dew-point measurement is about twice that of the psychrometric measurement (Savage, Cass, and de Jager, 1981). The temperature dependence of output sensitivity is also less for dew-point measurements. These advantages, however, are partially offset by the temperature dependence of the dew-point cooling coefficient (Campbell et al., 1973; Savage et al., 1981). Although this temperature dependence is relatively simple to measure, it is more difficult to implement. The corrections for temperature and pressure can be applied after the psychrometric measurement; however, the temperature correction must be made to the measurement circuitry itself for the dew-point measurement. The calibration of thermocouple psychrometers will provide the data set and experience necessary to decide which technique will be best for the intended application.

\section{CALIBRATION METHODS}

Three separate types of calibration are required for the instrumentation to be used. First, pore-water content must be set to 
calibrate the resistance blocks and thermocouple psychrometers. Second, relative humidity must be established to calibrate the relative humidity sensors and thermocouple psychrometers. Third, pressure and temperature effects on the readings of all sensors must be measured.

\section{Pore-water Content}

Pore-water content calibrations will be performed using a pressure chamber apparatus (Figure 25). This device establishes a differential pressure across a sample of porous material (Figure 26). An amount of water is removed from the sample due to the overpressure on the water. When the overpressure equals the force holding the remaining water in the porous material, the sample comes to equilibrium. As Figure 26 shows, water-content equilibrium must exist in the aquifer material (sandstone core, the backfill material (Ottawa sand), and the sensors to be calibrated. In practice, this is a difficult state to achieve because the water flow in unsaturated porous media is quite slow. It is, however, critical to the calibration process. The sensors must be assumed to be in equilibrium with the backfill materials and, in turn, with the sandstone core. Equilibrium is necessary in order to measure a calibration point relating sensor output to sandstone porewater content. Calibration at four or more water-content values between saturation and residual pore-water content $(-0.1,-0.5,-2,-15$ bars water potential) will be completed. Once each pore-water content is established, calibration can be quickly performed for a range of pressure and temperature combinations.

It should be reiterated that the equilibrium assumption required for calibration may also be a problem for field measurements. The data acquisition system will measure the electrical output from the sensor and that value will be converted to pore-water content, assuming that the sensor and sandstone are in equilibrium. Often, in unsaturated media, disequilibrium can exist; data analysts must constantly search for indirect verification of the equilibrium assumption. 


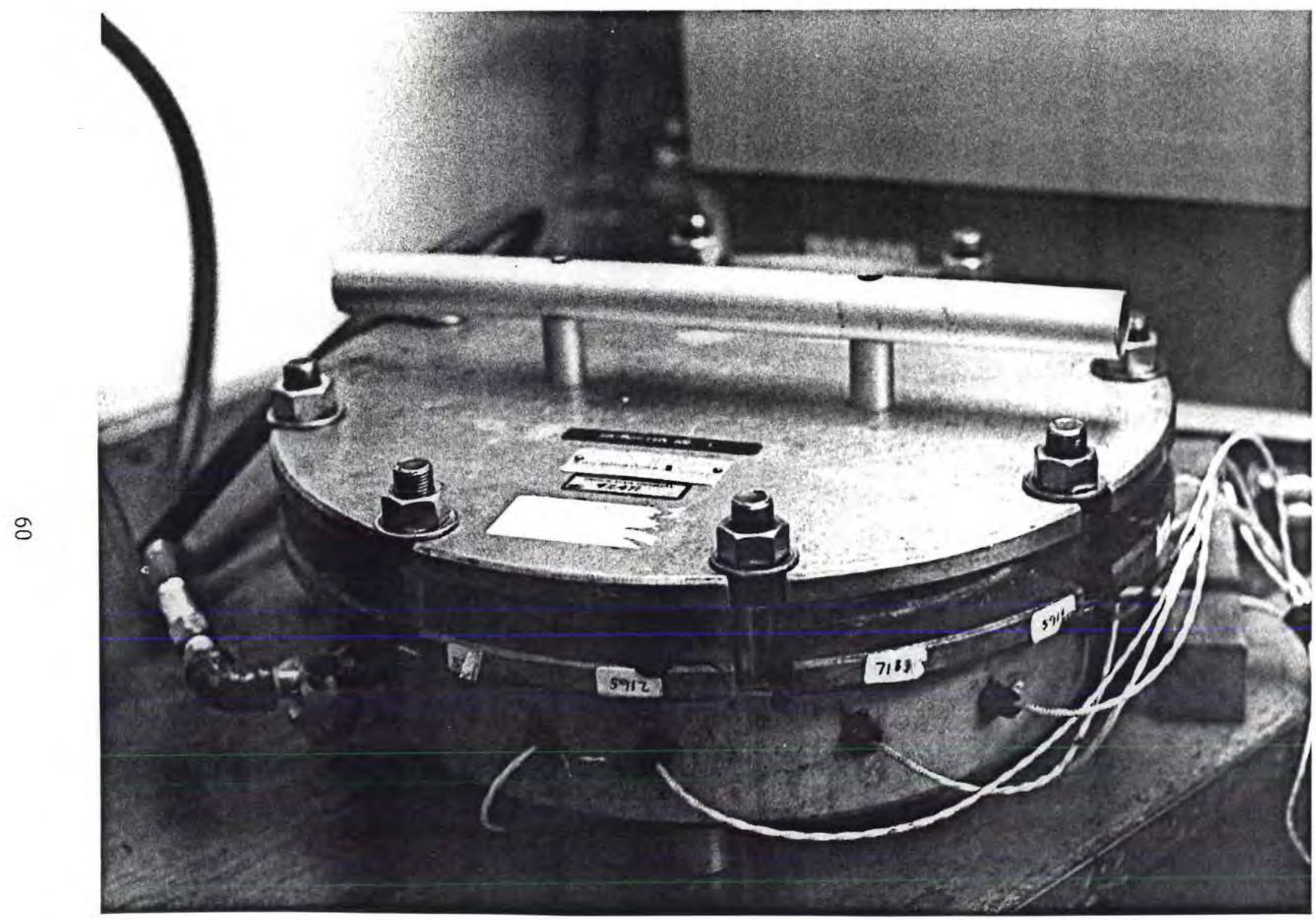

Figure 25. Pressure chamber apparatus 


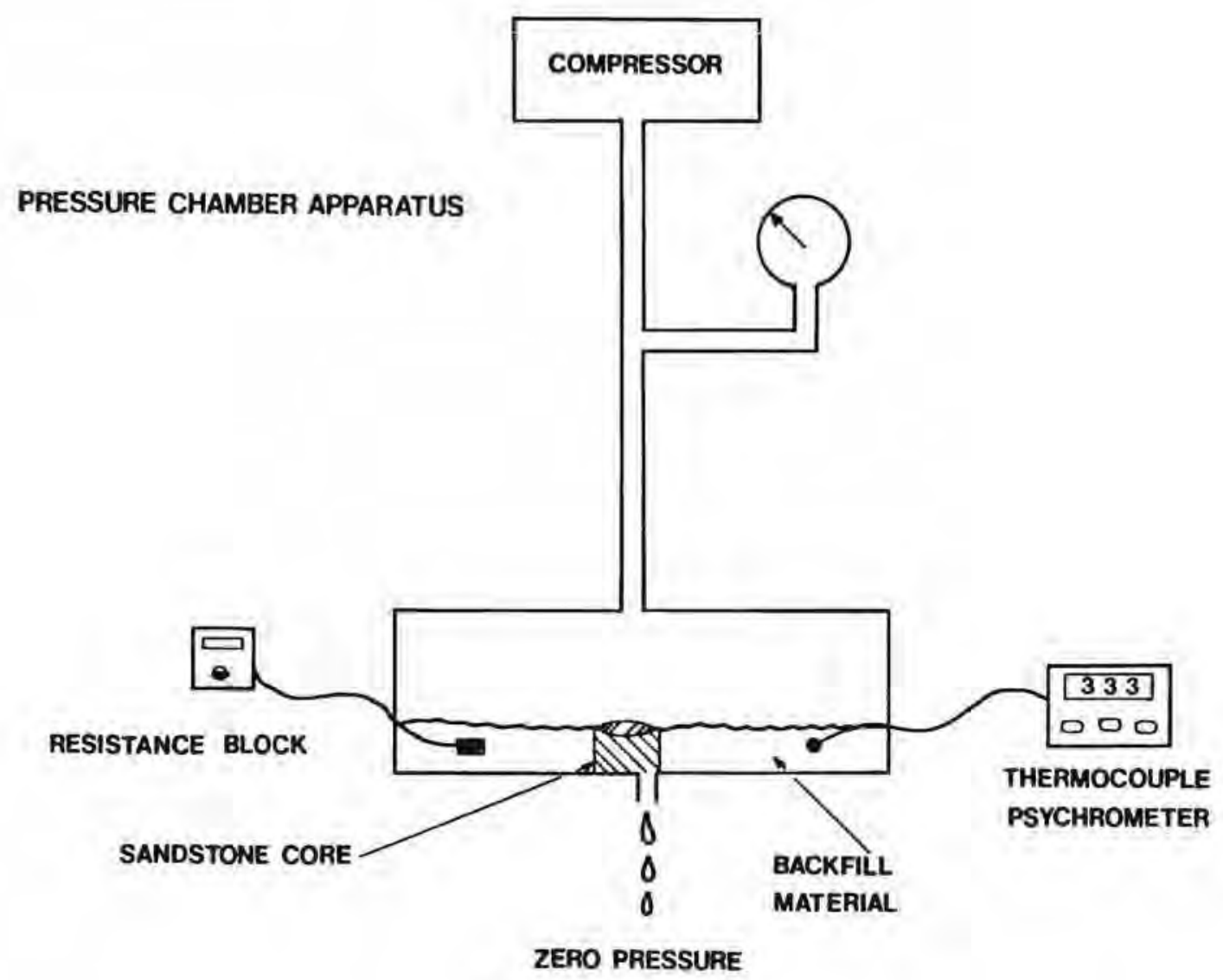

Figure 26. Generalized drawing of pressure chamber apparatus 
Relative Humidity

The relative humidity calibration can be accomplished using various salt solutions to control the vapor pressure in an enclosed space. These calibrations will be run in a pressure chamber apparatus. This apparatus differs from the pressure plate in that it is not vented to the atmosphere. The salt solutions selected for the relative humidity calibration are shown in Table 5 . In most cases, the relative humidity for a given salt is temperature dependent. In addition to direct calibration of the sensors, the calibration procedure will provide data on the lowest relative humidities that can be reliably measured using a thermocouple psychrometer.

Table 5. Relative humidity for salt solutions at various temperatures. -- From Greenspan (1977).

\begin{tabular}{ccccccc}
\hline $\mathrm{T},{ }^{\circ} \mathrm{C}$ & $\mathrm{K}_{2} \mathrm{SO}_{4}$ & $\mathrm{KCl}$ & $\mathrm{KI}$ & $\mathrm{NaBr}$ & $\mathrm{MgCl}_{2}$ & $\mathrm{LiCl}$ \\
\hline 25 & 97 & 84 & 69 & 58 & 33 & 11 \\
50 & 96 & 81 & 64 & 51 & 31 & 11 \\
75 & & 79 & 61 & 50 & 27 & 11 \\
90 & & 79 & 60 & & 24 & 10 \\
\hline
\end{tabular}

$\underline{\text { Pressure and Temperature }}$

The effects of pressure and temperature will be calibrated with a pressure chamber device. This calibration procedure can be used on pore-water content and relative humidity samples. Because discovery pressure of the CAES site is near 10 bars, three calibrations points will be measured: atmospheric, 10 bars, and 20 bars. It is expected that pressure will have a minor effect on all sensors, except the thermocouple psychrometer in the psychrometric mode. 
Temperature levels for calibration will be established using a constant temperature water bath for low temperatures and an electric drying oven for temperatures greater than $75^{\circ} \mathrm{C}$. It is anticipated that measurements for all sensors will be made at $25^{\circ} \mathrm{C}, 50^{\circ} \mathrm{C}, 75^{\circ} \mathrm{C}, 90^{\circ} \mathrm{C}$, $150^{\circ} \mathrm{C}$, and $200^{\circ} \mathrm{C}$. In addition to simple calibrations at various temperatures, a pilot study of the effects of differential heating of lead wires will be performed. If there is an appreciable effect shown, this line of study will be expanded.

\section{USE OF CALIBRATION DATA}

As a result of the three calibration procedures outlined above, calibration formulae will be derived for correcting sensor readings for reservoir temperature and pressure. Because most sensors will be irretrievably installed, no posttest calibration or examination will be possible for these sensors. In addition to the calculating equations, the calibration procedure should yield estimates of the reliable operating ranges for each sensor as well as an estimate of measurement precision. This information will be of value when assessment of the validity of various data points is required. 


\section{FIELD INSTALLATION AND TESTING}

\section{OF SENSOR SYSTEMS}

Field installation and testing consist of three primary considerations: installation procedures, testing of all sensors and sensor systems, and contingency plans. These considerations are addressed at every stage of field deployment and, hence, integrated into an overall deployment procedure. The deployment of sensor systems involves a number of sequential steps to assure the functional reliability of each sensor under ambient and elevated temperature and pressure reservoir conditions. Deployment also involves the combined testing of sensor systems and data logging equipment. Hence, both sensor and complete sensor systems (sensors, power supplies, signal conditioning electronics, and data loggers) are checked for operability and baseline conditions. The steps of field installation and testing are: (1) field checkout, (2) sensor string deployment, (3) in-well testing, (4) backfilling and cementing, (5) static testing, and (6) complete monitoringsystem operational checkout. This sequence is shown diagrammatically in Figure 27. The following sections describe these steps in greater detail.

\section{FIELD CHECKOUT}

Subsequent to calibration and operational checkout in the laboratory, monitoring systems are assembled and tested in the field. Each sensor is checked for operability under ambient (atmospheric) conditions at the surface. This operational test will determine if in-transit damage or degradation of sensors or lead wires has occurred. On the remote chance that a sensor is not operable, it will be removed from the string and replaced with a backup sensor that has been calibrated in the laboratory. Replacement of the sensor will require additional calibration under atmospheric conditions in the field. 


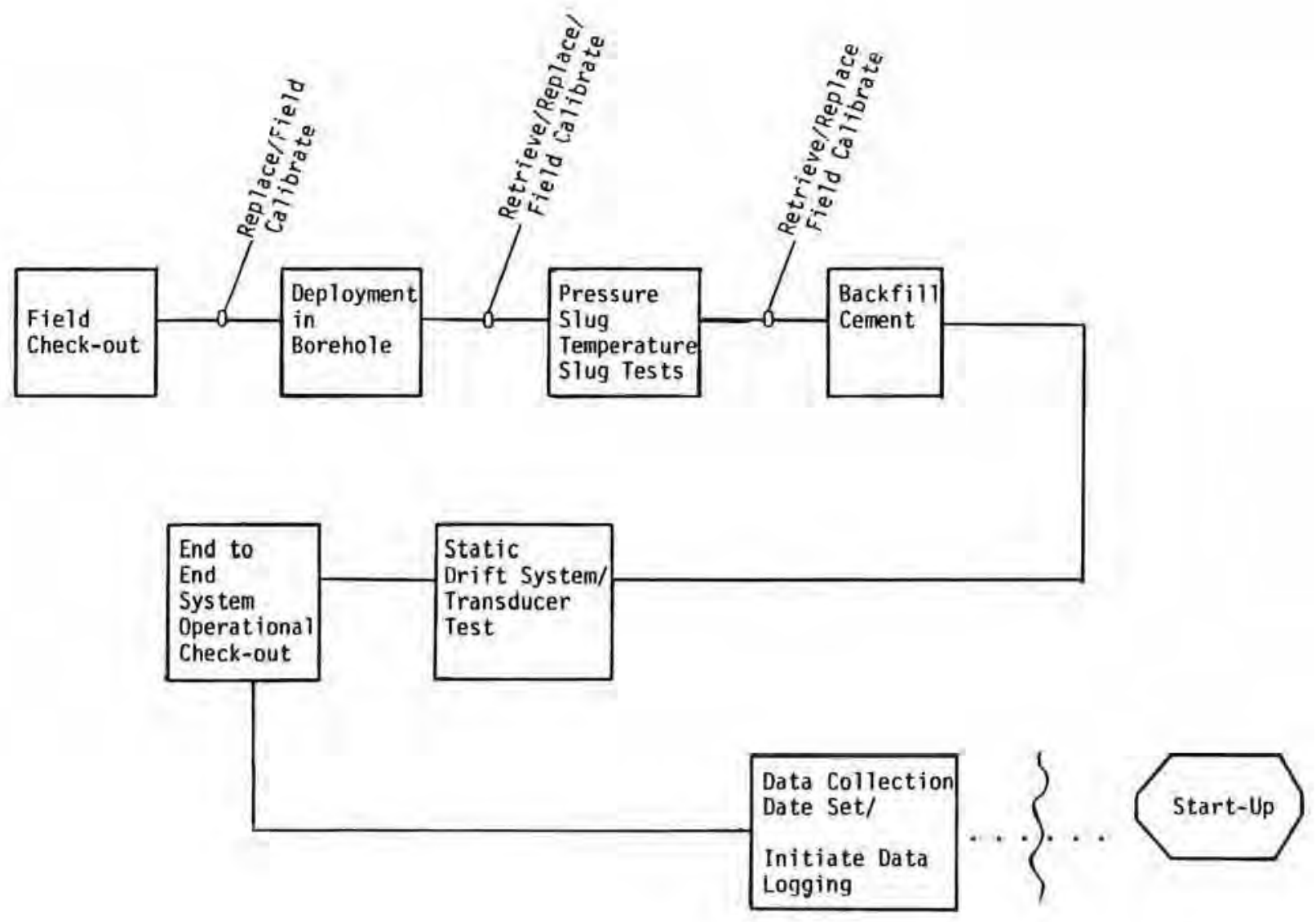

Figure 27. Generalized procedure for field testing and deployment of sensors and system evaluation 
SENSOR-STRING DEPLOYMENT

Sensor String Description

Sensors, lead wires, and support cable will be prefabricated into a sensor string in the laboratory. One continuous sensor string will be provided for each of the three wells to be instrumented. A sma1l-diameter stainless-steel cable will be used to support and attach sensors and lead wires. Sensors and lead wires will be wound around the support cable. The support cable will have a weight attached to the downwell end to maintain tension during and after vertical deployment of the sensor string.

Sensor types and their vertical locations in each of the instrumented wells are shown in Figure 16. Note that high-temperature shielded lead wire is used throughout the I/W well and within the vertical interval below the caprock-reservoir interface in the instrument wells. Lead wiresensor splices occur above this interface, thus minimizing potential splice degradation. Figure 28 shows sensors deployed in sets of six (or five), with one set for each of nine instrumented intervals (one in the I/W we11, three in the $3-\mathrm{m}$ instrument wel1, and five in the 6-m instrument we11). The location of each sensor set is predetermined to optimize monitoring of reservoir performance.

Instrument sensors are located on the sensor string to function under both horizontal or vertical mass-transfer conditions, but the sensors will be physically oriented in a vertical position. Sensors are located at specific intervals within each zone. Between each zone in instrument wells, the sensor string and lead wires are potted with a high-temperature sealant. This minimizes the potential of a preferential pathway for mass transfer vertically through the wellbore. Note that these wells will be backfilled with sand. 


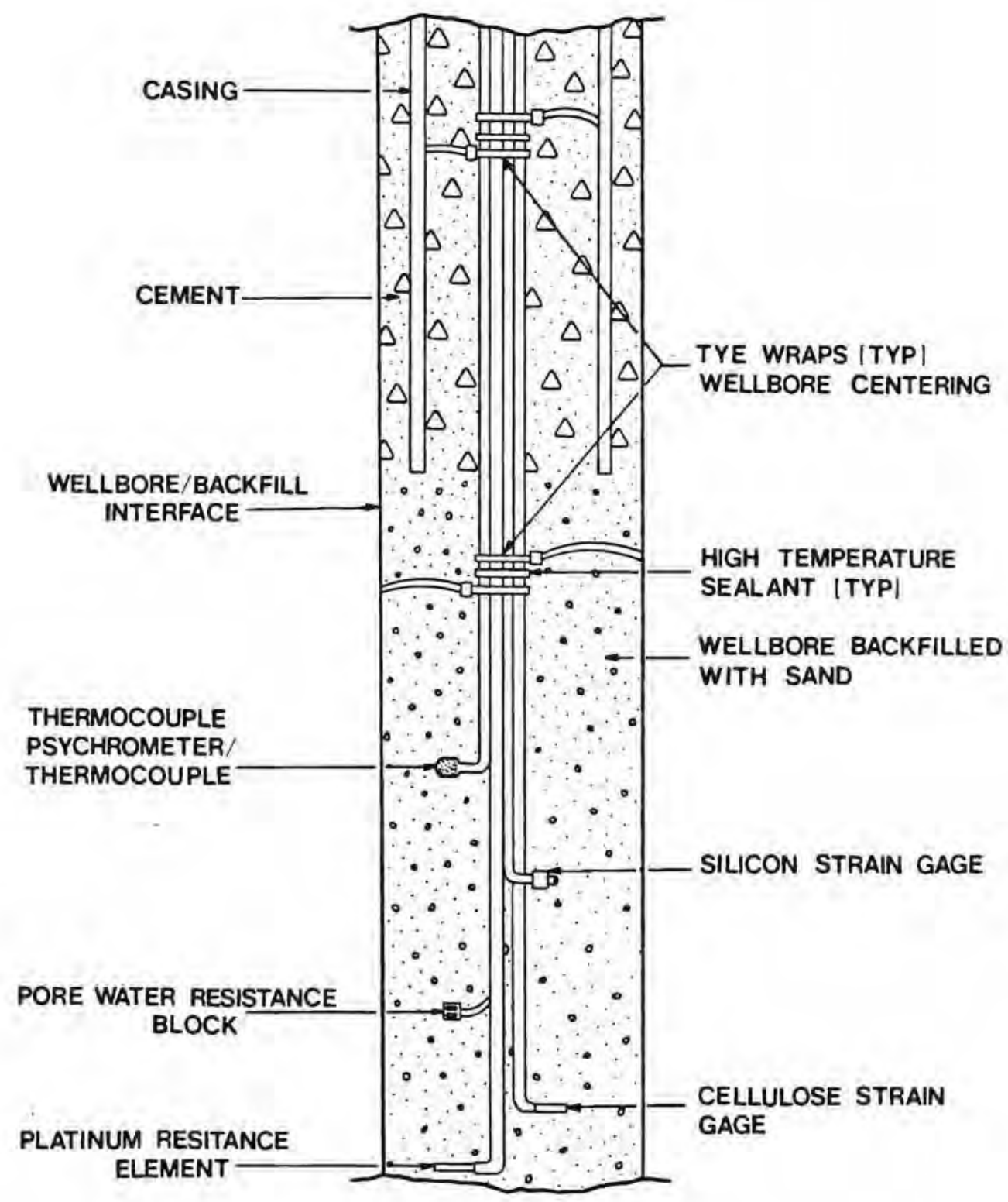

Figure 28. Drawing of sensor deployment in an instrumented interval 
Within the two instrument wells, one zone in each houses a porous container, with sensors inside (Figure 29). This differs from other instrumented intervals where sensors are in intimate contact with backfill material. The purpose of these two deployment configurations (one backfilled, the other enclosed in a porous container) is to evaluate the ability of the sensors to monitor reservoir nonequilibrium materialdependent performance. Specifically, if heat and mass transfer through the reservoir and backfill material exhibit somewhat different characteristics, this must be determined in order to understand performance of the reservoir and to provide reliable data. Thus, a porous container with a set of sensors is installed in both instrument wells as an integral part of the sensor string. This container is specifically designed to permit backfilling the instrument wells while retaining the design objective of monitoring open wellbore temperature, pressure, and relative humidity. Because the container has no backfill material inside, no resistance blocks monitor pore-water content.

Lead wires are fixed to the stainless-steel cable and to one another by high-temperature tye wraps. These function to maintain instrument lead-wire string integrity, to center the sensor string in the wellbore, to prevent sensor damage, and to prevent sensor-string binding when the string is lowered down through the well casing. Tye wraps are also used in the $I / W$ well to prevent sensor damage during high air-flow conditions when the string may be subject to lateral oscillation in the well casing. Spiral wrap covers the bundle at the wellhead where the sensor leads exit. Spiral wrap surrounding the string reduces the potential of physical abrasion of lead wires and consequent severing of cable shielding or signal leads.

\section{Sensor String Deployment}

Sensor strings are deployed by lowering through standing air and water columns to predetermined locations. Also, it will be possible to deploy the string in the $I / W$ well through piping and pressure sealing devices located at the wellhead. This will allow for access during 


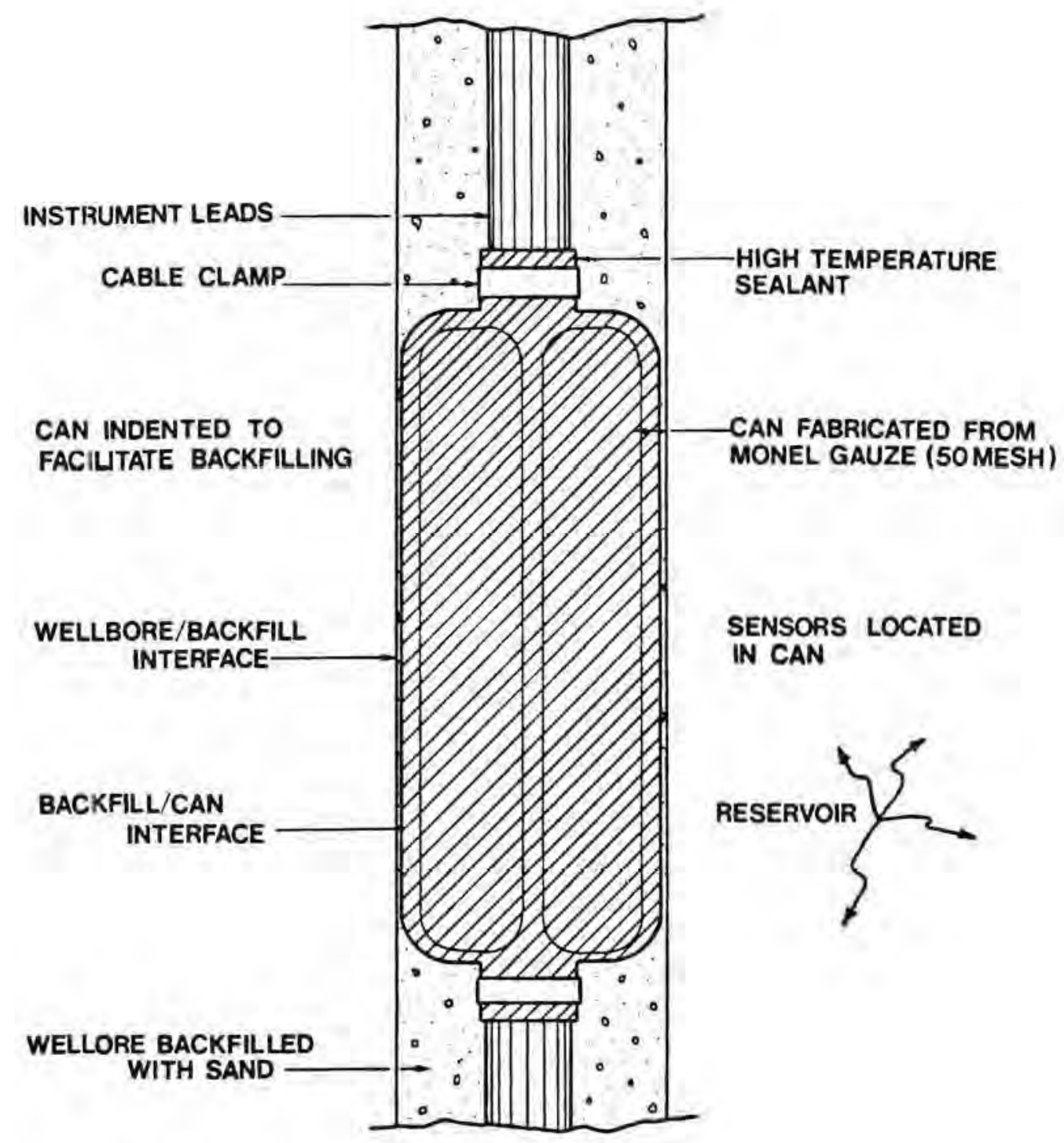

Figure 29. Drawing of instrument container (can) located in backfilled instrument well 
operation. The sensor string is marked at specific depth intervals to permit control of vertical sensor location. The sensor-string cable is installed under constant tension; i.e., the cable weight at the bottom of the string is suspended slightly above the lower terminus of the wellbore (with the possible exception of the $\mathrm{I} / \mathrm{W}$ well, where the weight may be on the bottom). The non-sensor end of the string is suspended directly above the well casing in the surface facility. Control of vertical sensor location within the wellbore with an accuracy of $\pm 10 \mathrm{~cm}$ is expected.

\section{IN-WELL TESTING}

Following deployment of sensor strings in the I/W and instrument wells, preoperational in-well testing will begin. A standing water column will exist in each well. Each temperature and pressure sensor is tested under ambient reservoir conditions. Relative humidity and pore-water content sensors are checked only for integrity. In-well testing of sensors under saturated conditions permits retrieval of the sensor string if the response of any sensor is less than expected. This essentially checks for damage during deployment.

In addition to monitoring ambient reservoir conditions during deployment, temperature and pressure slug tests may be performed. Pressure slug tests can be performed by introducing several liters of water down the well or by applying rapid bursts of compressed air at the wellhead. Such testing permits evaluation of sensor baseline and transient response characteristics while subjected to hydrostatic conditions. Also, slug testing has been effectively used to estimate the hydraulic properties of saturated porous and fractured media (Walter and Thompson, 1980). Slug testing can be performed on wells individually or with observation wells. This testing may provide additional information about the connection between wells and the pressure response of the backfilled media.

Temperature slug testing may be possible by introducing several hundred liters of heated or chilled water into the wellbore. The 
height of the standing water column in each well may preclude the utility of such tests unless performed prior to complete lowering of the sensor string. In any event, information regarding temperature-sensor function and response should be gained during lowering of the sensor string through air and water columns.

WELL BACKFILLING AND CEMENTING

The two instrument wells will be backfilled with 20/40-mesh sand after sensor string placement. Backfilling will provide increased flow resistance within the wellbore. This will minimize the vertical movement of air and water in the wellbore. Also horizontal flow conditions will be more typical of the sandstone reservoir. After backfilling, the instrument well will be cemented to the surface. The I/W well obviously remains open to pernit effective air flow.

Sand backfilling is completed simply by introducing a specific volume of sand into the top of the well casing. The volume of sand introduced into each well is determined by bench-scale testing during calibration. Stokian fall of sand particles and the resultant packing configuration in a simulated wellbore will be observed. Thus, sand introduced at the wellhead of the instrument wells falls through an open air-filled interval and through a water-filled interval and subsequently surrounds the sensor string. By this method the wellbore is backfilled with sand from the bottom to the caprock. At the interface of the caprock and reservoir, the lead wires of the sensor string are configured to withstand the dynamic stress due to sand backfilling and subsequent cement injection.

An option exists at completion of sand backfilling to introduce pelletized bentonite into the wellbore at the caprock-reservoir interface. Bentonite in this configuration will swell when hydrated and is used to act as a sea1. Although bentonite will act to preclude liquid-phase mass transfer out of the reservoir, on dehydration the bentonite will potentially damage the sensor lead wires due to shrinking. Hence, bentonite plugs are not recommended. 
Immediately following backfilling, cement is introduced into the well casing. The cement will surround the sensor lead wires forming an air and liquid seal. The interval from the uppermost limit of sand backfill to the surface is cemented. The cement acts as a physical and thermal barrier. Another positive attribute of backfilling and cementing is the minimization of well-abandonment requirements imposed after the CAES prototype facility is decommissioned. Bench-scale tests are being performed to evaluate the integrity of sensor lead wires during cement hardening (Bakhtiari, 1982, oral commuication). No lead-wire degradation is expected.

\section{STATIC TESTING}

Final static testing of sensors is conducted after backfilling and cementing. This testing phase verifies preoperational sensor performance and provides final baseline data for ambient reservoir temperature and pressure conditions. Evaluation of sensor drift over moderate time intervals is also completed.

MONITORING SYSTEM OPERATIONAL CHECKOUT

On completion of sensor string installation testing, the final hookup and operational verification of sensors, electronics modules, and interface components are conducted. Sensor strings exiting each wellhead are bundled and attached to the surface facility overhead and entered into the surface facility office through a booted bulkhead (Figure 30). Final attachment of all surface electronics components is then completed.

A series of temperature and pressure data logger dumps is then completed to permit evaluation of instantaneous or time-averaged data. This information allows operators to optimize data collection during initial air injection and after start-up during cyclic reservoir testing. 


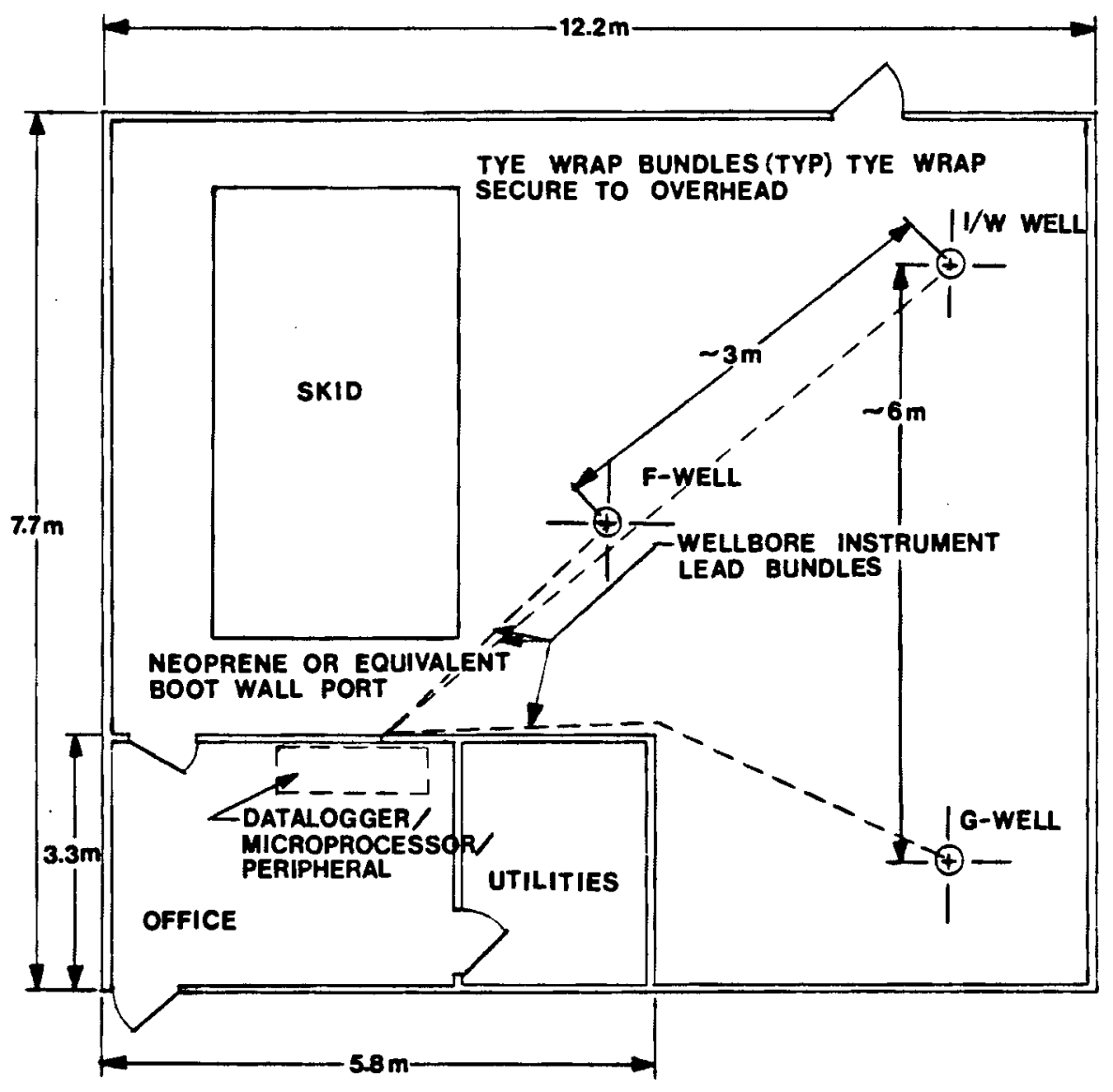

Figure 30. Drawing of instrument wiring layout in surface facility building 
This information also allows verification of total subsurface instrumentation monitoring performance during static, initial conditions. Additional pressure slug testing could be performed to check the dynamic response characteristics of backfilled sensors. At completion of sensor and overall systems testing, the monitoring system is relinquished to the site operator along with operating procedures documentation and related instructions for the system. The site operator then operates the subsurface monitoring system to control injection-closurewithdrawal sequencing. 


\section{MONITORING SYSTEM OPERATION DURING EXPERIMENTATION}

The data acquisition system has been designed to minimize required operator interaction while maximizing system reliability. In fact, after system startup and initialization, the only required daily tasks are collection of printed output, scanning of output for obvious malfunction or output of warning messages by the system software, and preventative maintenance. Approximately every 3 days, output stored in the thermocouple-psychrometer scanner must be dumped to the microcomputer. The following paragraphs outline system operating procedures, general data processing, system maintenance, and contingency plans.

\section{SYSTEM START-UP}

Initialization of the computer memory and loading of utility software are only required for system start-up or restart. In order to minimize the occurrence of system failures requiring restarting, the 110 $\mathrm{V}$ ac power supply will be protected against surges and short-term power interruptions. If the system does fail, however, the system should be powered down and the start-up procedure reinitiated.

System start-up is initiated by powering up the microcomputer and its peripherals. In addition to the signal conditioning processors for each sensor, there are only two power switches: one on the printer and one on the computer. The system will now respond to operator commands. The first commands should be issued to load and execute system utility software from the cassette tape recorder. System utilities include:

1. A program to test each memory location and initialize the parity bits for runtime checking.

2. Software drivers for the printer and system audio alarm. 
3. Software to service an interrupt from either the external data logger (see Figure 20) or the scanner.

4. Software for the real-time clock.

5. Software to write-protect all the system utility programs.

After these utility software modules have been loaded and executed, the BASIC monitor is started and data collection software can be loaded. At this point, the cassette recorder can be removed from the system. The data collection program is interactive and can direct the remaining startup procedures.

\section{DATA PROCESSING}

The data processing program is entered from BASIC by typing RUN. The operator must then respond to prompts to set the real-time clock, specify the sampling interval, specify the first sample time, select the sensors to be scanned, and supply a cross-reference table to relate thermocouple-psychrometer location to channel number. (This is discussed in the following section.) When these steps are completed, the program begins to sample and report data.

At each sample time, raw data are collected, stored in RAM, and printed. Thermocouple-psychrometer data are stored in the external scanner memory. The signals that enter the microcomputer are converted using calibration curves and checked for malfunction. If malfunctions occur or if sensors are operating outside of their calibrated range, a diagnostic warning is printed. This serves to alert the operator. Then, the processed data are printed.

\section{THERMOCOUPLE-PSYCHROMETER}

SCANNER OPERATION

The thermocouple-psychrometer scanner has its own initialization routine, which involves setting the real-time clock, setting the total number of chennels to scan, setting scan interval, and inputting various sensor and scanner parameters. Once these functions are 
performed, the system begins to log data into its internal memory. The memory contents are periodically copied to the microcomputer using an interrupt routine. Also the raw data can be dumped to the printer by connecting the printer directly to the scanner.

When the psychrometer data enter the computer they are stored for further processing. First, the data are checked by examining the zero offset information printed for each sensor at each time interval. If these are excessively large, a diagnostic warning is printed. Next, the calibration curves are used to calculate temperatures and pore-water contents. If these are suspect, warning messages are printed. Next, these values are compared with the other temperature, relative humidity, and pore-water-content measurements. If the agreement between paired sensors is poor, a warning message is printed.

The comparisons between sensor types are difficult because the comparisons must be done from stored output of both the microcomputer and the psychrometer scanner. This can only be done when a psychrometer scan is performed. As a result, much of this checking will be done well after the measurement time. Another difficulty to overcome for these comparisons is the proper matching of signals. Because the data collection network has 17 thermocouple-psychrometer sensors and the scanner has only 15 channels, the sensors read will change channel numbers. The cross-reference table for channel/sensor location is the only means of keeping track of the proper signals to be compared. Great care is required in connecting the sensors to the scanner and in matching the connection scheme to the microcomputer.

\section{MAINTENANCE}

Actual system maintenance requirements are quite low, but a number of preventative maintenance procedures should be performed regularly. The most important daily function of the system operator is entry of all actions taken with the system. To understand the printed record of raw and processed data, it is imperative that a written record 
be kept of system maintenance, dates of changes in sensor configuration, cassette drive use, etc.

A daily maintenance and operations schedule will include the following:

1. Check whether the system is operating normally.

2. Check printer paper, ribbon failure, or other failures of printer output.

3. Scan output data for diagnostic and warning messages.

4. Scan output data for obvious trends or discrepancies.

5. Connect printer to scanner and dump memory.

6. Dump scanner memory to microcomputer.

7. Watch the data-logger display during a scan.

8. Check scanner and microcomputer timing.

9. Check scanner battery voltage and recharge if necessary.

\section{CONTINGENCY PLANS}

Two kinds of contingency plans can be made for the data acquisition system. One involves plans for data acquisition system failure and the other involves building flexibility into the data collection program for other data needs. One contingency, for example, relates to high-speed sampling of the pressure transducers during initial air bubble development. To measure any shock-wave effects that might occur, a data collection program is being developed that measures only pressure sensors and prints only during the measurement period of the A/D converter. This program will allow for maximum speed of data collection. It is anticipated that this speed will not be required at any other time during the field test.

Another software modification contingency is a program to time air or heat breakthrough between the two instrumentation wells. This program would output the time between sensor value changes rather 
than simply report hourly values. For most other applications, it is anticipated that the main monitoring program will be suitable. It should be noted, however, that the ability to program data collection routines in BASIC will allow data collection program changes to be easily accomplished.

Contingency plans for equipment failure are not elaborate. Plans are under way to add disk storage to the present system. This would provide a second copy of the raw data so that a printer failure would not stop data collection. Also the AIM 65 is supplied with a 3-inch paper-tape output that could be used in the event of a printer failure. If the entire microcomputer system fails, a voltmeter may be used so that manual readings of most sensors can be made. Also, a supply of fuses, extra program tapes, printer ribbons, and paper will be available on site. 


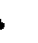




\section{REFERENCES}

Allen, R. D. 1981. Basis for compressed air energy storage (CAES) field test at Pittsfield, Illinois. Proceedings International Conference on Managing Energy Through Energy Storage, Seasonal Thermal and Compressed Air Energy Storage: Seattle, WA.

Allen, R. D., Kannberg, L. D., and Doherty, T. J., 1981, Aquifer field test for compressed air energy storage. Proceedings, 16th Intersociety Energy Conversion Engineering Conference: Atlanta, GA.

Bakhtiari, H, 1982, CAES midyear review: Houston, TX, PB-KBB, Inc.

Campbell, E. C., Campbell, G. S., and Barlow, W. K., 1973, A dewpoint hygrometer for water potential measurement. Agric. Meteorol., v. 12, 113-121.

Greenspan, Lewis, 1977, Humdity fixed points of binary saturated aqueous solutions: J. Res., National Bureau of Standards, v. 81.A, no. $1,89-96$.

Istvan, J. A, 1981, Compressed air energy storage aquifer field test conceptual design, construction and operation, in Proceedings, 1981 Annual Mechanical, Magnetic, and Underground Energy Storage Review Meeting: Washington, DC.

Istvan, J. A, 1982, Oral communication. Project Manager, CAES Field Experiment, $\mathrm{PB}-\mathrm{KBB}$, Inc., Houston, $\mathrm{TX}$.

Peck, A. J. 1968. Theory of the Spanner psychrometer, I. The thermocouple: Agric. Meteorol., v. 5, 433-447.

Richards, L. A., Low, P. F. and Decker, D. L., 1964 Pressure dependence of the relative vapor pressure of water in soil: Soil Sci. Soc. Proc., v. 28, no. $1,5-8$.

Savage, M. J., Cass, A, and de Jager, J. M., 1981, Calibration of thermocouple hygrometers. Irrig. Sci., v. 2, 113-125. 
Stottlemyre, J. A., 1978, Preliminary stability criteria for compressed air energy storage in porous media reservoirs. PNL-2685: Richland, WA, Pacific Northwest Laboratory.

Stottlemyre, J. A., and R. L. Erikson, R. L., 1980, An experimental study of the response of the Galesville Sandstone to simulated CAES conditions. PNL-3399: Richland, WA, Pacific Northwest Laboratory.

Walter, G. R., and Thompson, G. M., 1981. A repeated pulse technique for determining the hydraulic properties of tight formations: Tucson, Dept. of Hydrology and Water Resources, University of Arizona.

Wiles, L. E., 1979a, The effect of water on compressed air energy storage in porous rock reservoirs. PNL-2869: Richland, WA, Pacific Northwest Laboratory.

Wiles, L. E., 1979b, Numerical analysis of temperature and flow effects in a dry, two-dimensional, porous-media reservoir used for compressed air energy storage. PNL-3047: Richland, WA, Pacific Northwest Laboratory.

Wiles, L. E., Erikson, R. L., Allen, R. D., and Doherty, T. J., 1981, Numerical and experimental analyses of the porous medium reservoir at Pittsfield, Illinois. Paper presented at the Annual Contractors Review Meeting, Washington, DC.

Wiles, L. E., and McCann, R. A., 1981a, Water coning in porous media reservoirs for compressed air energy storage. PNL-3470: Richland, WA, Pacific Northwest Laboratory.

Wiles, L. E., and McCann, R. A., 1981b, Prediction of the thermohydraulic performance of porous media reservoirs for compressed air energy storage. Paper presented at the CAES/STES Conference, Seattle, WA. 
APPENDIX

VENDOR INFORMATION 


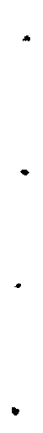




\section{CELLULOSE STRAIN GAGES}

- Environmental

isolation:

- Temperature:

- Relative humidity:

- Electronic package

Size:

Weight :

Type :

- Sensor element type:

- Hygromechanical force of xeric element:

- Flectrical type:

- Electrical

configuration:

- Resistance per leg:

- Total resistance:

- Excitation:

- Output signal:

- Contamination isolation:

- Operating temperature:

\section{- Operating pressure:}

Moisture-sensing element nonconductive. Electrical circuit and strain gages environmentally isolated by parylene coating.

$-20^{\circ} \mathrm{C}$ to $+65^{\circ} \mathrm{C}$

0 웅 to $100 \%$

$7.5^{\prime \prime} \times 6.25^{\prime \prime} \times 4.3^{\prime \prime}$

$4.5 \mathrm{lb}$

JIC std. EGP-1-1967 dust, oil \& water tight

Inert cellulose crystallite, conditioned (xeric element)

$200 \mathrm{mgs} / \mathrm{q}$ decrease in relative humidity (nominal)

Silicon, piezoresistive, thermally matched strain gages

Half Wheatstone bridge

Approximately 500 ohms at $72^{\circ} \mathrm{F}$ and 0 strain (wet)

Approximately 1,000 ohms at $72^{\circ} \mathrm{F}$ nonpolarizing

Maximum 0.3 volts de or ac

0.5 millivolt/volt/\% relative humidity (nominal)

Moisture-sensing element nonconductive. Electrical circuit and strain gages environmentally isolated by parylene coating.

$-40^{\circ} \mathrm{C}$ to $125^{\circ} \mathrm{C}$. Normal temperature compensation for strain gages is required.

Ambient (vacuum to over $3,000 \mathrm{psi}$ ) 
- Permitted moisture overload without recalibration:

Water immersion

- Airflow requirements: 0 (diffusion exchange) to $88 \mathrm{fps}$ without special housing

- Moisture exchange with environment:

$0.015 \mathrm{mgs} / \%$ change in relative humidity (step)

- Size:

Probe: $0.375^{\prime \prime}$ diameter $\times 3.000 "$ long Cable: nonstandard.

- Terminations:

Four conductors with bare ends

- Exposed materials:

Stainless steel; inert cellulose crystalline sensing element; all except crystallite sensing element will be capable of withstanding temperatures to $200^{\circ} \mathrm{C}$. The sensing element shall withstand temperatures up to $125^{\circ} \mathrm{C}$ without damage.

- Range:

$0 \%-100 \%$ relative humidity

- Linearity :

\pm 2 웅 $(0-100)$

- Repeatability:

$\pm 1 \%$

- Resolution:

Infinite

- Accuracy :

$\pm 4 \%$ total error, FS

- Hysteresis:

$\pm 2 \frac{8}{6}$

- Speed of response:

Nominal 3 min per $63 \%$ of step change (faster at higher temperature, humidity, and air flow)

- Drift :

Not detectable

Vendor: Hygrometrix, Inc. 7800 Macarthur Blvd.

Oakland, California 94605 
PLATINUM RESISTANCE ELEMENTS (RTDS)

- Temperature range: $-200^{\circ} \mathrm{C}$ to $+540^{\circ} \mathrm{C}\left(-320^{\circ} \mathrm{F}\right.$ to $\left.+1000^{\circ} \mathrm{F}\right)$

- Sensing element: Thin-film platinum $0.00375 \mathrm{ohms} / \mathrm{ohms} /{ }^{\circ} \mathrm{C}$

- Resistance at $0^{\circ} \mathrm{C}\left(\mathrm{R}_{\mathrm{o}}\right): \quad \quad 1000$ ohms $\pm 0.2 \%$

- Interchangeability: $\pm 0.25^{\circ} \mathrm{C}$ to $\pm 0.5 \frac{\circ}{8}$ of temperature

- Stability: $\quad \pm 0.25^{\circ} \mathrm{C} /$ year

- Pressure: $\quad 3000$ psi

- Recommended current:

- Insulation resistance: 50 megohms minimum at $50 \mathrm{Vdc}$

- Probe configuration: Offered as a ceramic element with integral leads, and in a variety of probe and surface sensor configurations. Standard ceramic elements are $0.110^{\prime \prime}$ or $0.124 " x$ 0.6" long, with 2-wire leads. Standard probes are $3 / 16^{\prime \prime}$ dia.; standard surface sensor is $3 / 4^{\prime \prime} \times 3 / 8^{\prime \prime}$.

- Lead wire:

Shall be modified to three-conductor, shielded, TFE Teflon-insulated, 24-gage, copper lead wires capable of operational use in $200^{\circ} \mathrm{C}$ environments. The lead wires shall have an extruded outer Teflon jacket.

- Input:

ULTRA-7* platinum resistance sensor

- Input/Output terminals:

Miniature terminal strip.

- Standard output:

- Optional outputs:

$1 \mathrm{mV} /{ }^{\circ} \mathrm{C}$ over specified temperature range.

0 to $10 \mathrm{Vdc}$.

- Linearization:

- Bridge network:

- Zero \& span adjust:

Total circuit and sensor linearization over the temperature range.

Integral bridge completion network for each channel.

- Output impedance:

- Response tim

- Load current:

- Ambient operating range: Adjustable to 6 degrees.

Less than 5 ohms.

250 milliseconds.

$1 \mathrm{~mA}$ (typical); $10 \mathrm{~mA}$ maxinulum.

$0{ }^{\circ} \mathrm{C}$ to $+55^{\circ} \mathrm{C}$. 
- Ambient non-

operating range: $\quad-25^{\circ} \mathrm{C}$ to $+85^{\circ} \mathrm{C}$.

- Power requirements: 15-Vdc-regulated power supply.

- Configuration: Single board $10^{\prime \prime} \times 4^{\prime \prime}$ contains ten individual channels. May be divided in appropriate groups, or multiple boards for greater than ten.

- Accuracy: $\pm 0.1^{\circ} \mathrm{C}$.

- Range: $\quad-100^{\circ} \mathrm{C}$ to $+250^{\circ} \mathrm{C}$.

Vendor: $\mathrm{Hy}-\mathrm{Cal}$ Engineering 12105 Los Nietos Road

Santa Fe Springs, CA 90670 


\section{SILICONN STRAIN GAGE}

- Pressure range:

- Overpressure:

- Excitation voltage:

- Output voltage:

- Nonlinearity:

- Temperature error band:

- Compensation:

- Housing:

- Type:
1 to $325 \mathrm{psi}$

$4 \mathrm{X}$

10 Vdc maximum

0 to $10 \mathrm{Vdc}$ $\pm 0.1 \% \mathrm{BSL}$ to $70 \mathrm{~b}$

$\pm 1.5 \%,-20^{\circ} \mathrm{C}$ to $+80^{\circ} \mathrm{C}$

$\pm 2.5 \frac{8}{5},-25^{\circ} \mathrm{C}$ to $125^{\circ} \mathrm{C}$

fully temperature compensated

electron-beam welded, triple seal, heatshrink boot, titanium body

silicon crystal diaphragm four-arm strain gage

Vendor: Petur Instrument Co. 11300 - 25th Ave. N.E.

Seattle, Washington 98125

\section{RESISTANCE BLOCK}

- Type:

- Dimensions :

- Weight:

- Housing: standard soil moisture cell (two-wire configuration

$1 \times 1 \frac{1}{2} \times 1 / 8$ in. $(2.5 \times 3.8 \times 0.3 \mathrm{~cm})$

$28.3 \mathrm{~g}$

corrosion-resistant metal (Al)

Vendor: Soiltest, Inc.

2205 Lee St.

Evanston, Illinois 60202 
NEUTRON LOGGING DEVICE

- Length:

- Weight:

- Diameter:

- Pressure rating:

- Temperature range:

- Logging speed:

- Access :

- Casing :
133 in. $(3.38 \mathrm{~m})$

$35 \mathrm{lb}(16 \mathrm{~kg})$;

$49 \mathrm{lb}(22 \mathrm{~kg})$ with centralizers

2 in. $(50.8 \mathrm{~mm})$

$3000 \mathrm{psi}\left(2.1 \mathrm{kN} / \mathrm{m}^{2}\right)$

$0^{\circ} \mathrm{C}$ to $70^{\circ} \mathrm{C}$

general-30 $\mathrm{ft} / \mathrm{min}(10 \mathrm{~m} / \mathrm{min})$

detail-9 $\mathrm{ft} / \mathrm{min}(3 \mathrm{~m} / \mathrm{min})$

air filled

uncased or cased over measured distance $2 \frac{1}{2}$ in. to 16 in. diameter $(85 \mathrm{~mm}-410$ $\mathrm{mm}$ )

Vendor: $\quad$ BPB Instruments 16098 Allens Ln.

Evansville, Indiana 47710

THERMOCOUPLE PSYCHROMETERS

- Geometry:

Controlled junction size and chamber geometry

- Internal connections: Gold plated

- Calibration: Individually calibrated

- Psychrometer output: Typically $0.47 \mu \mathrm{V} / \mathrm{bar} \pm 5 \frac{9}{6}$ at $25^{\circ} \mathrm{C}$

- Hygrometer output: Typically $0.75 \mu \mathrm{V} / \mathrm{bar}$ at $25^{\circ} \mathrm{C}$

- $\mathrm{TT}_{\mathrm{v}}$ : $40 \mu \mathrm{V}$ minimum

Vendor: Wescor, Inc. 459 S. Main

Logan, Utah 84321 


\section{THERMOCOUPLE PSYCHROMETERS SCANNER}

- Weight:

- Channels:

- Power:

- Output:

- Function:

- Dimensions:

- Temperature range:
$5.5 \mathrm{~kg}$

15

$12-\mathrm{V}$ rechargeable battery

Time, dew-point reading, zero offset, and temperature

Dew-point or psychrometric mode

$28 \mathrm{~cm} \times 25 \mathrm{~cm} \times 18 \mathrm{~cm}$

$0^{\circ} \mathrm{C}$ to $45^{\circ} \mathrm{C}$

Vendor: Wescor, Inc.

459 S. Main

Logan, Utah 84321

ROCKWELL AIM 65 MICROCOMPUTER

- Keyboard:

- Display

- Ports:

- On-board memory:

- Weight :

- Processor:

- Interface:
54 key

20-character alphanumeric

Two 8-bit serial, two 8-bit parallel

Up to $48 \mathrm{~K}$

$18 \mathrm{lb}$

6502 chip

STD-BUS

Vendor: Forethought Products 87070 Dukhobar Rd. Eugene, Oregon 97402 


\section{A/D CONVERTER (16-channel)}

- Input channels:

- Output channels:

- Resolution:

- Power:

- I/O:

- System throughput:

- Settling time:
16 single-ended or 8 differential 2

10-bit $A / D$ and 8-bit D/A $+5 \mathrm{Vdc}$

Memory mapped

25,000 channels/seconds

$25 \mu \mathrm{S}$

Vendor: Analog Devices

234 SW 43 rd

Renton, Washington 98055

A/D CONVERTER (32-channel)

- Input channels:

- Resolution:

- Power:

- I/O:

- System throughput:
32 single-ended or 16 differential

12 bit

$+5 \mathrm{Vdc}$

Memory mapped

25,000 channels/second

Vendor: Analog Devices

234 SW 43rd

Renton, Washington 98055 
PRINTER (Epson MX-80)

- Print method:

- Print rate:

- Print direction:

- Matrix :

- Throughput:

- Character set:

- Power:

- Weight:

- Dimensions:
Serial impact dot matrix

80 CPS

Bidirectional

$9 \times 9$

46 LPM ( $80 \mathrm{CPL}, 10 \mathrm{CPI}$ )

Full 96-character ASCII

$115 \mathrm{Vac},<1 \mathrm{amp}$

$12 \mathrm{Ib}$

$4.2^{\prime \prime} \times 14.7^{\prime \prime} \times 12.0^{\prime \prime}$

Vendor: Wescor, Inc.

439 S. Main

Logan, Utah 84321

CASSETTE TAPE RECORDER (Panasonic)

- Power:

- Tape speed:

- Track system :

- Speaker:

- Dimensions:

- Weight:
$6 \mathrm{~V}$ battery or $120 \mathrm{Vac}$ with adaptor

$4.8 \mathrm{~cm} / \mathrm{s}$

Two-track monaural recording and playback

5-cm PM dynamic speaker

$15.8 \mathrm{~cm} \times 9.7 \mathrm{~cm} \times 3.8 \mathrm{~cm}$

530 grams

Vendor: Panasonic Company

Division of Matsushita Electric

Corporation of America

One Panasonic Way

Secaucus, New Jersey 07094 


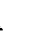

.

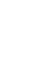




\section{DISTRIBUTION}

No of

Copies

OFFSITE

US Department of Energy

Attn: I. Gyuk

Office of Energy Systems Res.

Forrestal B1dg., CE-141 5E-052

Washington, DC 20585

US Department of Energy

Attn: R. Shivers

Office of Energy Systems Res.

Forrestal B1dg., CE-141 5E-052

Washington, DC 20585

US Department of Energy

Attn: J. H. Swisher

Office of Energy Systems Res.

Forrestal B1dg., CE-141 5E-052

Washington, DC 20585

27 DOE Technical Information Center

Acres American, Inc.

Attn: C. Driggs

The Clark Building

Suite 329

Colurnbia, MD 21044

Electric Power Research Inst.

Attn: R. B. Schainker

3412 Hillview Avenue

PO Box 10412

Palo Alto, CA 94303

Illinois Power Company

Attn: G. E. Huck

Manager of Planning

500 South 27th St.

Decatur, IL 62525
No of

Copies

2 PB-KBB Inc.

Attn: J. Istvan

PO Box 19672

Houston, TX 77024

Potomac Electric Power Co.

Attn: P. E. Schaub

1900 Pennsylvania Ave

Washington, DC 20006

Public Service of Indiana

Attn: T. W. McCafferty

1000 E. Main Street

Plainfield, IN 46168

Sargent and Lundy Engineers

Attn: W. C. Walke

Project Manager

55 East Monroe Street

Chicago, IL 60603

Union Electric Co.

Attn: H.C. Allen

Vice President

Research \& Development

PO Box 149

St. Louis, MO 63166

University of Massachusetts

Attn: 0. C. Farquhar

Dept. of Geology \& Geography

Morrill Science Center

Amherst, MA 01003

University of Michigan

Attn: Donald L. Katz

Dept. of Chemical Eng. 2042 E. Engr. Bldg.

Ann Arbor, MI 48109 
University of Wisconsin

Attn: H. J. Pincus

Dept. of Geological Sciences

Sabin Hal1 and Greene Museum

PO Box 413

Milwaukee, WI 53201

Westinghouse Electric Corp.

Attn: W. F. Kobett

CAES Project Manager

Combustion Turbine Sys. Div.

Long Range Develop-Lab 100

PO Box 251

Concordville, PA 19331

\section{ONSITE}

DOE Richland Operations Office

H.E. Ransom/D.R. Segna

Pacific Northwest Laboratory

L.D. Kannberg (5)

Technical Information (5)

Publishing Coordination (2) 